\title{
Nonstationary-volatility robust panel unit root tests and the great moderation
}

Citation for published version (APA):

Hanck, C. H. (2009). Nonstationary-volatility robust panel unit root tests and the great moderation. METEOR, Maastricht University School of Business and Economics. METEOR Research Memorandum No. 009 https://doi.org/10.26481/umamet.2009009

Document status and date:

Published: 01/01/2009

DOI:

10.26481/umamet.2009009

Document Version:

Publisher's PDF, also known as Version of record

\section{Please check the document version of this publication:}

- A submitted manuscript is the version of the article upon submission and before peer-review. There can be important differences between the submitted version and the official published version of record.

People interested in the research are advised to contact the author for the final version of the publication, or visit the DOI to the publisher's website.

- The final author version and the galley proof are versions of the publication after peer review.

- The final published version features the final layout of the paper including the volume, issue and page numbers.

Link to publication

\footnotetext{
General rights rights.

- You may freely distribute the URL identifying the publication in the public portal. please follow below link for the End User Agreement:

www.umlib.nl/taverne-license

Take down policy

If you believe that this document breaches copyright please contact us at:

repository@maastrichtuniversity.nl

providing details and we will investigate your claim.
}

Copyright and moral rights for the publications made accessible in the public portal are retained by the authors and/or other copyright owners and it is a condition of accessing publications that users recognise and abide by the legal requirements associated with these

- Users may download and print one copy of any publication from the public portal for the purpose of private study or research.

- You may not further distribute the material or use it for any profit-making activity or commercial gain

If the publication is distributed under the terms of Article $25 \mathrm{fa}$ of the Dutch Copyright Act, indicated by the "Taverne" license above, 


\section{Maastricht University}

Christoph Hanck

Nonstationary-Volatility Robust Panel Unit Root Tests and the Great Moderation

RM/09/009

\section{METEOR}

Faculty of Economics and Business Administration Maastricht Research School of Economics

of Technology and Organization

\section{P.O. Box 616}

NL - 6200 MD Maastricht

The Netherlands 


\title{
Nonstationary-Volatility Robust Panel Unit Root Tests and the Great Moderation*
}

\author{
Christoph Hanck ${ }^{\dagger}$
}

February 9, 2009

\begin{abstract}
This paper proposes a new testing approach for panel unit roots that is, unlike previously suggested tests, robust to nonstationarity in the volatility process of the innovations of the time series in the panel. Nonstationarity volatility arises for instance when there are structural breaks in the innovation variances. A prominent example is the reduction in GDP growth variances enjoyed by many industrialized countries, known as the 'Great Moderation.' The panel test is based on Simes' [Biometrika 1986, "An Improved Bonferroni Procedure for Multiple Tests of Significance"] classical multiple test, which combines evidence from time series unit root tests of the series in the panel. As time series unit root tests, we employ recently proposed tests of Cavaliere and Taylor [Journal of Time Series Analysis, "Time-Transformed Unit Root Tests for Models with Non-Stationary Volatility"]. The panel test is robust to general patterns of cross-sectional dependence and yet straightforward to implement, only requiring valid $p$-values of time series unit root tests, and no resampling. Monte Carlo experiments show that other panel unit root tests suffer from sometimes severe size distortions in the presence of nonstationary volatility, and that this defect can be remedied using the test proposed here. The new test is applied to test for a unit root in an OECD panel of gross domestic products, yielding inference robust to the 'Great Moderation.' We find little evidence of trend stationarity.
\end{abstract}

Keywords: Nonstationary Volatility, Multiple Testing, Panel Unit Root Test, CrossSectional Dependence

JEL classification: $\mathrm{C} 12, \mathrm{C} 23$

\footnotetext{
*Helpful comments from seminar participants in Maastricht, in particular by Franz Palm and Jean-Pierre Urbain, are gratefully acknowledged.

${ }^{\dagger}$ Universiteit Maastricht, Tongersestraat 53, 6211 LM Maastricht, The Netherlands. Tel. (+31) 43-3883815, c.hanck@ke.unimaas.nl.
} 


\section{Introduction}

The problem of testing for unit roots in panel data has recently attracted much attention, as the additional cross-sectional dimension provided by panel data is seen as a way to overcome the low power of traditional time series unit root tests. So called 'first generation' tests [Maddala and Wu, 1999; Im, Pesaran and Shin, 2003; Levin, Lin and Chu, 2002] rely on the assumption that the individual time series in the panel are cross-sectionally independent. It is, however, now widely recognized that this assumption is not met in typical macroeconometric panel data sets. For instance, common global shocks induce cross-sectional dependence among the test statistics [see, e.g., O’Connell, 1998].

The aim of 'second generation' panel unit root tests (PURTs) therefore is to provide reliable inference in the presence of cross-sectional dependence. Phillips and Sul [2003], Moon and Perron [2004], and Bai and Ng [2004] assume the dependence to be driven by (multiple) factors in the error terms. Suitably 'de-factoring' the observations, e.g. by the principal component method, asymptotically removes the common factors, then allowing for the application of standard panel unit root tests. Breitung and Das [2005], in turn, propose a feasible generalized least-squares approach that can be applied when $T>n$, where $T$ denotes the number of time series observations on each of the $n$ series. Pesaran [2007] adds the cross-section averages of lagged levels and of first-differences of the individual series to Augmented Dickey-Fuller 1979 $(\mathrm{ADF})$ regressions. Panel unit root tests can then be based on the simple averages of the individual cross-sectionally augmented ADF statistics. The approach most closely related to the one to be put forward here is by Demetrescu, Hassler and Tarcolea [2006], who draw on the meta-analytic literature to derive their $p$-value combination tests.

All of the above-cited tests are, in some way or another, suitable panel generalizations of traditional Dickey and Fuller [1979] or other well-known time series unit root tests. As such, they also invoke the traditional assumption in the unit root testing literature that the variance of the innovations driving the time series stays constant over time. Hamori and Tokihisa [1997] and Kim, Leybourne and Newbold [2002] show that traditional unit root tests perform poorly if this assumption is not met, e.g. because there is abrupt change in the innovation variance at some point during the sample period. We show that similarly negative results obtain for 
popular second generation panel unit root tests, many of which overreject severely while others are overly conservative.

Our goal therefore is to provide a new panel unit root test that avoids this potential shortcoming. The test is based on Simes' [1986] classical intersection test of the 'global' null hypothesis $H_{0}$ that all individual null hypotheses $H_{i, 0}, i=1, \ldots, n$, are true. (Here, that all $n$ time series are unit root processes.) Simes' [1986] test is widely applied in, among many other areas, genetical micro-array experiments [e.g., Dudoit, Shaffer and Boldrick, 2003]. The new panel test is straightforward to implement, only requiring valid $p$-values of time series unit root tests. Such suitable $p$-values are obtained from recently proposed time series unit root tests by Cavaliere and Taylor [2008] that are robust to general patterns of nonstationary volatility. Moreover, the multiple testing approach of Simes [1986] yields a panel test that is robust to cross-sectional dependence.

As an additional advantage, the new test allows to identify the units in the panel for which the alternative of stationarity appears to hold. Doing so, it still controls the 'Familywise Error Rate' (FWER), i.e. the probability to falsely reject at least one true individual time series null hypothesis, at some chosen level $\alpha$. This would not be achieved by the widely applied strategy to reject for all those time series unit root tests statistics that exceed some fixed level- $\alpha$ critical value, as this latter approach ignores the multiple testing nature of the problem. ${ }^{1}$

In an empirical application of the new test, we revisit the debate of whether output levels contain a unit root. Nonstationary-volatility robust tests are particularly important in this context in view of what has come to be known as the 'Great Moderation' [Stock and Watson, 2002], i.e. the reduction in the volatility of economic growth rates enjoyed by many industrialized countries since the 1980s. This change in volatility implies that traditional (panel) unit root tests of output level stationarity may be misspecified. The application of our new panel test yields little evidence of trend stationarity in the investigated panel of OECD countries.

The next section motivates the need for nonstationary-volatility robust PURTs and develops the new test. Section 3 reports results of a Monte Carlo study. Section 4 presents the empirical application. The last section concludes.

\footnotetext{
${ }^{1}$ Recently, procedures taking multiplicity into account have begun to find their way into the econometrics literature. Romano and Wolf [2008] provide a survey of available methods and Hanck [2009] an application.
} 


\section{The Panel Unit Root Test}

We consider the following dynamic panel model:

$$
y_{i, t}=\mu_{i}\left(1-\phi_{i}\right)+\phi_{i} y_{i, t-1}+\epsilon_{i, t} \quad\left(i \in \mathbb{N}_{n}, t \in \mathbb{N}_{T}\right),
$$

where $j \in \mathbb{N}_{a}$ is shorthand for $j=1, \ldots, a, \phi_{i} \in(-1,1], i \in \mathbb{N}_{n}$, and $n$ denotes the number of series in the panel. Equation (1) says that the time series $\left\{y_{i, 0}, \ldots, y_{i, T}\right\}$ are generated by a simple first-order autoregressive process for each cross-sectional unit $i$. The panel unit root null hypothesis states that all time series are unit-root nonstationary [Breitung and Pesaran, 2008]. Formally,

$$
H_{0}: \phi_{1}=\phi_{2}=\ldots=\phi_{n}=1
$$

Put differently, $H_{0}$ states that all single time series hypotheses $H_{i, 0}: \phi_{i}=1$ are true,

$$
H_{0}=\bigcap_{i \in \mathbb{N}_{n}} H_{i, 0}
$$

where $\bigcap_{i \in \mathbb{N}_{n}}$ denotes the intersection over the $n$ individual time series hypotheses.

\subsection{The Need for Nonstationary-Volatility Robust PURTs}

To complete the model in Eq. (1) one needs to specify the properties of $\epsilon_{i, t}$. First, we note that 'first generation' PURTs assumed the $\epsilon_{i, t}$ to be independent across $i$, an assumption which is now widely agreed to be overly restrictive and has therefore been relaxed in recent work [e.g., Breitung and Das, 2005; Demetrescu et al., 2006; Moon and Perron, 2004; Pesaran, 2007]. We shall follow that route here. Second, whether or not $\phi_{i}=1$, it is often expedient to allow for serial dependence in $\epsilon_{i, t}$. A standard assumption in the (panel) unit root literature [Pesaran, 2007] is

Assumption 1.

$$
\epsilon_{i, t}=\sum_{j=0}^{\infty} c_{i, j} u_{i, t-j}=: C_{i}(L) u_{i, t},
$$

where $C_{i}(z) \neq 0$ for $z \leqslant 1$ and $\sum_{j=0}^{\infty} j\left|c_{i, j}\right|<\infty$. Eq. (1) is then driven by $u_{i, t}$, which is assumed to be i.i.d. with finite, constant variance $\sigma^{2}{ }^{2}$

\footnotetext{
${ }^{2}$ Pesaran [2007] allows $u_{i, t} \sim$ i.i.d. $\left(0, \sigma_{i}^{2}\right)$, that is, heterogeneity in the innovation variance across $i$, not $t$.
} 
Table I-Empirical Size of Second Generation PURTs Under Nonstationary Volatility.

\begin{tabular}{|c|c|c|c|c|c|c|c|c|c|c|}
\hline \multirow[b]{2}{*}{$n$} & & \multirow[b]{2}{*}{$T$} & \multicolumn{4}{|c|}{ Heteroscedasticity } & \multicolumn{4}{|c|}{ Homoscedasticity } \\
\hline & & & 30 & 50 & 100 & 200 & 30 & 50 & 100 & 200 \\
\hline \multirow{5}{*}{8} & $S$ & & .306 & .344 & .355 & .357 & .053 & .058 & .058 & .049 \\
\hline & $t_{r o b}$ & & .073 & .088 & .083 & .101 & .047 & .052 & .051 & .047 \\
\hline & $C I P S^{*}$ & & .562 & .563 & .610 & .567 & .068 & .049 & .070 & .059 \\
\hline & $t_{\hat{\rho}^{*}, \kappa}$ & & .188 & .233 & .255 & .284 & .075 & .081 & .072 & .074 \\
\hline & $t_{a}^{*}$ & & .002 & .005 & .023 & .029 & .040 & .066 & .089 & .091 \\
\hline \multirow{5}{*}{12} & $S$ & & .370 & .405 & .440 & .402 & .052 & .049 & .047 & .047 \\
\hline & $t_{r o b}$ & & .082 & .090 & .102 & .089 & .042 & .043 & .041 & .039 \\
\hline & $C I P S^{*}$ & & .507 & .598 & .598 & .584 & .035 & .033 & .045 & .036 \\
\hline & $t_{\hat{\rho}^{*}, \kappa}$ & & .213 & .262 & .321 & .308 & .077 & .080 & .080 & .064 \\
\hline & $t_{a}^{*}$ & & .001 & .003 & .004 & .021 & .016 & .045 & .065 & .090 \\
\hline \multirow{5}{*}{24} & $S$ & & .477 & .525 & .573 & .516 & .048 & .057 & .044 & .050 \\
\hline & $t_{r o b}$ & & .109 & .100 & .093 & .096 & .044 & .035 & .045 & .049 \\
\hline & $C I P S^{*}$ & & .624 & .664 & .658 & .607 & .024 & .037 & .044 & .035 \\
\hline & $t_{\hat{\rho}^{*}, \kappa}$ & & .242 & .287 & .348 & .387 & .094 & .081 & .068 & .088 \\
\hline & $t_{a}^{*}$ & & .000 & .000 & .001 & .006 & .012 & .023 & .048 & .084 \\
\hline
\end{tabular}

Homoscedasticity corresponds to $\delta=1$, heteroscedasticity to $\delta=5 . \psi=0, \phi=\boldsymbol{\imath}_{n}, \tau=0.1$. Equicorrelated disturbances with $\theta=0.5$. (See Section 3 for a precise description of the DGP.) 2500 replications.

While i.i.d.-ness could be relaxed to a martingale difference assumption on $u_{i, t}$ [Davidson, 1994, Thm. 27.14], heterogeneity in the innovation variances that takes the form of "nonstationary volatility', e.g., structural breaks or trending variances is not covered by the assumptions made above [Hamori and Tokihisa, 1997]. Thus, currently available PURTs are potentially misspecified in the presence of nonstationary volatility. ${ }^{3}$

To verify whether nonstationary volatility matters for recent PURTs, we conduct a small scale simulation experiment. The simulated panel data sets exhibit intermediate degrees of crosssectional dependence and a relatively early moderately negative break in the innovation variance (see Section 3 for details on the Data-Generating Process, henceforth DGP). We compare the following cross-sectional correlation, but not nonstationary-volatility-robust PURTs ${ }^{4}$ : CIPS* by Pesaran [2007], $t_{r o b}$ from Breitung and Das [2005], the $S$ test of Hanck [2008], $t_{\hat{\rho}^{*}, \kappa}$ from

\footnotetext{
${ }^{3}$ The deleterious effect on the properties of time series unit root tests has long been recognized in the literature. See, e.g., Hamori and Tokihisa [1997] and Kim et al. [2002]. See also Sen [2007].

${ }^{4}$ We waive to include first generation tests such as those by Levin et al. [2002], which are not robust to cross-sectional dependence, such that we cannot expect reasonable performance even under homoscedasticity.
} 
Demetrescu et al. [2006] and $t_{a}^{*}$ by Moon and Perron [2004]. Table I reports the results. The right panel of Table I shows that all tests perform quite well under homoscedasticity, at least for sufficiently large $T$. When there is nonstationary volatility (left panel), all considered tests exhibit moderate to severe size distortions. In particular, while $t_{a}^{*}$ appears to be undersized, $C I P S^{*}, S$ and $t_{\hat{\rho}^{*}, \kappa}$ are drastically oversized. The $t_{r o b}$ test performs relatively best, though also noticeably worse than under homoscedasticity. Also, the size distortions, not vanishing with either increasing $n$ or $T$, show no sign of being a small sample phenomenon. We therefore conclude that currently available PURTs should not be relied upon when researchers suspect a break (or otherwise nonstationary behavior) in the innovation variances.

\subsection{A Nonstationary-Volatility Robust PURT}

This subsection develops the new Nonstationary-Volatility Robust PURT. We draw on classical results from the multiple testing literature that are well-suited for deriving tests in the present non-standard situation. Simes [1986] provides a simple test for testing the 'global' or 'intersection' null hypothesis (2). Suppose for the moment that valid $p$-values $p_{i}, i \in \mathbb{N}_{n}$, of suitable test statistics for the individual time series hypotheses $H_{i, 0}$ are available. Denote by $p_{(1)}, \ldots, p_{(n)}$ the ordered $p$-values $p_{(1)} \leqslant \ldots \leqslant p_{(n)}$. Then, Simes' Heteroscedasticity-Robust intersection test (henceforth $S^{H}$ test, for short) rejects $H_{0}$ at level $\alpha$ if and only if

$$
p_{(j)} \leqslant j \cdot \alpha / n \quad \text { for some } j \in \mathbb{N}_{n}
$$

That is, one sorts the $p$-values from most to least significant and compares these to gradually less challenging critical points $j \alpha / n$. If there exists at least one $p$-value sufficiently small so as to be smaller than the corresponding critical point, the $S^{H}$ test rejects the panel unit root null. Simes [1986, Thm. 1] proves that the $S^{H}$ test has type I error probability equal to $\alpha$ when the test statistics are independent. As argued in the Introduction, the assumption of independence is unlikely to be met in most, if not all, applications of panel unit root tests. Fortunately, Sarkar [1998] shows that the assumption of independence is not necessary and can, in fact, be weakened substantially. The following is adapted from Sarkar [1998, Prop. 3.1]

Proposition 1.

If the test statistics for testing the $H_{i, 0}, i \in \mathbb{N}_{n}$, are multivariate totally positive of order 2 
$\left(M T P_{2}\right)$, then

$$
\mathrm{P}_{H_{0}}\left(\exists j \in \mathbb{N}_{n}: p_{(j)} \leqslant j \alpha / n\right)=\mathrm{P}_{H_{0}}(S \text { rejects }) \leqslant \alpha,
$$

where $\mathrm{P}_{H_{0}}$ denotes the probability under (2).

A vector of random variables $X=\left(X_{1}, \ldots, X_{n}\right)^{\prime}$ is said to be $\mathrm{MTP}_{2}$ if its joint density $f$ satisfies

$$
\begin{array}{r}
f\left(\min \left(T_{1}, U_{1}\right), \ldots, \min \left(T_{n}, U_{n}\right)\right) \cdot f\left(\max \left(T_{1}, U_{1}\right), \ldots, \max \left(T_{n}, U_{n}\right)\right) \geqslant \\
f\left(T_{1}, \ldots, T_{n}\right) \cdot f\left(U_{1}, \ldots, U_{n}\right),
\end{array}
$$

for any two points $\left(T_{1}, \ldots, T_{n}\right)$ and $\left(U_{1}, \ldots, U_{n}\right)$. The $\mathrm{MTP}_{2}$ class is rather large, including the multivariate normal with nonnegative correlations, the absolute-valued multivariate normal with some specific covariance structures, multivariate gamma, absolute-valued central multivariate $t$, and central multivariate $F$ distributions. Sarkar [1998] further verifies that even the $\mathrm{MTP}_{2}$ assumption of Proposition 1 is not necessary.

Hanck [2008] finds Simes' test to work well under constant volatility when employing standard Dickey and Fuller [1979] $t$-statistics. (See also Hanck [2008] for further discussion of the test's properties.) To obtain $p$-values valid under nonstationary volatility we make use of the recently proposed time-transformed unit root tests by Cavaliere and Taylor [2008]. We follow Cavaliere and Taylor [2008] and generalize Assumption 1 to

\section{Assumption 2.}

$$
\epsilon_{i, t}=\sum_{j=0}^{\infty} c_{i, j} u_{i, t-j}=C_{i}(L) u_{i, t},
$$

where $C_{i}(z) \neq 0$ for $z \leqslant 1$ and $\sum_{j=0}^{\infty} j\left|c_{i, j}\right|<\infty$. Further, $u_{i, t}=\sigma_{i, t} \varsigma_{i, t}, \varsigma_{i, t} \sim$ i.i.d. $(0,1) . \sigma_{i, t}$ satisfies, for all $s \in[0,1], \sigma_{i, \mid s T\rfloor} \in \mathcal{D}$, the set of cadlag functions on $[0,1]$.

This assumption covers the above-mentioned cases of structural breaks and trending variances, with $\sigma_{\lfloor s T\rfloor}=\sigma_{0}+\sigma_{1} \mathbb{I}(s>\tau), \tau \in(0,1)$, and $\sigma_{\lfloor s T\rfloor}=\sigma_{0}+\sigma_{1} s$, respectively.

Defining the 'variance profile' $\eta_{i}(s)=\left(\int_{0}^{1} \sigma_{i,\lfloor r T]}^{2} \mathrm{~d} r\right)^{-1} \int_{0}^{s} \sigma_{i,\lfloor r T]}^{2} \mathrm{~d} r$, Cavaliere and Taylor [2007] show that standard unit root test statistics converge to functionals of 'time-transformed' Brownian Motions $B(\eta(s))$ [Davidson, 1994, Sec. 29.4] under nonstationary volatility, thus invalidating the standard limiting distributions. They further demonstrate that transforming $y_{i, t}$ with 
$g_{i}(s):=\eta_{i}^{-1}(s)$, the (unique) inverse of the variance profile, via

$$
\tilde{y}_{i, t}=y_{i,\left\lfloor g_{i}(t / T) T\right\rfloor}, \quad t=0, \ldots, T
$$

yields a series that satisfies the invariance principle [Cavaliere and Taylor, 2008, Eq. 19]

$$
T^{-1 / 2} \tilde{y}_{i,\lfloor s T\rfloor} \Rightarrow \sqrt{\int_{0}^{1} \sigma_{i,\lfloor r T\rfloor}^{2} \mathrm{~d} r} C_{i}(1) B(s) .
$$

Numerically inverting the (uniformly consistent) estimator of $\eta_{i}(s)$,

$$
\hat{\eta}_{i}(s)=\frac{\sum_{t=1}^{\lfloor s T\rfloor} \hat{u}_{i, t}^{2}+(s T-\lfloor s T\rfloor) \hat{u}_{i,\lfloor s T\rfloor+1}^{2}}{\sum_{t=1}^{T} \hat{u}_{i, t}^{2}}
$$

to obtain $\hat{g}_{i}(s)$, one can then transform the series via $y_{i,\left\lfloor\hat{g}_{i}(t / T) T\right\rfloor}$ so as to converge to standard Brownian Motions. Here, $\hat{u}_{i, t}$ denotes the residuals of a regression of $y_{i, t}$ on $y_{i, t-1}$. Unit root statistics applied to the transformed data will then satisfy their well-known homoscedastic limiting null distributions. More specifically, Cavaliere and Taylor [2008] consider the $M$ tests by $\mathrm{Ng}$ and Perron $[2001] .^{5}$ Let

$$
s_{i, \mathrm{AR}}^{2}\left(k_{i}\right):=\frac{\hat{\sigma}_{i}^{2}}{1-\sum_{j=1}^{k_{i}} \hat{\beta}_{i, j}},
$$

where $\hat{\beta}_{i, j}$ and $\hat{\sigma}_{i}^{2}$ can be estimated with an OLS regression of $\hat{u}_{i, t}$ on $k_{i}$ lagged values. The lag orders $k_{i}$ can be chosen by one of the common selection criteria. The tests are then defined by the statistics

$$
\begin{gathered}
\mathcal{M Z}_{\alpha, i}:=\frac{T^{-1} y_{i, T}^{2}-s_{i, \mathrm{AR}}^{2}(k)}{2 T^{-2} \sum_{t=1}^{T} y_{i,\left\lfloor\hat{g}_{i}(t / T) T\right\rfloor}^{2}}, \quad \mathcal{M S B}_{i}:=\left(T^{-2} \sum_{t=1}^{T} y_{i,\left\lfloor\hat{g}_{i}(t / T) T\right\rfloor}^{2} / s_{i, \mathrm{AR}}^{2}(k)\right)^{1 / 2}, \\
\mathcal{M Z}_{t, i}:=\mathcal{M Z}_{\alpha, i} \times \mathcal{M S B}_{i},
\end{gathered}
$$

and associated limiting distributions

$$
\begin{gathered}
\mathcal{M Z}_{\alpha, i} \Rightarrow \frac{B(1)^{2}-1}{2 \int_{0}^{1} B(s)^{2} \mathrm{~d} s}, \quad \mathcal{M S B}_{i} \Rightarrow\left(\int_{0}^{1} B(s)^{2} \mathrm{~d} s\right)^{1 / 2} \\
\mathcal{M Z}_{t, i} \Rightarrow \frac{B(1)^{2}-1}{\left(4 \int_{0}^{1} B(s)^{2} \mathrm{~d} s\right)^{1 / 2}}
\end{gathered}
$$

\footnotetext{
${ }^{5}$ As given here, the statistics are for the no deterministics case $\mu_{i}=0$. See Cavaliere and Taylor [2008, Sec. 5] for the suitable modifications in the presence of deterministic trends.
} 
$\mathcal{M Z}_{\alpha, i}$ and $\mathcal{M Z}_{t, i}$ reject for large negative values, whereas $\mathcal{M S B}_{i}$ rejects for small values.

In addition, we propose nonstationary-volatility robust versions of the well-known Dickey and Fuller [1979] tests, given by the $t$-statistic $t_{\phi_{i}}$ of the augmented regression

$$
\Delta y_{i,\left\lfloor\hat{g}_{i}(t / T) T\right\rfloor}=\left(\phi_{i}-1\right) y_{i,\left\lfloor\hat{g}_{i}\left(\frac{t-1}{T}\right) T\right\rfloor}+\sum_{j=1}^{k_{i}} \delta_{i, j} \Delta y_{i,\left\lfloor\hat{g}_{i}\left(\frac{t-j}{T}\right) T\right\rfloor}+u_{i, t}
$$

and the coefficient statistic $T\left(\hat{\phi}_{i}-1\right) /\left(1-\sum_{j=1}^{k_{i}} \hat{\delta}_{i, j}\right)$. The asymptotic null distributions of $t_{\phi_{i}}$ and $T\left(\hat{\phi}_{i}-1\right) /\left(1-\sum_{j=1}^{k_{i}} \hat{\delta}_{i, j}\right)$ are given in the following Lemma.

Lemma 1.

Under Assumption 2 and $\phi_{i}=1$,

$$
\begin{aligned}
& \text { (i) } T\left(\hat{\phi}_{i}-1\right) /\left(1-\sum_{j=1}^{k_{i}} \hat{\delta}_{i, j}\right) \Rightarrow \frac{B(1)^{2}-1}{2 \int_{0}^{1} B(s)^{2} \mathrm{~d} s}, \\
& \text { (ii) } t_{\phi_{i}} \Rightarrow \frac{B(1)^{2}-1}{\left(4 \int_{0}^{1} B(s)^{2} \mathrm{~d} s\right)^{1 / 2}} .
\end{aligned}
$$

Proof. Let $\omega_{i}=\sqrt{\int_{0}^{1} \sigma_{i,\lfloor r T\rfloor}^{2} \mathrm{~d} r}, \breve{y}_{i, t}=y_{i,\left\lfloor\hat{g}_{i}(t / T) T\right\rfloor}$ and $\breve{u}_{i, t}=\Delta \breve{y}_{i, t}$. The proof follows straightforwardly from (4), uniform consistency of the $\hat{g}_{i}$ and the Continuous Mapping Theorem. As in Hamilton [1994, Sec. 17.7], under the null we jointly have $T^{-1} \breve{y}_{i, t-1} \breve{u}_{i, t} \Rightarrow 1 / 2 \omega_{i}^{2} C_{i}(1)\left(B(1)^{2}-1\right)$ and $T^{-2} \breve{y}_{i, t-1}^{2} \Rightarrow \omega_{i}^{2} C_{i}(1)^{2} \int_{0}^{1} B(s)^{2} \mathrm{~d} s$. Asymptotically, we can disregard the estimation error of the $\delta_{i, j}$ [Hamilton, 1994, Eq. 17.7.18] and

$$
\begin{aligned}
T\left(\hat{\phi}_{i}-1\right) & =T^{-1} \breve{y}_{i, t-1} \breve{u}_{i, t} / T^{-2} \breve{y}_{i, t-1}^{2}+o_{p}(1) \\
& \Rightarrow 0.5 \omega_{i}^{2} C_{i}(1)\left(B(1)^{2}-1\right) / \omega^{2} C_{i}(1)^{2} \int_{0}^{1} B(s)^{2} \mathrm{~d} s \\
& =0.5\left(B(1)^{2}-1\right) / C_{i}(1) \int_{0}^{1} B(s)^{2} \mathrm{~d} s .
\end{aligned}
$$

Result $(i)$ then follows by Hamilton [1994, Eq. 17.7.34], from which $1 /\left(1-\sum_{j=1}^{k_{i}} \hat{\delta}_{i, j}\right) \rightarrow{ }_{p} C_{i}(1)$. Result (ii) follows analogously.

The $p$-values required for the $S^{H}$ test can thus be obtained by simulating the asymptotic distributions (5) and (6). ${ }^{6}$

\footnotetext{
${ }^{6}$ We also worked with MacKinnon [1996]-type response surface $p$-values. These did however not perform consistently better than the ones relying on (5) and (6). Detailed results are available upon request.
} 


\subsection{Identifying Stationary Units}

Existing panel unit root tests are silent about the size of the fraction or the identity of the cross section units that are stationary. Using the $p$-values from the $S^{H}$ test, one can easily determine those units in the panel for which the alternative of stationarity can be said to hold, once the null hypothesis is rejected. Hommel [1988, Sec. 2] proves that the following procedure controls the FWER, i.e. the probability to falsely reject at least one true $H_{i, 0}$, at multiple level $\alpha$ whenever the $S^{H}$ test is a level- $\alpha$ test for the intersection hypothesis.

\section{HOMMEL's PROCEDURE}

A. Compute

$$
j=\max \left\{i \in \mathbb{N}_{n}: p_{(n-i+k)}>k \alpha / i \text { for } k \in \mathbb{N}_{i}\right\}
$$

B1. If the maximum does not exist, reject all $H_{i, 0}\left(i \in \mathbb{N}_{n}\right)$.

B2. If the maximum exists, reject all $H_{i, 0}$ with $p_{i} \leqslant \alpha / j$.

\section{Monte Carlo Evidence}

This section investigates the size and power of the $S^{H}$ test discussed in the previous section. We use the following simple DGP:

$$
y_{i, t}=\phi_{i} y_{i, t-1}+\epsilon_{i, t} \quad\left(i \in \mathbb{N}_{n}, t \in \mathbb{N}_{T}\right)
$$

To introduce nonstationary volatility into the DGP, we generate a permanent break in the innovation variance of standard normal variates $\xi_{i, t}$ at time $\lfloor\tau T\rfloor$, where $\operatorname{Var}\left(\xi_{i, t}\right)=1$ for $t=1, \ldots,\lfloor\tau T\rfloor$ and $\operatorname{Var}\left(\xi_{i, t}\right)=1 / \delta^{2}$ for $t=\lfloor\tau T\rfloor+1, \ldots, T$. We consider $\tau \in\{0.1,0.5,0.9\}$, corresponding to early, middle and late breaks, and $\delta \in\{1 / 5,5\}$ to generate positive and negative breaks, respectively. To gauge the effect of serial correlation, we apply the filter $\psi(L)=1+\psi L$ to $\xi_{i, t}$ to get $\tilde{\xi}_{i, t}=\psi(L) \xi_{i, t}$, where $\psi \in\{0,0.5\}$. Finally, we consider two different schemes to generate cross-sectional correlation among the error terms $\epsilon_{i, t}{ }^{7}$

\footnotetext{
${ }^{7}$ We run the recursion for 30 initial observations before using the $y_{i, t}$ to mitigate the effect of initial conditions under $H_{A}$.
} 
Table II-Size of the $S^{H}$ Test Using Different Time

SERIES Tests.

\begin{tabular}{|c|c|c|c|c|c|c|c|c|c|c|c|c|c|c|c|}
\hline \multirow[b]{2}{*}{$n$} & \multirow[b]{2}{*}{$T$} & \multicolumn{5}{|c|}{$\tau=0.1$} & \multicolumn{5}{|c|}{$\tau=0.5$} & \multicolumn{4}{|c|}{$\tau=0.9$} \\
\hline & & 30 & 50 & 100 & 150 & 200 & 30 & 50 & 100 & 150 & 200 & 30 & 50 & 100 & $150 \quad 200$ \\
\hline
\end{tabular}

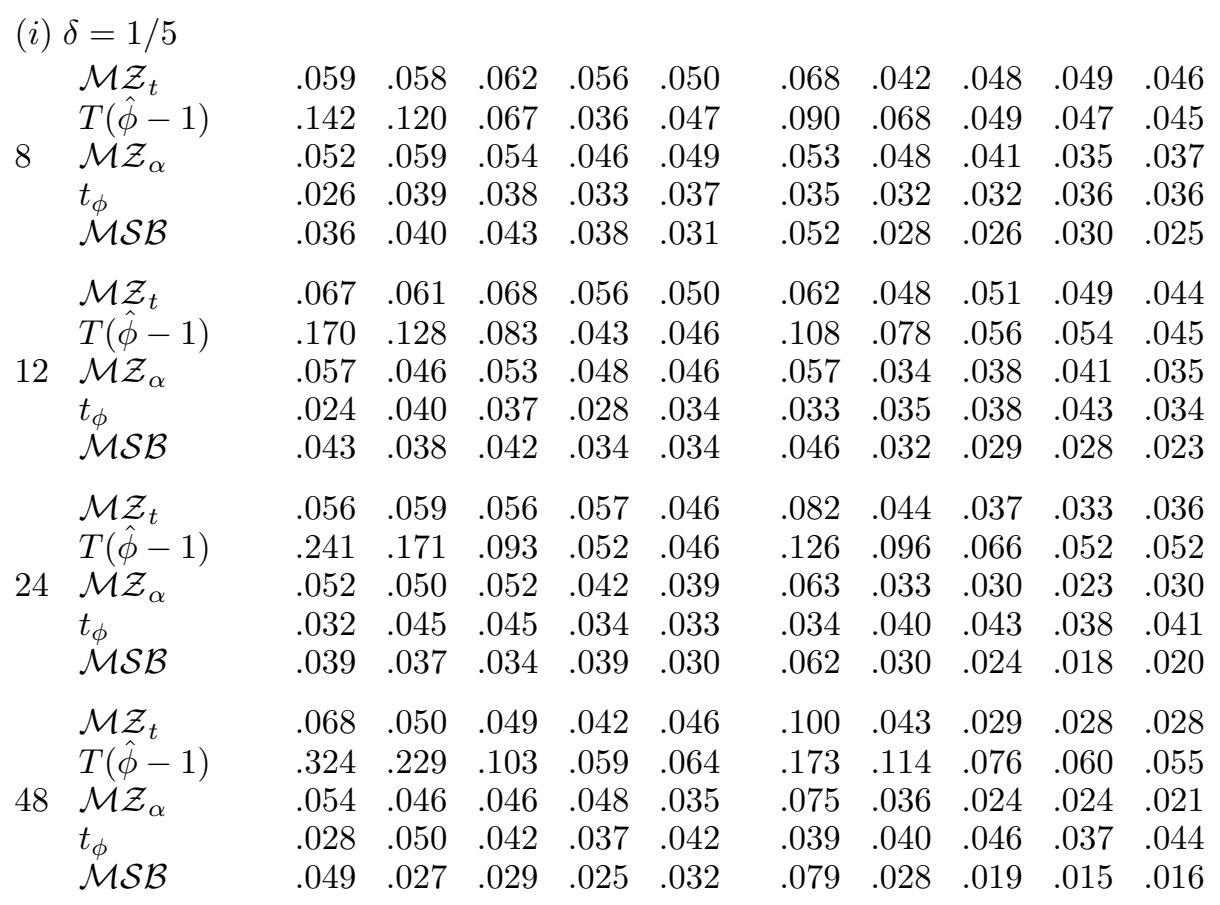

(ii) $\delta=5$

$\begin{array}{llllll}\mathcal{M Z}_{t} & .028 & .007 & .003 & .004 & .006\end{array}$

$\begin{array}{llllll}T(\hat{\phi}-1) & .164 & .198 & .194 & .188 & .160\end{array}$

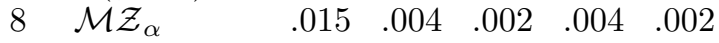

$\begin{array}{llllll}t_{\phi} & .019 & .036 & .056 & .057 & .050\end{array}$

$\begin{array}{llllll}\mathcal{M S B} & .012 & .002 & .002 & .003 & .002\end{array}$

$\begin{array}{llllll}\mathcal{M Z}_{t} & .028 & .008 & .006 & .002 & .004\end{array}$

$\begin{array}{llllll}T(\hat{\phi}-1) & .205 & .256 & .227 & .185 & .180\end{array}$

$12 \mathcal{M Z}_{\alpha}$

$t_{\phi}$

$\mathcal{M S B}$

$\begin{array}{lllll}012 & .005 & .004 & .001 & .003\end{array}$

$\begin{array}{lllll}.020 & .042 & .063 & .052 & .055\end{array}$

$\begin{array}{lllll}.010 & .004 & .002 & .001 & .002\end{array}$

$\mathcal{M Z}_{t}$

$T(\hat{\phi}-1)$

$24 \mathcal{M Z}_{\alpha}$

$t_{\phi}$

$\mathcal{M S B}$

$\begin{array}{lllll}.040 & .011 & .003 & .002 & .003\end{array}$

$\begin{array}{lllll}.295 & .336 & .304 & .254 & .222\end{array}$

$\begin{array}{lllll}.020 & .008 & .002 & .001 & .002\end{array}$

$\begin{array}{lllll}.028 & .058 & .072 & .065 & .068\end{array}$

$\begin{array}{lllll}.018 & 004 & .001 & .001 & .001\end{array}$

$\mathcal{M Z}_{t}$

$T(\hat{\phi}-1)$

$48 \mathcal{M Z}_{\alpha}$

$\mathcal{M S B}$ $\begin{array}{lllll}.055 & .008 & .003 & .002 & .004\end{array}$

$\begin{array}{lllll}.372 & .441 & .401 & .352 & .308\end{array}$

$\begin{array}{lllll}.029 & .005 & .002 & .001 & .003\end{array}$

$\begin{array}{lllll}.029 & .060 & .084 & .093 & .099\end{array}$ $\begin{array}{lllll}.118 & .092 & .071 & .059 & .058\end{array}$

$\begin{array}{llllll}.007 & .008 & .014 & .013 & .010\end{array}$

$\begin{array}{lllll}.005 & .004 & .008 & .008 & .011\end{array}$

$\begin{array}{lllll}.011 & .011 & .011 & .017 & .013\end{array}$

$\begin{array}{llllll}.126 & .107 & .070 & .070 & .071\end{array}$

$\begin{array}{lllll}.006 & .010 & .011 & .014 & .010\end{array}$

$\begin{array}{lllll}.008 & .014 & .025 & .024 & .033\end{array}$

$\begin{array}{lllll}.004 & .004 & .004 & .009 & .006\end{array}$

$\begin{array}{lllll}.011 & .006 & .014 & .011 & .013\end{array}$

$\begin{array}{llllll}.164 & .126 & .080 & .072 & .071\end{array}$

$\begin{array}{lllll}.009 & .003 & .010 & .011 & .012\end{array}$

$\begin{array}{lllll}.012 & .014 & .019 & .024 & .032\end{array}$

$\begin{array}{llllll}.004 & .003 & .006 & .007 & .006\end{array}$

$\begin{array}{lllll}.010 & .010 & .008 & .012 & .011\end{array}$

$\begin{array}{lllll}.216 & .159 & .097 & .084 & .079\end{array}$

$\begin{array}{lllll}.008 & .004 & .008 & .008 & .010\end{array}$

$\begin{array}{lllll}.010 & .016 & .022 & .022 & .030\end{array}$

$\begin{array}{lllll}.006 & .006 & .005 & .006 & .007\end{array}$ $\begin{array}{lllll}.014 & .010 & .019 & .016 & .016\end{array}$

$\begin{array}{lllll}.010 & .016 & .021 & .022 & .025\end{array}$ $\begin{array}{lllll}.201 & .100 & .037 & .020 & .034\end{array}$

$\begin{array}{lllll}.014 & .024 & .016 & .018 & .027\end{array}$

$\begin{array}{lllll}.183 & .086 & .033 & .015 & .029\end{array}$

$\begin{array}{llllll}.011 & .011 & .007 & .012 & .017\end{array}$

$\begin{array}{lllll}.173 & .075 & .028 & .009 & .018\end{array}$

$\begin{array}{lllll}.242 & .110 & .035 & .016 & .030\end{array}$

$\begin{array}{lllll}.010 & .023 & .015 & .019 & .023\end{array}$

$\begin{array}{lllll}.226 & .0101 & .030 & .012 & .024\end{array}$

$\begin{array}{lllll}.008 & .016 & .009 & .010 & .016\end{array}$

$\begin{array}{lllll}.214 & .090 & .023 & .010 & .016\end{array}$

$\begin{array}{lllll}.358 & .0143 & .035 & .008 & .018\end{array}$

$\begin{array}{lllll}.012 & .021 & .011 & .012 & .018\end{array}$

$\begin{array}{llllll}.343 & .138 & .028 & .006 & .014\end{array}$

$\begin{array}{lllll}.011 & .013 & .006 & .006 & .011\end{array}$

$\begin{array}{lllll}.327 & .122 & .023 & .004 & .009\end{array}$

$\begin{array}{lllll}.502 & .181 & .042 & .009 & .016\end{array}$

$\begin{array}{lllll}.017 & .022 & .020 & .015 & .018\end{array}$

$\begin{array}{lllll}.483 & .169 & .036 & .007 & .012\end{array}$

$\begin{array}{lllll}.013 & .010 & .010 & .007 & .010\end{array}$

$\begin{array}{lllll}.461 & .154 & .028 & .004 & .009\end{array}$

Note: $\psi=0, \boldsymbol{\phi}=\boldsymbol{\imath}_{n}$. Equicorrelated Disturbances.

$\begin{array}{lllll}.018 & .020 & .025 & .032 & .029\end{array}$

$\begin{array}{lllll}.068 & .054 & .051 & .054 & .048\end{array}$

$\begin{array}{lllll}.012 & .014 & .020 & .025 & .026\end{array}$

$\begin{array}{lllll}.007 & .010 & .021 & .027 & .027\end{array}$

$\begin{array}{lllll}.010 & 009 & .015 & .018 & .019\end{array}$

$\begin{array}{lllll}.020 & .016 & .020 & .031 & .026\end{array}$

$\begin{array}{lllll}.074 & .058 & .053 & .060 & .055\end{array}$

$\begin{array}{lllll}.012 & .010 & .021 & .024 & .020\end{array}$

$\begin{array}{lllll}.005 & .010 & .020 & .032 & .028\end{array}$

$\begin{array}{lllll}.007 & .007 & .014 & .018 & .017\end{array}$

$\begin{array}{lllll}.016 & .017 & .024 & .017 & .023\end{array}$

$\begin{array}{llllll}.081 & .076 & .057 & .044 & .052\end{array}$

$\begin{array}{lllll}.015 & .010 & .017 & .021 & .016\end{array}$

$\begin{array}{lllll}.004 & .010 & .019 & .019 & .024\end{array}$

$\begin{array}{lllll}.010 & 008 & 016 & .012 & .012\end{array}$

$\begin{array}{lllll}.016 & .016 & .015 & .018 & .020\end{array}$

$\begin{array}{llllll}.087 & .087 & .063 & .058 & .053\end{array}$

$\begin{array}{llllll}.009 & .008 & .017 & .016 & .018\end{array}$

$\begin{array}{lllll}.003 & .010 & .017 & .016 & .027\end{array}$

$\begin{array}{lllll}.006 & .008 & .006 & .008 & .010\end{array}$ 
Table III-Size of the $S^{H}$ Test Using Different Time

Series Tests.

\begin{tabular}{|c|c|c|c|c|c|c|c|c|c|c|c|c|c|c|c|}
\hline \multirow[b]{2}{*}{$n$} & \multirow[b]{2}{*}{$T$} & \multicolumn{5}{|c|}{$\tau=0.1$} & \multicolumn{5}{|c|}{$\tau=0.5$} & \multicolumn{4}{|c|}{$\tau=0.9$} \\
\hline & & 30 & 50 & 100 & 150 & 200 & 30 & 50 & 100 & 150 & 200 & 30 & 50 & 100 & $150 \quad 200$ \\
\hline
\end{tabular}

\begin{tabular}{|c|c|c|c|c|c|c|c|c|c|c|c|}
\hline \multicolumn{12}{|c|}{ (i) $\delta=1 / 5$} \\
\hline \multirow{5}{*}{8} & $\mathcal{M \mathcal { Z } _ { t }}$ & .070 & .058 & .064 & .059 & .051 & .057 & .048 & .047 & .050 & .045 \\
\hline & $T(\hat{\phi}-1)$ & .163 & .103 & .067 & .040 & .044 & .092 & .070 & .056 & .049 & .044 \\
\hline & $\mathcal{M} \mathcal{Z}_{\alpha}$ & .045 & .042 & .053 & .055 & .042 & .051 & .036 & .039 & .033 & .036 \\
\hline & & .036 & .041 & .038 & .033 & .035 & .036 & .042 & .047 & .039 & .040 \\
\hline & $\mathcal{M S B}$ & .045 & .038 & .040 & .040 & .032 & .040 & .034 & .033 & .033 & .032 \\
\hline \multirow{5}{*}{12} & $\mathcal{M} \mathcal{Z}_{t}$ & .067 & .056 & .063 & .056 & .048 & .064 & .042 & .042 & .044 & .044 \\
\hline & $T(\hat{\phi}-1)$ & .198 & .131 & .072 & .039 & .048 & .107 & .067 & .058 & .046 & .052 \\
\hline & $\mathcal{M} \mathcal{Z}_{\alpha}$ & .054 & .048 & .044 & .049 & .030 & .052 & .036 & .035 & .032 & .037 \\
\hline & & .031 & .036 & .040 & .027 & .038 & .034 & .029 & .038 & .034 & .043 \\
\hline & $\mathcal{M S B}$ & .043 & .034 & .042 & .038 & .030 & .044 & .027 & .022 & .028 & .030 \\
\hline \multirow{5}{*}{24} & $\mathcal{M \mathcal { Z } _ { t }}$ & .056 & .046 & .060 & .046 & .048 & .074 & .040 & .042 & .034 & .035 \\
\hline & $T(\hat{\phi}-1)$ & .263 & .193 & .091 & .049 & .052 & .123 & .091 & .070 & .059 & .052 \\
\hline & $\mathcal{M} \mathcal{Z}_{\alpha}$ & .053 & .032 & .056 & .035 & .039 & .060 & .037 & .029 & .028 & .033 \\
\hline & $t_{\phi}$ & .036 & .051 & .043 & .032 & .041 & .028 & .044 & .045 & .040 & .040 \\
\hline & $\mathcal{M S B}$ & .039 & .030 & .041 & .030 & .030 & .053 & .028 & .027 & .021 & .020 \\
\hline \multirow{5}{*}{48} & $\mathcal{M \mathcal { Z } _ { t }}$ & .051 & .052 & .064 & .060 & .039 & .085 & .042 & .031 & .029 & .031 \\
\hline & $T(\hat{\phi}-1)$ & .420 & .253 & .106 & .062 & .052 & .184 & .117 & .074 & .065 & .065 \\
\hline & $\mathcal{M} \mathcal{Z}_{\alpha}$ & .051 & .049 & .048 & .032 & .031 & .072 & .028 & .033 & .025 & .021 \\
\hline & & .032 & .044 & .046 & .044 & .039 & .035 & .042 & .041 & .043 & .046 \\
\hline & $\mathcal{M S B}$ & .031 & .028 & .042 & .036 & .019 & .068 & .027 & .016 & .017 & .020 \\
\hline
\end{tabular}

$\begin{array}{lllll}.158 & .079 & .040 & .018 & .032\end{array}$

$\begin{array}{lllll}.018 & .026 & .017 & .022 & .024\end{array}$

$\begin{array}{lllll}.145 & .071 & .034 & .014 & .024\end{array}$

$\begin{array}{lllll}.007 & .013 & .011 & .012 & .018\end{array}$

$\begin{array}{lllll}.134 & .059 & .026 & .011 & .021\end{array}$

$\begin{array}{llllll}.231 & .083 & .036 & .020 & .028\end{array}$

$\begin{array}{lllll}.018 & .024 & .014 & .029 & .025\end{array}$

$\begin{array}{lllll}.212 & .074 & .028 & .012 & .022\end{array}$

$\begin{array}{lllll}.012 & .010 & .011 & .017 & .013\end{array}$

$\begin{array}{lllll}.197 & .064 & .022 & .007 & .017\end{array}$

$\begin{array}{lllll}.330 & .115 & .033 & .009 & .022\end{array}$

$\begin{array}{lllll}.015 & .021 & .017 & .018 & .018\end{array}$

$\begin{array}{lllll}.312 & .106 & .028 & .008 & .018\end{array}$

$\begin{array}{lllll}.010 & .010 & .010 & .009 & .010\end{array}$

$\begin{array}{lllll}.288 & .091 & .022 & .006 & .012\end{array}$

$\begin{array}{lllll}.483 & .186 & .036 & .007 & .014\end{array}$

$\begin{array}{lllll}.016 & .021 & .019 & .017 & .024\end{array}$

$\begin{array}{lllll}.460 & .169 & .031 & .006 & .010\end{array}$

$\begin{array}{lllll}.009 & .010 & .010 & .010 & .015\end{array}$

$\begin{array}{lllll}.437 & .153 & .024 & .004 & .007\end{array}$

(ii) $\delta=5$

$\begin{array}{lllllllllll}\mathcal{M Z}_{t} & .018 & .015 & .012 & .012 & .017 & .016 & .013 & .018 & .022 & .025\end{array}$

$\begin{array}{lllll}.090 & .087 & .057 & .050 & .052\end{array}$

$\begin{array}{lllll}.016 & .023 & .024 & .031 & .031\end{array}$

$\begin{array}{llllll}T(\hat{\phi}-1) & .106 & .111 & .112 & .098 & .087\end{array}$

$\begin{array}{lllll}.009 & .006 & .018 & .016 & .018\end{array}$

$\begin{array}{lllll}.068 & .056 & .047 & .048 & .048\end{array}$

$8 \mathcal{M Z}_{\alpha}$

$\begin{array}{lllll}.010 & .011 & .010 & .010 & .013\end{array}$

$\begin{array}{lllll}.013 & .018 & .021 & .022 & .026\end{array}$

$\begin{array}{lllll}.014 & .014 & .023 & .024 & .021\end{array}$

$\begin{array}{llllll}t_{\phi} & .011 & .018 & .026 & .027 & .034\end{array}$

$\begin{array}{lllll}.008 & .006 & .012 & .015 & .015\end{array}$

$\begin{array}{lllll}.006 & .012 & .016 & .025 & .029\end{array}$

$\begin{array}{llllll}\mathcal{M S B} & 011 & .009 & .007 & .008 & .011\end{array}$

$\begin{array}{lllll}.014 & .012 & .017 & .020 & .019\end{array}$

$\begin{array}{lllll}.010 & 011 & 016 & .016 & .014\end{array}$

$\mathcal{M Z}_{t}$

$\begin{array}{lllll}.019 & .013 & .013 & .014 & .016\end{array}$

$\begin{array}{lllll}.106 & .082 & .070 & .054 & .058\end{array}$

$\begin{array}{lllll}.016 & .017 & .026 & .027 & .024\end{array}$

$\begin{array}{llllll}T(\hat{\phi}-1) & .120 & .146 & .132 & .120 & .094\end{array}$

$\begin{array}{lllll}.007 & .009 & .014 & .016 & .017\end{array}$

$\begin{array}{lllll}.070 & .056 & .052 & .052 & .051\end{array}$

$12 \mathcal{M Z}_{\alpha}$

$\begin{array}{lllll}.011 & .009 & .010 & .010 & .013\end{array}$

$\begin{array}{lllll}.007 & .010 & .024 & .021 & .027\end{array}$

$\begin{array}{lllll}.011 & .011 & .012 & .026 & .023\end{array}$

$\mathcal{M S B}$

$\begin{array}{lllll}.008 & .007 & .008 & .007 & .009\end{array}$

$\begin{array}{llllll}.005 & .007 & .011 & .010 & .010\end{array}$

$\begin{array}{lllll}.006 & .010 & .022 & .022 & .025\end{array}$

$\begin{array}{lllll}.008 & .007 & .014 & .016 & .013\end{array}$

$\begin{array}{lllllllllll}\mathcal{M Z}_{t} & .020 & .010 & .012 & .011 & .011 & .008 & .012 & .015 & .016 & .018\end{array}$

$\begin{array}{lllll}.011 & .018 & .023 & .023 & .025\end{array}$

$\begin{array}{lllllllllll}T(\hat{\phi}-1) & .157 & .185 & .152 & .137 & .123 & .136 & .108 & .069 & .064 & .063\end{array}$

$\begin{array}{lllll}.086 & .078 & .054 & .056 & .058\end{array}$

$24 \mathcal{M Z}_{\alpha}$

$\begin{array}{lllll}.012 & .006 & .006 & .009 & .010\end{array}$

$\begin{array}{lllll}.012 & .006 & .010 & .013 & .018\end{array}$

$\begin{array}{lllll}.011 & .011 & .015 & .022 & .019\end{array}$

$t_{\phi}$

$\begin{array}{lllll}.011 & .020 & .030 & .034 & .041\end{array}$

$\begin{array}{lllll}.010 & .011 & .017 & .026 & .028\end{array}$

$\begin{array}{lllll}.003 & .009 & .019 & .026 & .031\end{array}$

$\mathcal{M Z _ { t }}$

$\begin{array}{llllll}.010 & .005 & .003 & .006 & .008\end{array}$

$\begin{array}{lllll}.004 & .006 & .009 & .012 & .013\end{array}$

$\begin{array}{lllll}.006 & 010 & .014 & .015 & .018\end{array}$

$T(\hat{\phi}-1)$

$\begin{array}{lllll}.021 & .010 & .010 & .008 & .014\end{array}$

$\begin{array}{lllll}.011 & .006 & .019 & .016 & .014\end{array}$

$\begin{array}{lllll}.016 & .013 & .016 & .020 & .015\end{array}$

$48 \mathcal{M Z}_{\alpha}$

$\begin{array}{llllll}.217 & .252 & .220 & .180 & .160\end{array}$

$\begin{array}{lllll}.176 & .138 & .092 & .078 & .060\end{array}$

$\begin{array}{lllll}.115 & .092 & .072 & .060 & .048\end{array}$

$t_{\phi}$

$\begin{array}{lllll}.011 & .006 & .007 & .006 & .012\end{array}$

$\begin{array}{llllll}.015 & .008 & .007 & .014 & .010\end{array}$

$\begin{array}{lllll}.012 & .008 & .017 & .020 & .017\end{array}$

$\begin{array}{lllll}.004 & .012 & .020 & .025 & .020\end{array}$

$\begin{array}{lllll}.010 & .023 & .044 & .042 & .044\end{array}$

$\begin{array}{lllll}.005 & .016 & .024 & .026 & .026\end{array}$

$\begin{array}{lllll}.008 & .008 & .008 & .011 & .011\end{array}$

Note: $\psi=0, \phi=\boldsymbol{\imath}_{n}$. Factor dependent Disturbances. 
TABle IV-Power of the $S^{H}$ Test Using Different

Time Series Tests.

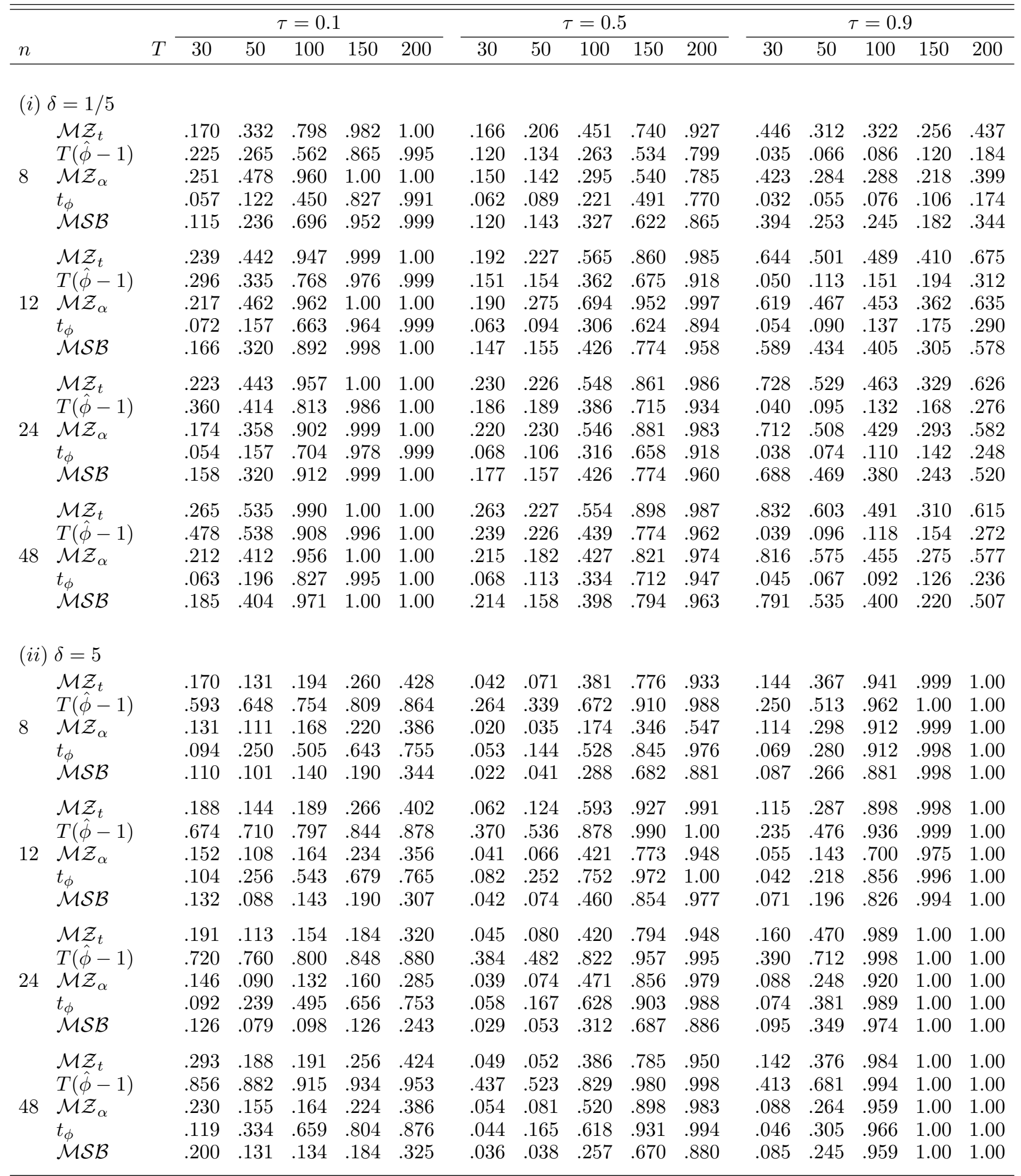

Note: $\psi=0, \phi=\left(\boldsymbol{\imath}_{n / 2}^{\prime}, \widetilde{\phi}_{n / 2}^{\prime}\right)^{\prime}$ with $\left(\widetilde{\phi}_{n / 2}\right)_{i} \sim \mathcal{U}(.75,1)$. Equicorrelated Disturbances. 
Table V-Power of the $S^{H}$ Test Using Different Time

Series Tests.

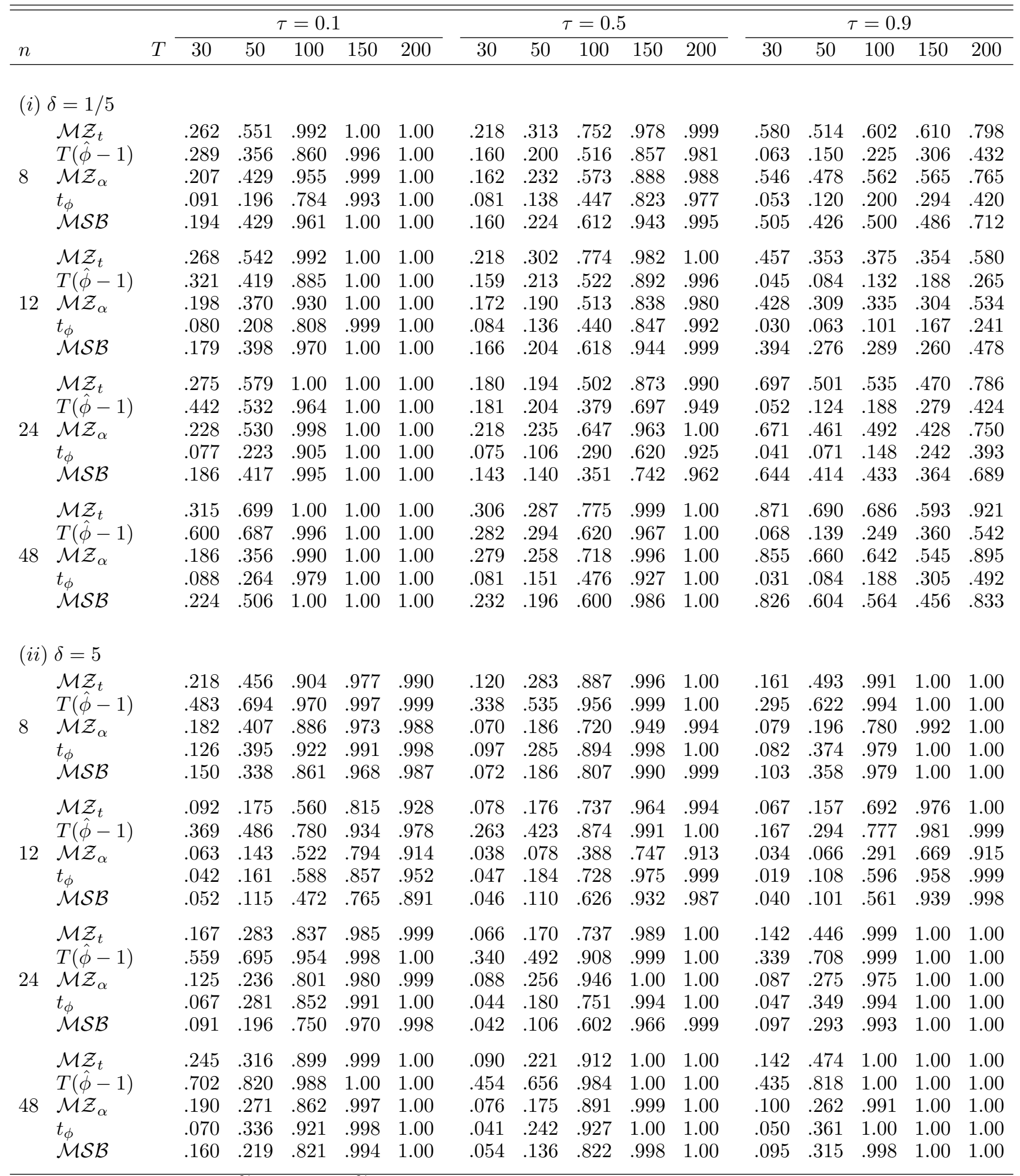

Note: $\psi=0, \phi=\left(\boldsymbol{\imath}_{n / 2}^{\prime}, \widetilde{\phi}_{n / 2}^{\prime}\right)^{\prime}$ with $\left(\widetilde{\phi}_{n / 2}\right)_{i} \sim \mathcal{U}(.75,1)$. Factor dependent Disturbances. 
Table VI-Power of the $S^{H}$ Test Using Different

Time Series Tests.

\begin{tabular}{|c|c|c|c|c|c|c|c|c|c|c|c|c|c|c|c|c|c|}
\hline & & & & & $=0$. & & & & & $=0$. & & & & & $=0$ & & \\
\hline$n$ & & $T$ & 30 & 50 & 100 & 150 & 200 & 30 & 50 & 100 & 150 & 200 & 30 & 50 & 100 & 150 & 200 \\
\hline & $1 / 5$ & & & & & & & & & & & & & & & & \\
\hline & $\mathcal{M} \mathcal{Z}_{t}$ & & .180 & .248 & .587 & .860 & .973 & .141 & .140 & .225 & .361 & .486 & .425 & .311 & .271 & .245 & .398 \\
\hline & $T(\hat{\phi}-1)$ & & .222 & .236 & .420 & .641 & .896 & .097 & .106 & .145 & .248 & .360 & .026 & .061 & .086 & .130 & .178 \\
\hline 8 & $\hat{\mathcal{M}} \mathcal{Z}_{\alpha}$ & & .130 & .169 & .363 & .641 & .834 & .099 & .098 & .123 & .175 & .233 & .397 & .281 & .237 & .206 & .352 \\
\hline & & & .050 & .103 & .312 & .581 & .868 & .044 & .070 & .117 & .215 & .328 & .024 & .042 & .071 & .110 & .162 \\
\hline & $\mathcal{M S B}$ & & .124 & .172 & .453 & .752 & .931 & .102 & .090 & .150 & .259 & .355 & .370 & .249 & .197 & .156 & .298 \\
\hline & $\mathcal{M \mathcal { Z } _ { t }}$ & & .127 & .187 & .416 & .670 & .880 & .166 & .170 & .308 & .461 & .634 & .518 & .341 & .279 & .227 & .404 \\
\hline & $T(\hat{\phi}-1)$ & & .244 & .235 & .316 & .453 & .748 & .118 & .123 & .206 & .313 & .502 & .031 & .055 & .092 & .122 & .199 \\
\hline 12 & $\hat{\mathcal{M}} \mathcal{Z}_{\alpha}$ & & .169 & .236 & .568 & .855 & .968 & .146 & .153 & .249 & .442 & .633 & .490 & .316 & .237 & .186 & .360 \\
\hline & & & .051 & .079 & .196 & .376 & .693 & .056 & .084 & .160 & .270 & .455 & .025 & .043 & .066 & .097 & .171 \\
\hline & $\mathcal{M S B}$ & & .084 & .122 & .307 & .535 & .777 & .120 & .113 & .213 & .333 & .485 & .461 & .280 & .196 & .148 & .296 \\
\hline & $\mathcal{M \mathcal { Z } _ { t }}$ & & .163 & .211 & .530 & .819 & .961 & .171 & .149 & .254 & .434 & .592 & .668 & .431 & .319 & .220 & .444 \\
\hline & $T(\hat{\phi}-1)$ & & .346 & .316 & .433 & .642 & .900 & .163 & .139 & .206 & .334 & .505 & .030 & .068 & .094 & .142 & .214 \\
\hline 24 & $\mathcal{M} \mathcal{Z}_{\alpha}$ & & .128 & .162 & .434 & .721 & .905 & .160 & .139 & .219 & .378 & .530 & .645 & .400 & .279 & .184 & .399 \\
\hline & & & .051 & .098 & .279 & .558 & .862 & .057 & .080 & .146 & .276 & .453 & .032 & .046 & .072 & .114 & .189 \\
\hline & $\mathcal{M S B}$ & & .114 & .144 & .398 & .720 & .912 & .132 & .103 & .178 & .308 & .448 & .626 & .369 & .230 & .134 & .341 \\
\hline & $\mathcal{M Z _ { t }}$ & & .164 & .188 & .475 & .776 & .932 & .214 & .150 & .205 & .356 & .508 & .768 & .465 & .253 & .140 & .379 \\
\hline & $T(\hat{\phi}-1)$ & & .430 & .406 & .474 & .603 & .874 & .196 & .183 & .222 & .320 & .473 & .024 & .056 & .076 & .120 & .196 \\
\hline 48 & $\mathcal{M} \mathcal{Z}_{\alpha}$ & & .150 & .211 & .546 & .814 & .956 & .176 & .114 & .146 & .248 & .346 & .755 & .442 & .228 & .112 & .338 \\
\hline & & & .053 & .105 & .278 & .501 & .834 & .055 & .087 & .161 & .257 & .424 & .028 & .039 & .054 & .076 & .150 \\
\hline & $\mathcal{M S B}$ & & .115 & .129 & .343 & .650 & .860 & .170 & .105 & .132 & .229 & .362 & .732 & .403 & .192 & .076 & .272 \\
\hline & 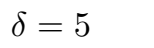 & & & & & & & & & & & & & & & & \\
\hline & $\mathcal{M Z}_{t}$ & & .094 & .053 & .066 & .106 & .165 & .029 & .043 & .174 & .326 & .492 & .052 & .073 & .228 & .490 & .716 \\
\hline & $T(\hat{\phi}-1)$ & & .560 & .585 & .592 & .611 & .666 & .258 & .278 & .434 & .583 & .776 & .128 & .173 & .337 & .627 & .815 \\
\hline 8 & $\mathcal{M} \mathcal{Z}_{\alpha}$ & & .059 & .038 & .051 & .088 & .141 & .025 & .036 & .156 & .300 & .458 & .052 & .084 & .325 & .672 & .900 \\
\hline & & & .060 & .137 & .262 & .352 & .438 & .040 & .089 & .230 & .418 & .635 & .016 & .055 & .200 & .481 & .719 \\
\hline & $\mathcal{M S B}$ & & .050 & .030 & .040 & .068 & .112 & .015 & .026 & .106 & .226 & .353 & .031 & .044 & .158 & .375 & .585 \\
\hline & $\mathcal{M Z _ { t }}$ & & .096 & .047 & .055 & .078 & .142 & .030 & .039 & .132 & .277 & .407 & .066 & .121 & .425 & .786 & .944 \\
\hline & $T(\hat{\phi}-1)$ & & .569 & .604 & .622 & .646 & .676 & .237 & .266 & .407 & .559 & .733 & .174 & .266 & .581 & .866 & .972 \\
\hline 12 & $\hat{\mathcal{M}} \mathcal{Z}_{\alpha}$ & & .064 & .031 & .040 & .060 & .118 & .026 & .038 & .166 & .340 & .503 & .041 & .076 & .246 & .544 & .756 \\
\hline & & & .055 & .132 & .252 & .365 & .437 & .024 & .060 & .197 & .384 & .592 & .025 & .082 & .382 & .763 & .940 \\
\hline & $\mathcal{M S B}$ & & .052 & .028 & .028 & .046 & .093 & .016 & .020 & .087 & .186 & .291 & .036 & .078 & .299 & .672 & .889 \\
\hline & & & .144 & .064 & .065 & .090 & .178 & .034 & .036 & .150 & .342 & .51 & .055 & .098 & .376 & .738 & .925 \\
\hline & $T(\hat{\phi}-1)$ & & .721 & .761 & .748 & .778 & .810 & .334 & .367 & .514 & .711 & .860 & .192 & .278 & .586 & .856 & .966 \\
\hline 24 & $\mathcal{M} \mathcal{Z}_{\alpha}$ & & .100 & .045 & .048 & .072 & .148 & .022 & .027 & .117 & .209 & .326 & .044 & .064 & .296 & .664 & .886 \\
\hline & & & .071 & .194 & .378 & .507 & .584 & .039 & .087 & .260 & .510 & .73 & .016 & .063 & .369 & .721 & .932 \\
\hline & $\mathcal{M S B}$ & & .076 & .035 & .035 & .058 & .114 & .019 & .022 & .095 & .238 & .362 & .029 & .058 & .271 & .616 & .858 \\
\hline & $\mathcal{M Z}_{t}$ & & .178 & .070 & .058 & .068 & .144 & .033 & .031 & .099 & .220 & .324 & .058 & .085 & .405 & .774 & .955 \\
\hline & $T(\hat{\phi}-1)$ & & .796 & .834 & .828 & .834 & .858 & .389 & .358 & .453 & .622 & .767 & .244 & .307 & .639 & .900 & .984 \\
\hline 48 & $\mathcal{M} \mathcal{Z}_{\alpha}$ & & .123 & .052 & .044 & .051 & .118 & .032 & .026 & .108 & .257 & .390 & .040 & .061 & .347 & .706 & .917 \\
\hline & & & .084 & .216 & .426 & .569 & .653 & .025 & .068 & .188 & .379 & .598 & .018 & .062 & .380 & .777 & .960 \\
\hline & $\mathcal{M S B}$ & & .103 & .040 & .028 & .039 & .086 & .020 & .018 & .058 & .148 & .210 & .032 & .044 & .281 & .658 & .894 \\
\hline
\end{tabular}

Note: $\psi=0, \phi=\widetilde{\phi}_{n}$ with $\left(\widetilde{\phi}_{n}\right)_{i} \sim \mathcal{U}(.9,1)$. Equicorrelated Disturbances. 
Table VII-Power of the $S^{H}$ Test Using Different

Time Series Tests.

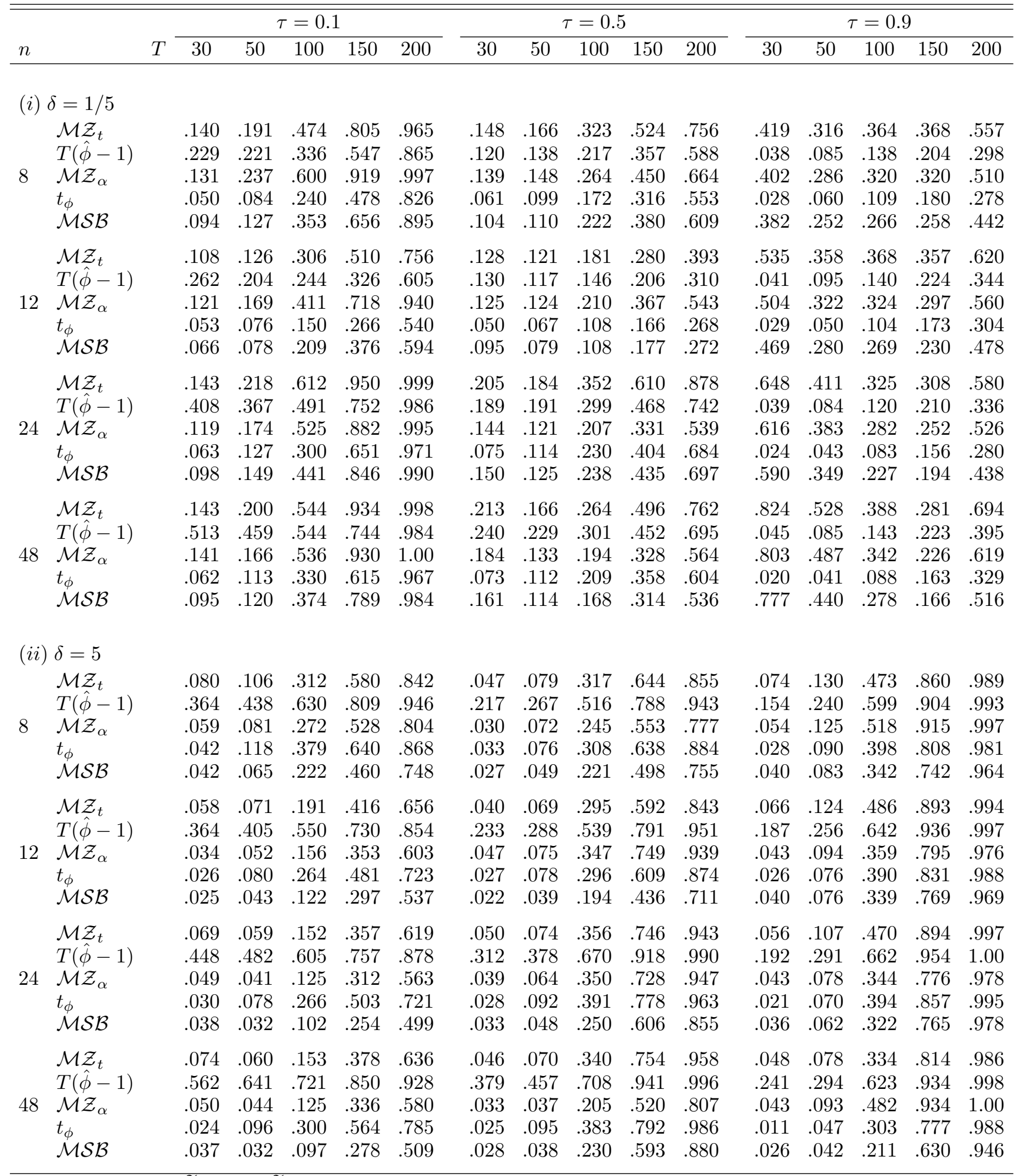

Note: $\psi=0, \phi=\widetilde{\phi}_{n}$ with $\left(\widetilde{\phi}_{n}\right)_{i} \sim \mathcal{U}(.9,1)$. Factor dependent Disturbances. 
A. Equicorrelation: Let $\tilde{\boldsymbol{\xi}}_{t}=\left(\tilde{\xi}_{1, t}, \ldots, \tilde{\xi}_{n, t}\right)^{\prime}$. Then, generate $\boldsymbol{\varepsilon}_{t}:=\left(\epsilon_{1, t}, \ldots, \epsilon_{n, t}\right)^{\prime}=\boldsymbol{\Sigma}^{1 / 2} \tilde{\boldsymbol{\xi}}_{t}$, where $\boldsymbol{\Sigma}=\theta \boldsymbol{\imath}_{n} \boldsymbol{\imath}_{n}^{\prime}+(1-\theta) \boldsymbol{I}_{n}$ with $\boldsymbol{\imath}_{n}=(1, \ldots, 1)^{\prime},(n \times 1), \theta=0.5$ and $\boldsymbol{I}_{n}$ the $(n \times n)$ identity matrix.

B. Factor Structure: Let $\epsilon_{i, t}:=\lambda_{i} \cdot \nu_{t}+\tilde{\xi}_{i, t}$, where $\nu_{t}$ are i.i.d. $\mathcal{N}(0,1)$ and $\lambda_{i} \sim \mathcal{U}(-1,3)$, with $\mathcal{U}$ denoting the uniform distribution.

When $\boldsymbol{\phi}:=\left(\phi_{1}, \ldots, \phi_{n}\right)^{\prime}=\boldsymbol{\imath}_{n}, H_{0}=\bigcap_{i \in \mathbb{N}_{n}} H_{i, 0}$ is true, allowing us to study the size of the tests. Choosing $\phi$ such that $\min _{i}|\phi|<1$, we analyze power of the tests. More specifically, we let $\phi=\left(\boldsymbol{v}_{n / 2}^{\prime}, \widetilde{\boldsymbol{\phi}}_{n / 2}^{\prime}\right)^{\prime}$ and $\boldsymbol{\phi}=\widetilde{\boldsymbol{\phi}}_{n}$ to investigate stationary alternatives. The components of $\widetilde{\boldsymbol{\phi}}$ are distributed as $(\widetilde{\phi})_{i} \sim \mathcal{U}(3 / 4,1)$ in the first power experiment and as $(\widetilde{\phi})_{i} \sim \mathcal{U}(0.9,1)$ in the second power experiment. Based on 2,500 replications, we calculate the rejection rates of the $S^{H}$ test based on the statistics from (5) and (6). When $\psi \neq 0$, we select $k_{i}$ using the criterion of $\mathrm{Ng}$ and Perron [1995].

Selected results of the experiments are reported in Tables II to VII. ${ }^{8}$ The entries after, e.g., $\mathcal{M S B}$ denote the rejection rates for the $S^{H}$ test when the $p$-values (3) are calculated from $n$ $\mathcal{M S B}_{i}$ test statistics, defined in (5). The main findings can be summarized as follows.

The $S^{H}$ test is a level- $\alpha$ test throughout, at least for moderate and large $T$ (there are some exceptions to this finding for $T(\hat{\phi}-1))$. When $\delta$ is large and $\tau$ is small, or vice-versa, $S^{H}$ is somewhat conservative. This is not surprising as this is precisely the case when the time series tests of Cavaliere and Taylor [2008] underreject, too. In other cases, size is well-controlled. Overall, the differences between the equicorrelated scenario (Table II) and the factor-dependence scenario (Table III) are small, suggesting robustness of the $S^{H}$ test to general patterns of crosssectional dependence. No clear pattern emerges as to which underlying time series yields the best performance of the $S^{H}$ test. Thus, a case can be made to recommend the popular and widely implemented Dickey and Fuller [1979] nonstationary-volatility robust $t_{\phi}$ test developed here.

\footnotetext{
${ }^{8}$ The full set of results is available upon request. In particular, we do not report results for $\psi \neq 0$ for brevity. As one would expect, these are worse than those under no autocorrelation, with some severe upward size distortions for small $T$, which however vanish with increasing $T$. These size distortions are caused by the well-known sensitivity of time series unit root tests to moving-average disturbances, which then carry over into the panel test.
} 
Concerning power (Tables IV to VII), we again find no clear ranking of the different underlying tests, as power quickly grows with $T$ for all variants of the $S^{H}$ test. Similar to the findings for size, the tests perform better in the sense of having higher power when the breaks in the innovation variance are either early positive (both $\delta$ and $\tau$ small) or late negative (both $\delta$ and $\tau$ large), consistent with the time series evidence of Cavaliere and Taylor [2008]. Also note that power is higher in those panels where only half of the series are stationary $\left(\phi=\left(\boldsymbol{\imath}_{n / 2}^{\prime}, \widetilde{\boldsymbol{\phi}}_{n / 2}^{\prime}\right)^{\prime}\right)$ than in the entirely stationary panel $\left(\phi=\widetilde{\phi}_{n}\right)$. This is because the cutoff criterion for the $S^{H}$ test, (3), is more likely to be satisfied for some $i$ when there are strongly stationary series in the panel, as the corresponding $p$-values will then already be closer to their probability limit of 0 for finite $T$ than if $\boldsymbol{\phi} \approx \boldsymbol{\imath}$.

\section{GDP Stationarity in Panel Data and the 'Great Mod- eration'}

We now present an application of the $S^{H}$ test to investigate the null hypothesis that there is a unit root in the (logarithms of) GDPs in a panel of OECD countries. At least since the seminal work of Nelson and Plosser [1982], the possible nonstationarity of GDPs has been a cornerstone of empirical macroeconomics. As emphasized for instance by Campbell and Perron [1991], the distinction between trend stationarity and difference stationarity is potentially important in many contexts, such as forecasting, because the trend- and difference stationary models may imply very different dynamics. If the series contain a unit root, shocks have persistent effects. As a result, the series do not return to their former path following a random disturbance, and the level of the series shift permanently. On the other hand, if the series do not contain a unit root, the underlying trends are deterministic. In this case the series return to their steady trend after the shock. Hence, the forecasts implied by the two models are vastly different.

Some prominent papers in this literature are Cochrane [1988], who finds a small random walk component in U.S. GDP, whereas Cogley [1990] and Kormendi and Meguire [1990] identify stronger random-walk behavior in multi-country studies. Kwiatkowski, Phillips, Schmidt and Shin [1992] report weak evidence against the null of trend stationarity for U.S. GNP. Relying on Bayesian techniques, DeJong and Whiteman [1991] forcefully argue against the presence of 
a unit root in U.S. GDP. The debate appears to be far from settled, with recent contributions both supporting [Vougas, 2007] and rejecting [Murray and Nelson, 2000] stationarity.

Recently, panel methods have been used to investigate GDP stationarity in industrialized countries. Using first generation tests, Strauss [2000] finds evidence of stationarity in a panel of U.S. states. On the contrary, Rapach's [2002] study using Levin et al.'s [2002] and Im et al.'s [2003] tests cannot reject the null of nonstationarity for a panel of international output levels.

However, all of the above results are obtained within the paradigm of homoscedastic (panel) unit root tests. We believe that these results may not be reliable in view of what is known as the 'Great Moderation.' It is a well-established stylized fact that many countries enjoy a moderation of the business cycle and, more generally, reduced volatility in the growth rates of GDPs. See, for instance, Blanchard and Simon [2001] for some international evidence. The reasons for this decline are surveyed in Stock and Watson [2002] and include structural changes in output from goods to services, information-technology-led improvements in inventory management and innovations in financial markets.

See Figure I for some selected time series of historical growth rates of OECD countries (see below for a description of the dataset). It is readily apparent that the volatility of GDP growth is smaller since, in most cases, the 1980s. Concretely, the United States and Australia appear to experience reduced GDP-growth variance since the mid-80s, whereas the reduction seems to have set in somewhat later in Canada and the United Kingdom. As we saw in Section 2.1, traditional (panel) unit root tests produce misleading results in the presence of such nonstationary volatility. Furthermore, the above-mentioned panel studies disregard the unquestionable presence of cross-sectional dependence among output levels-better known as 'Globalization.'

We therefore compute the $S^{H}$ test to provide potentially more reliable inference in the presence of nonstationary volatility. An attractive feature of constructing a panel test of GDP stationarity using Cavaliere and Taylor's approach is that we can easily sidestep the debate whether the reduction in volatility is due to a break or a continuing downward trend in innovation variances. (The former view is held by Kim and Nelson [1999] and McConnell and Perez-Quiros [2000] whereas the findings of Blanchard and Simon [2001] support the latter.) As long as the innovation variances satisfy the mild assumption (see ass. 2) that $\sigma_{i,\lfloor s T\rfloor} \in \mathcal{D}$, the time-transformed 

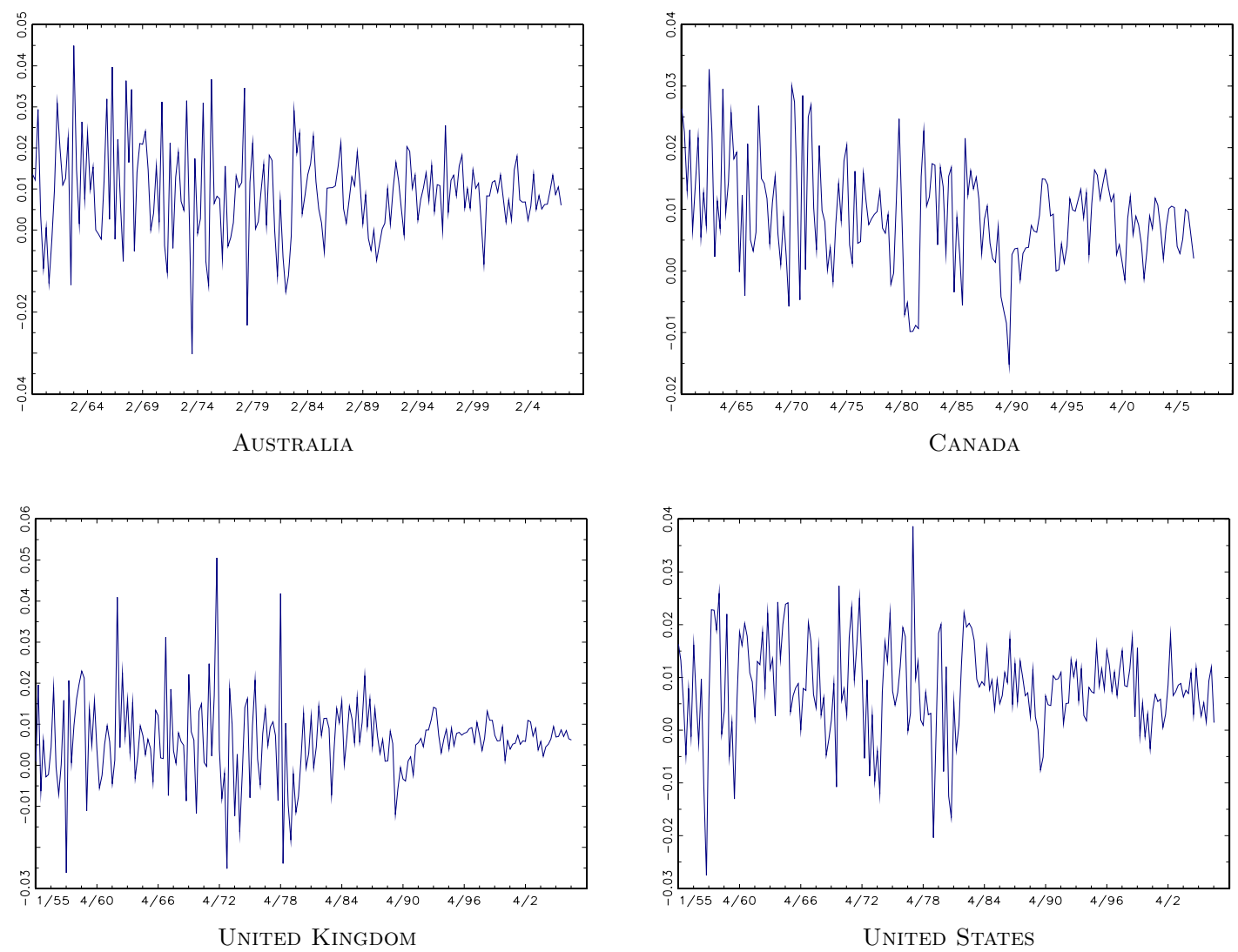

Figure I-SOME Historical Growth RATES

time series unit root tests employed here will automatically adjust to the variance patterns in the different countries.

Our dataset comprises the seasonally adjusted quarterly GDP levels from all current 30 OECD members, constructed from data made available on the OECD website (series LNBQRSA, at 2000 prices in most cases). The series start at varying dates, ranging from 1955Q1 in the case of the United Kingdom and the United States to 2000Q1 for Greece, Hungary and Ireland, yielding time series lengths ranging from $T=32$ to $T=212$. In view of the secular trend in Gross Domestic Products, we need to accommodate time trends the construction of the test statistics in the present application. We thus calculate the time series test statistics from (5) and (6) employing the trend-corrected statistics as outlined in Cavaliere and Taylor [2008, Sec. 5]. The $p$-values are then computed from the corresponding limiting distributions that are then functionals of detrended Brownian Motions. The lag orders $k_{i}$ required to account for autocorrelation in growth rates are chosen with the automatic criterion of $\mathrm{Ng}$ and Perron 
TABLE VIII-SORTED $p$-VALUES OF Nonstationary-Volatility Robust Unit Root Tests.

\begin{tabular}{lllllll}
\hline \hline & $\mathcal{M Z}_{t}$ & $t_{\phi}$ & $\mathcal{M Z}_{\alpha}$ & $T(\hat{\phi}-1)$ & $\mathcal{M S B}$ & Simes' cutoff \\
\hline & & & & & & \\
$p_{(1)}$ & 0.010 & 0.000 & 0.042 & 0.004 & 0.033 & 0.002 \\
$p_{(2)}$ & 0.012 & 0.032 & 0.120 & 0.125 & 0.115 & 0.003 \\
$p_{(3)}$ & 0.068 & 0.239 & 0.174 & 0.253 & 0.212 & 0.005 \\
$p_{(4)}$ & 0.112 & 0.278 & 0.220 & 0.258 & 0.257 & 0.007 \\
$p_{(5)}$ & 0.149 & 0.291 & 0.290 & 0.313 & 0.278 & 0.008 \\
$p_{(6)}$ & 0.255 & 0.332 & 0.307 & 0.355 & 0.471 & 0.010 \\
$p_{(7)}$ & 0.331 & 0.347 & 0.308 & 0.359 & 0.630 & 0.012 \\
$p_{(8)}$ & 0.336 & 0.363 & 0.454 & 0.363 & 0.806 & 0.013 \\
$p_{(9)}$ & 0.385 & 0.400 & 0.622 & 0.410 & 0.810 & 0.015 \\
$p_{(10)}$ & 0.431 & 0.411 & 0.676 & 0.440 & 0.811 & 0.017 \\
$p_{(11)}$ & 0.462 & 0.601 & 0.756 & 0.591 & 0.853 & 0.018 \\
$p_{(12)}$ & 0.553 & 0.631 & 0.791 & 0.735 & 0.876 & 0.020 \\
$p_{(13)}$ & 0.673 & 0.735 & 0.813 & 0.780 & 0.900 & 0.022 \\
$p_{(14)}$ & 0.708 & 0.738 & 0.828 & 0.795 & 0.900 & 0.023 \\
$p_{(15)}$ & 0.783 & 0.780 & 0.854 & 0.805 & 0.906 & 0.025 \\
$p_{(16)}$ & 0.838 & 0.794 & 0.914 & 0.808 & 0.924 & 0.027 \\
$p_{(17)}$ & 0.851 & 0.810 & 0.964 & 0.816 & 0.969 & 0.028 \\
$p_{(18)}$ & 0.922 & 0.824 & 0.964 & 0.818 & 0.976 & 0.030 \\
$p_{(19)}$ & 0.935 & 0.841 & 0.965 & 0.866 & 0.984 & 0.032 \\
$p_{(20)}$ & 0.958 & 0.843 & 0.971 & 0.867 & 0.986 & 0.033 \\
$p_{(21)}$ & 0.964 & 0.874 & 0.972 & 0.868 & 0.990 & 0.035 \\
$p_{(22)}$ & 0.966 & 0.880 & 0.974 & 0.869 & 0.992 & 0.037 \\
$p_{(23)}$ & 0.973 & 0.885 & 0.977 & 0.872 & 0.993 & 0.038 \\
$p_{(24)}$ & 0.974 & 0.888 & 0.980 & 0.932 & 0.997 & 0.040 \\
$p_{(25)}$ & 0.986 & 0.935 & 0.992 & 0.936 & 0.999 & 0.042 \\
$p_{(26)}$ & 0.999 & 0.951 & 0.999 & 0.955 & 1.00 & 0.043 \\
$p_{(27)}$ & 1.00 & 0.971 & 0.999 & 0.961 & 1.00 & 0.045 \\
$p_{(28)}$ & 1.00 & 0.977 & 0.999 & 0.967 & 1.00 & 0.047 \\
$p_{(29)}$ & 1.00 & 0.999 & 1.00 & 0.999 & 1.00 & 0.048 \\
$p_{(30)}$ & 1.00 & 0.999 & 1.00 & 0.999 & 1.00 & 0.050 \\
\hline & & & & & & \\
\hline
\end{tabular}

Note: The sorted $p$-values from the test statistics described in (5) and (6) applied to OECD output level data.

[1995].

Results are reported in Table VIII. It is apparent that there is rather little evidence of stationarity of GDPs in the present OECD panel dataset. We only find a rejection based on the $t_{\phi}$ test for Ireland. We are, however, cautious about this finding as the Irish series only comprises $T=32$ observations, the shortest series in the panel (see above). This rejection may therefore well be caused by small-sample size distortions. Figure II plots the first few sorted $p$-values of 


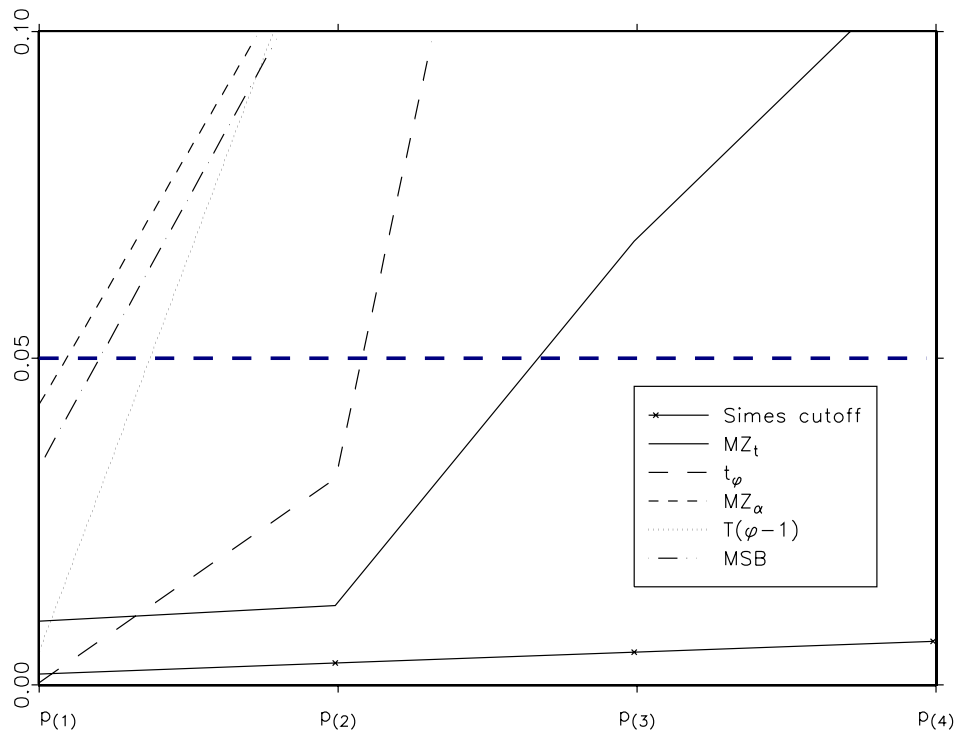

Figure II-First SORTED $p$-VALUES OF DIFFERENT TEStS REQUIRED FOR SIMES' TEST

the different tests along with the cutoff values of Simes' test. It is seen that the sorted $p$-values all increase rather quickly, so as to move away from Simes' cutoff value. Only in the case of the $t_{\phi}$-test is the first $p$-value sufficiently small so as to lead to a rejection of $H_{0}$. Note also that the first one or two $p$-values of all tests are below the 5\%-line. That is, if one had conducted separate nonstationary volatility-robust unit root tests on the series and rejected the single null for each series for which $p_{i} \leqslant 0.05$, one would have found a certain amount of evidence in favor of GDP trend stationarity. Our multiple testing approach, however, suggests that these rejections are to be seen as spurious (except, perhaps, for $t_{\phi}$ ), as that approach does not control the FWER - by conducting a sufficient amount of hypotheses tests, one is bound to eventually reject some null hypothesis even if all are correct.

\section{Conclusion}

This paper proposes a new test for a panel unit root against the alternative of a partially stationary panel, making use of Simes' [1986] classical test of the intersection null hypothesis. Unlike previously proposed panel tests, the one put forward here is robust to the presence of nonstationary volatility. Moreover, the test is intuitive, straightforward to implement and yet 
robust to general patterns of cross-sectional dependence. Importantly, unlike other tests, Simes' [1986] approach allows to shed light on the important question for how many and also which of the units in the panel the alternative can be said to hold when the null hypothesis is rejected. Hence, the test suggested here allows to decide, for instance, for each unit individually, whether to forecast the respective time series using a deterministic or stochastic trend specification.

Monte Carlo simulations investigate the performance of the new $S^{H}$ test based on several different underlying nonstationary-volatility robust time series unit root tests, two of which are derived specifically for this paper. The results show that the $S^{H}$ test controls size and is powerful for different patterns of cross-sectional dependence, nonstationary volatility and serial correlation.

An application of the new test to the question of nonstationarity of output levels demonstrates its practical usefulness. Unlike in previous panel studies, the test results are not contaminated by the 'Great Moderation', i.e. the reduction in the volatility of GDP growth rates experienced by many industrialized countries. We find only very weak evidence of stationarity in the investigated panel of OECD output levels, thus contributing to the view that output levels are well described by a stochastic trend.

Obviously, the framework used here is quite flexible and could hence be adopted to other macroeconometric topics. Essentially, one only requires valid time series $p$-values that can then be conveniently combined into a panel test statistic. As such, the present approach could be used to straightforwardly derive, say, panel unit root tests that allow for nonlinearity or panel cointegration tests, the development of which has often proved tedious using other approaches.

\section{References}

Bai J, Ng S. 2004. A panic attack on unit roots and cointegration. Econometrica 72: 1127-1177.

Blanchard O, Simon J. 2001. The long and large decline in u.s. output volatility. Brookings Papers on Economic Activity 1: 135-164.

Breitung J, Das S. 2005. Panel unit root tests under cross sectional dependence. Statistica Neerlandica 59: 414-433.

Breitung J, Pesaran MH. 2008. Unit roots and cointegration in panels. In Matyas L, Sevestre P (eds.) The Econometrics of Panel Data: Fundamentals and Recent Developments in Theory and Practice, chap. 9, Dordrecht: Kluwer Academic Publishers, 3rd edn., pages 279-322.

Campbell J, Perron P. 1991. Pitfalls and opportunities: What macroeconomists should know about unit roots. Technical Report 100, NBER. 
Cavaliere G, Taylor AMR. 2007. Testing for unit roots in time series models with non-stationary volatility. Journal of Econometrics 140: 919-947.

Cavaliere G, Taylor AMR. 2008. Time-transformed unit root tests for models with non-stationary volatility. Journal of Time Series Analysis 29: 300-330.

Cochrane J. 1988. How big is the random walk in gnp? Journal of Political Economy 96: 893-920.

Cogley T. 1990. International evidence on the size of the random walk in output. Journal of Political Economy 98: $501-518$.

Davidson J. 1994. Stochastic Limit Theory. Oxford: Oxford University Press.

DeJong DN, Whiteman CH. 1991. Reconsidering trends and random walks in macroeconomic time series. Journal of Monetary Economics 28: 221-254.

Demetrescu M, Hassler U, Tarcolea AI. 2006. Combining significance of correlated statistics with application to panel data. Oxford Bulletin of Economics and Statistics 68: 647-663.

Dickey DA, Fuller WA. 1979. Distribution of the estimators for autoregressive time series with a unit root. Journal of the American Statistical Association 74: 427-431.

Dudoit S, Shaffer JP, Boldrick JC. 2003. Multiple hypothesis testing in microarray experiments. Statistical Science 18: 71-103.

Hamilton JD. 1994. Time Series Analysis. Princeton: Princeton University Press.

Hamori S, Tokihisa A. 1997. Testing for a unit root in the presence of a variance shift. Economics Letters 57: $245-253$.

Hanck C. 2008. An intersection test for panel unit roots. Technical Report SFB 475 : 1-20.

Hanck C. 2009. For which countries did PPP hold? a multiple testing approach. Empirical Economics to appear.

Hommel G. 1988. A stagewise rejective multiple tests procedure based on a modified Bonferroni test. Biometrika 75: 383-386.

Im KS, Pesaran MH, Shin Y. 2003. Testing for unit roots in heterogeneous panels. Journal of Econometrics 115: $53-74$.

Kim CJ, Nelson CR. 1999. Has the u.s. economy become more stable? a bayesian approach based on a markovswitching model of the business cycle. The Review of Economics and Statistics 81: 608-616.

Kim TH, Leybourne S, Newbold P. 2002. Unit root tests with a break in innovation variance. Journal of Econometrics 109: 365-387.

Kormendi RC, Meguire P. 1990. A multicountry characterization of the nonstationarity of aggregate output. Journal of Money, Credit and Banking 22: 77-93.

Kwiatkowski D, Phillips PCB, Schmidt P, Shin Y. 1992. Testing the null hypothesis of stationarity against the alternative of a unit root. Journal of Econometrics 54: 159-78.

Levin A, Lin CF, Chu CSJ. 2002. Unit root tests in panel data: Asymptotic and finite-sample properties. Journal of Econometrics 108: 1-24.

MacKinnon JG. 1996. Numerical distribution functions for unit root and cointegration tests. Journal of Applied Econometrics 11: 601-618.

Maddala G, Wu S. 1999. A comparative study of unit root tests with panel data and a new simple test. Oxford Bulletin of Economics and Statistics 61: 631-652.

McConnell MM, Perez-Quiros G. 2000. Output fluctuations in the united states: What has changed since the early 1980's? American Economic Review 90: 1464-1476.

Moon HR, Perron B. 2004. Testing for a unit root in panels with dynamic factors. Journal of Econometrics 122: $81-126$.

Murray CJ, Nelson CR. 2000. The uncertain trend in u.s. gdp. Journal of Monetary Economics 46: 79-95.

Nelson CR, Plosser CI. 1982. Trends and random walks in macroeconomic time series. Journal of Monetary Economics 10: 139-162.

Ng S, Perron P. 1995. Unit root tests in arma models with data dependent methods for selection of the truncation lag. Journal of the American Statistical Association 90: 268-281.

Ng S, Perron P. 2001. Lag length selection and the construction of unit root tests with good size and power. 
Econometrica 69: 1519-1554.

O'Connell PG. 1998. The overvaluation of purchasing power parity. Journal of International Economics 44: $1-19$.

Pesaran MH. 2007. A simple panel unit root test in the presence of cross section dependence. Journal of Applied Econometrics 22: 265-312.

Phillips PCB, Sul D. 2003. Dynamic panel estimation and homogeneity testing under cross section dependence. The Econometrics Journal 6: 217-259.

Rapach DA. 2002. Are real gdp levels nonstationary? evidence from panel data tests. Southern Economic Journal 68: 473-495.

Romano JP, Wolf M. 2008. Formalized data snooping based on generalized error rates. Econometric Theory 24: 404-447.

Sarkar SK. 1998. Probability inequalities for ordered $\mathrm{MTP}_{2}$ random variables: A proof of the Simes conjecture. The Annals of Statistics 26: 494-504.

Sen A. 2007. On the distribution of dickey-fuller unit root statistics when there is a break in the innovation variance. Statistics \&3 Probability Letters 77: 63-68.

Simes RJ. 1986. An improved Bonferroni procedure for multiple tests of significance. Biometrika 73: 751-754.

Stock JH, Watson MW. 2002. Has the business cycle changed and why? NBER Macroeconomics Annual 17: 159-218.

Strauss J. 2000. Is there a permanent component in us real gdp. Economics Letters 66: 137-142.

Vougas DV. 2007. Is the trend in post-ww ii us real gdp uncertain or non-linear? Economics Letters 94: 348-355. 


\section{Additional Monte Carlo results}

Not for Publication

These tables also contain rows with test results for the $S^{H}$ test using $p$-values obtained from MacKinnon-type response surface regressions. The respective time series tests underlying the $S^{H}$ test are then indexed by an $M$. Dependence scheme 1 corresponds to the benchmark case of cross-sectional independence, scheme 2 to equicorrelation and scheme 3 to factor dependence. 
Table A-1-Rejection Rates of the Tests.

\begin{tabular}{|c|c|c|c|c|c|c|c|c|c|c|c|c|c|c|c|c|c|}
\hline \multirow[b]{2}{*}{$n$} & & \multirow[b]{2}{*}{$T$} & \multicolumn{5}{|c|}{$\tau=0.1$} & \multicolumn{5}{|c|}{$\tau=0.5$} & \multicolumn{5}{|c|}{$\tau=0.9$} \\
\hline & & & 30 & 50 & 100 & 150 & 200 & 30 & 50 & 100 & 150 & 200 & 30 & 50 & 100 & 150 & 200 \\
\hline \multirow{9}{*}{8} & $\mathcal{M Z _ { t }}$ & & .065 & .058 & .064 & .054 & .054 & .064 & .055 & .049 & .050 & .054 & .207 & .082 & .032 & .019 & .027 \\
\hline & $T(\hat{\phi}-1)$ & & .154 & .108 & .067 & .036 & .043 & .094 & .071 & .054 & .052 & .047 & .013 & .024 & .019 & .023 & .022 \\
\hline & $\mathcal{M Z _ { \alpha }}$ & & .046 & .042 & .043 & .035 & .034 & .044 & .034 & .028 & .036 & .034 & .196 & .075 & .026 & .014 & .021 \\
\hline & $t_{\phi}$ & & .028 & .036 & .035 & .026 & .034 & .034 & .041 & .039 & .041 & .039 & .010 & .012 & .014 & .013 & .014 \\
\hline & $\mathcal{M S B}$ & & .046 & .042 & .043 & .035 & .034 & .044 & .034 & .028 & .036 & .034 & .175 & .066 & .020 & .008 & .015 \\
\hline & $\mathcal{M} \mathcal{Z}_{t, M}$ & & .050 & .051 & .063 & .054 & .056 & .049 & .046 & .047 & .050 & .055 & .188 & .077 & .032 & .019 & .027 \\
\hline & $t_{\phi, M}$, & & .132 & .101 & .066 & .036 & .044 & .077 & .067 & .053 & .052 & .048 & .010 & .021 & .019 & .023 & .023 \\
\hline & $T(\hat{\phi}-1)_{M}$ & & .059 & .055 & .048 & .032 & .042 & .067 & .063 & .050 & .050 & .046 & .020 & .023 & .019 & .018 & .018 \\
\hline & $\mathcal{M} \mathcal{Z}_{\alpha, M}$ & & .117 & .088 & .076 & .058 & .056 & .103 & .078 & .055 & .052 & .055 & .250 & .101 & .038 & .020 & .027 \\
\hline \multirow{9}{*}{12} & $\mathcal{M Z _ { t }}$ & & .063 & .065 & .060 & .064 & .051 & .075 & .044 & .045 & .042 & .046 & .275 & .110 & .040 & .010 & .028 \\
\hline & $T(\hat{\phi}$ & & .168 & .131 & .079 & .050 & .045 & .108 & .079 & .052 & .050 & .048 & .013 & .016 & .017 & .018 & .027 \\
\hline & $\mathcal{M Z}_{\alpha}$ & & .041 & .039 & .043 & .042 & .033 & .052 & .026 & .028 & .024 & .024 & .255 & .102 & .032 & .008 & .023 \\
\hline & $t_{\phi}$ & & .030 & .040 & .037 & .038 & .035 & .034 & .036 & .036 & .037 & .034 & .009 & .008 & .010 & .010 & .015 \\
\hline & $\mathcal{M S B}$ & & .041 & .039 & .043 & .042 & .033 & .052 & .026 & .028 & .024 & .024 & .241 & .090 & .026 & .006 & .015 \\
\hline & $\mathcal{M} \mathcal{Z}_{t, M}$ & & .042 & .050 & .057 & .061 & .049 & .054 & .034 & .041 & .041 & .045 & .248 & .100 & .036 & .010 & .027 \\
\hline & $t_{\phi, M}$ & & .144 & .119 & .074 & .049 & .044 & .085 & .069 & .049 & .047 & .046 & .006 & .013 & .016 & .017 & .024 \\
\hline & $T(\hat{\phi}-1)_{N}$ & & .061 & .057 & .050 & .046 & .041 & .078 & .063 & .046 & .044 & .047 & .020 & .019 & .014 & .014 & .021 \\
\hline & $\mathcal{M} \mathcal{Z}_{\alpha, M}$ & & .123 & .090 & .068 & .067 & .051 & .126 & .072 & .050 & .044 & .046 & .332 & .130 & .044 & .011 & .027 \\
\hline \multirow{9}{*}{24} & $\mathcal{M Z _ { t }}$ & & .068 & .054 & .059 & .060 & .044 & .076 & .049 & .036 & .037 & .036 & .386 & .129 & .039 & .011 & .028 \\
\hline & $T(\hat{\phi}$ & & .251 & .166 & .094 & .057 & .04 & .146 & .098 & .068 & .050 & .05 & .014 & .022 & .021 & .018 & .024 \\
\hline & $\mathcal{M} \mathcal{Z}_{\alpha}$ & & .048 & .034 & .040 & .037 & .030 & .062 & .028 & .023 & . 023 & .021 & .366 & . 118 & .035 & .010 & .024 \\
\hline & $t_{\phi}$ & & .026 & .037 & .040 & .037 & .030 & .040 & .045 & .043 & .038 & .044 & .010 & .015 & .010 & .014 & .019 \\
\hline & $\mathcal{M S B}$ & & .048 & .034 & .040 & .037 & .030 & .062 & .028 & .023 & .023 & .021 & .351 & .109 & .028 & .008 & .016 \\
\hline & $\mathcal{M} \mathcal{Z}_{t, M}$ & & .038 & .035 & .050 & .054 & .043 & .053 & . 030 & .032 & .035 & .032 & .331 & . 108 & .032 & .010 & .026 \\
\hline & & & .208 & .142 & .086 & .052 & .040 & .111 & .085 & .059 & . 046 & .050 & .007 & .014 & .016 & .018 & .022 \\
\hline & $T(\hat{\phi}-1)_{\Lambda}$ & & .076 & .061 & .052 & .045 & .036 & .096 & .075 & .058 & .048 & .049 & .029 & .025 & .012 & .016 & .022 \\
\hline & $\mathcal{M} \mathcal{Z}_{\alpha, M}$ & & .150 & .097 & .072 & .063 & .045 & .137 & .078 & .043 & .040 & .038 & .468 & .163 & .047 & .013 & .028 \\
\hline \multirow{9}{*}{48} & $\mathcal{M Z}$ & & .064 & .046 & .054 & .051 & .05 & .102 & . 052 & .033 & . 024 & .03 & .564 & 198 & .042 & .008 & .012 \\
\hline & $T(\hat{\phi}-1$ & & .381 & .250 & .118 & .052 & .059 & .195 & . 113 & .080 & .058 & .067 & .015 & .020 & .020 & .016 & .024 \\
\hline & $\mathcal{M} \mathcal{Z}_{\alpha}$ & & .046 & .028 & .033 & .027 & .031 & .078 & . 031 & .017 & .013 & .022 & .542 & .182 & .036 & .007 & .011 \\
\hline & t & & .027 & .040 & .041 & .033 & .042 & .041 & .038 & .048 & .034 & .048 & .011 & .009 & .010 & .008 & .012 \\
\hline & $\mathcal{M S B}$ & & .046 & .028 & .033 & .027 & .031 & .078 & .031 & .017 & .013 & .022 & .519 & .160 & .030 & .004 & .009 \\
\hline & $\mathcal{M} \mathcal{Z}_{t, N}$ & & .034 & .027 & .040 & .034 & .041 & .062 & .029 & .022 & .017 & .031 & .494 & .160 & .033 & .007 & .010 \\
\hline & $t_{\phi, M}$ & & .296 & .202 & .104 & .045 & .054 & .126 & .079 & .062 & .052 & .061 & .008 & .008 & .014 & .013 & .020 \\
\hline & $T(\hat{\phi}-1)$ & & .094 & .075 & .057 & .038 & .047 & .112 & .075 & .063 & . 044 & .057 & .033 & .023 & .014 & .010 & .016 \\
\hline & $\mathcal{M} \mathcal{Z}_{\alpha, M}$ & & .168 & .087 & .064 & .053 & .050 & .184 & .085 & .042 & .027 & .034 & .657 & .242 & .050 & .009 & .012 \\
\hline
\end{tabular}

Note: Case $\psi=0, \phi=\boldsymbol{\imath}_{n}, \delta=0.2$. Dependence scheme 1 . 
Table A-2-Rejection Rates of the Tests.

\begin{tabular}{|c|c|c|c|c|c|c|c|c|c|c|c|c|c|c|c|c|c|}
\hline \multirow[b]{2}{*}{$n$} & & \multirow[b]{2}{*}{$T$} & \multicolumn{5}{|c|}{$\tau=0.1$} & \multicolumn{5}{|c|}{$\tau=0.5$} & \multicolumn{5}{|c|}{$\tau=0.9$} \\
\hline & & & 30 & 50 & 100 & 150 & 200 & 30 & 50 & 100 & 150 & 200 & 30 & 50 & 100 & 150 & 200 \\
\hline \multirow{9}{*}{8} & $\mathcal{M Z _ { t }}$ & & .059 & .058 & .062 & .056 & .050 & .068 & .042 & .048 & .049 & .046 & .201 & .100 & .037 & .020 & .034 \\
\hline & $T(\hat{\phi}-1)$ & & .142 & .120 & .067 & .036 & .047 & .090 & .068 & .049 & .047 & .045 & .014 & .024 & .016 & .018 & .027 \\
\hline & $\mathcal{M Z _ { \alpha }}$ & & .052 & .059 & .054 & .046 & .049 & .053 & .048 & .041 & .035 & .037 & .183 & .086 & .033 & .015 & .029 \\
\hline & & & .026 & .039 & .038 & .033 & .037 & .035 & .032 & .032 & .036 & .036 & .011 & .011 & .007 & .012 & .017 \\
\hline & $\mathcal{M S B}$ & & .036 & .040 & .043 & .038 & .031 & .052 & .028 & .026 & .030 & .025 & .173 & .075 & .028 & .009 & .018 \\
\hline & $\mathcal{M} \mathcal{Z}_{t, M}$ & & .045 & .050 & .059 & .056 & .050 & .055 & .038 & .046 & .050 & .048 & .182 & .090 & .036 & .020 & .034 \\
\hline & $t_{\phi, M}$ & & .127 & .112 & .066 & .036 & .047 & .071 & .059 & .048 & .047 & .046 & .010 & .021 & .016 & .017 & .027 \\
\hline & $T(\hat{\phi}-1)_{M}$ & & .049 & .058 & .050 & .038 & .042 & .068 & .056 & .044 & .048 & .043 & .018 & .021 & .012 & .015 & .026 \\
\hline & $\mathcal{M} \mathcal{Z}_{\alpha, M}$ & & .102 & .083 & .072 & .060 & .050 & .107 & .063 & .055 & .051 & .048 & .242 & .114 & .041 & .020 & .034 \\
\hline \multirow{9}{*}{12} & $\mathcal{M Z _ { t }}$ & & .067 & .061 & .068 & .056 & .050 & .062 & .048 & .051 & .049 & .044 & .242 & .110 & .035 & .016 & .030 \\
\hline & $T(\hat{\phi}$ & & .170 & .128 & .083 & .043 & .046 & .108 & .078 & .056 & .054 & .045 & .010 & .023 & .015 & .019 & .023 \\
\hline & $\mathcal{M} \mathcal{Z}_{\alpha}$ & & .057 & .046 & .053 & .048 & .046 & .057 & .034 & .038 & .041 & .035 & .226 & .101 & .030 & .012 & .024 \\
\hline & $t_{\phi}$ & & .024 & .040 & .037 & .028 & .034 & .033 & .035 & .038 & .043 & .034 & .008 & .016 & .009 & .010 & .016 \\
\hline & $\mathcal{M S B}$ & & .043 & .038 & .042 & .034 & .034 & .046 & .032 & .029 & .028 & .023 & .214 & .090 & .023 & .010 & .016 \\
\hline & $\mathcal{M} \mathcal{Z}_{t, M}$ & & .046 & .046 & .063 & .052 & .049 & .049 & .041 & .046 & .047 & .042 & .216 & .102 & .034 & .015 & .028 \\
\hline & $t_{\phi, M}$ & & .148 & .115 & .078 & .041 & .045 & .088 & .068 & .052 & .052 & .044 & .007 & .019 & .013 & .018 & .022 \\
\hline & $T(\hat{\phi}-1)_{\Lambda}$ & & .058 & .061 & .050 & .035 & .039 & .077 & .062 & .050 & .051 & .042 & .020 & .025 & .011 & .015 & .018 \\
\hline & $\mathcal{M} \mathcal{Z}_{\alpha, M}$ & & .120 & .087 & .074 & .058 & .049 & .110 & .072 & .056 & .052 & .044 & .300 & .130 & .039 & .016 & .030 \\
\hline \multirow{9}{*}{24} & $\mathcal{M} \mathcal{Z}_{t}$ & & .056 & .059 & .056 & .057 & .046 & .082 & .044 & .037 & .033 & .036 & .358 & .143 & .035 & .008 & .018 \\
\hline & $T(\hat{\phi}$ & & .241 & .171 & .093 & .052 & .04 & .126 & .096 & .066 & .052 & .05 & .012 & .021 & .011 & .012 & .018 \\
\hline & $\mathcal{M} \mathcal{Z}_{\alpha}$ & & .052 & .050 & .052 & .042 & .039 & .063 & .033 & .030 & .023 & .030 & .343 & .138 & .028 & .006 & .014 \\
\hline & $t_{\phi}$ & & .032 & .045 & .045 & .034 & .033 & .034 & .040 & .043 & .038 & .041 & .011 & .013 & .006 & .006 & .011 \\
\hline & $\mathcal{M S B}$ & & .039 & .037 & .034 & .039 & .030 & .062 & .030 & .024 & .018 & .020 & .327 & .122 & .023 & .004 & .009 \\
\hline & $\mathcal{M} \mathcal{Z}_{t, M}$ & & .036 & .040 & .046 & .051 & .042 & .056 & . 031 & .032 & .029 & .033 & .318 & .127 & .032 & .007 & .017 \\
\hline & & & .198 & .147 & .088 & .048 & .044 & .098 & .076 & .058 & .047 & .050 & .008 & .015 & .010 & .011 & .016 \\
\hline & $T(\hat{\phi}-1)_{1}$ & & .076 & .073 & .056 & .044 & .039 & .083 & .072 & .055 & .046 & .048 & .028 & .022 & .008 & .009 & .014 \\
\hline & $\mathcal{M} \mathcal{Z}_{\alpha, M}$ & & .120 & .095 & .068 & .062 & .047 & .138 & .071 & .044 & .037 & .036 & .420 & .174 & .042 & .009 & .020 \\
\hline \multirow{9}{*}{48} & $\mathcal{M}$ & & .068 & .050 & .049 & .042 & .04 & .100 & .043 & .029 & .028 & .02 & .502 & .181 & .042 & .009 & .016 \\
\hline & $T(\hat{\phi}-1$ & & .324 & .229 & .103 & .059 & .064 & .173 & .114 & .076 & .060 & .05 & .017 & .022 & .020 & .015 & .018 \\
\hline & $\mathcal{M} \mathcal{Z}_{\alpha}$ & & .054 & .046 & .046 & .048 & .035 & .075 & . 036 & .024 & .024 & .021 & .483 & .169 & .036 & .007 & .012 \\
\hline & t & & .028 & .050 & .042 & .037 & .042 & .039 & .040 & .046 & .037 & .044 & .013 & .010 & .010 & .007 & .010 \\
\hline & $\mathcal{M S B}$ & & .049 & .027 & .029 & .025 & .032 & .079 & .028 & .019 & .015 & .016 & .461 & .154 & .028 & .004 & .009 \\
\hline & $\mathcal{M} \mathcal{Z}_{t, N}$ & & .030 & .027 & .036 & .035 & .041 & .066 & .027 & .022 & . 020 & .023 & .444 & .150 & .033 & .007 & .014 \\
\hline & $t_{\phi, M}$ & & .262 & .192 & .088 & .050 & .054 & .127 & .083 & .062 & .048 & .051 & .008 & .011 & .013 & .013 & .015 \\
\hline & $T(\hat{\phi}-1)$ & & .095 & .080 & .054 & .045 & .047 & .111 & .078 & .060 & .048 & .050 & .033 & .019 & .014 & .009 & .013 \\
\hline & $\mathcal{M} \mathcal{Z}_{\alpha, M}$ & & .161 & .096 & .061 & .047 & .046 & .171 & .076 & .043 & .031 & .028 & .584 & .220 & .047 & .009 & .016 \\
\hline
\end{tabular}

Note: Case $\psi=0, \phi=\boldsymbol{\imath}_{n}, \delta=0.2$. Dependence scheme 2 . 
Table A-3-Rejection Rates of the Tests.

\begin{tabular}{|c|c|c|c|c|c|c|c|c|c|c|c|c|c|c|c|c|c|}
\hline \multirow[b]{2}{*}{$n$} & & \multirow[b]{2}{*}{$T$} & \multicolumn{5}{|c|}{$\tau=0.1$} & \multicolumn{5}{|c|}{$\tau=0.5$} & \multicolumn{5}{|c|}{$\tau=0.9$} \\
\hline & & & 30 & 50 & 100 & 150 & 200 & 30 & 50 & 100 & 150 & 200 & 30 & 50 & 100 & 150 & 200 \\
\hline \multirow{9}{*}{8} & $\mathcal{M Z _ { t }}$ & & .070 & .058 & .064 & .059 & .051 & .057 & .048 & .047 & .050 & .045 & .158 & .079 & .040 & .018 & .032 \\
\hline & $T(\hat{\phi}-1)$ & & .163 & .103 & .067 & .040 & .044 & .092 & .070 & .056 & .049 & .044 & .018 & .026 & .017 & .022 & .024 \\
\hline & $\mathcal{M Z _ { \alpha }}$ & & .045 & .042 & .053 & .055 & .042 & .051 & .036 & .039 & .033 & .036 & .145 & .071 & .034 & .014 & .024 \\
\hline & $t_{\phi}$ & & .036 & .041 & .038 & .033 & .035 & .036 & .042 & .047 & .039 & .040 & .007 & .013 & .011 & .012 & .018 \\
\hline & $\mathcal{M S B}$ & & .045 & .038 & .040 & .040 & .032 & .040 & .034 & .033 & .033 & .032 & .134 & .059 & .026 & .011 & .021 \\
\hline & $\mathcal{M} \mathcal{Z}_{t, M}$ & & .054 & .049 & .062 & .059 & .052 & .043 & .044 & .045 & .049 & .046 & .138 & .073 & .040 & .018 & .032 \\
\hline & $t_{\phi, M}$ & & .147 & .099 & .064 & .040 & .044 & .074 & .064 & .056 & .049 & .044 & .013 & .022 & .017 & .022 & .025 \\
\hline & $T(\hat{\phi}-1)_{M}$ & & .074 & .061 & .051 & .040 & .042 & .066 & .060 & .056 & .045 & .045 & .018 & .022 & .016 & .018 & .022 \\
\hline & $\mathcal{M} \mathcal{Z}_{\alpha, M}$ & & .122 & .084 & .075 & .062 & .051 & .092 & .070 & .052 & .051 & .046 & .199 & .093 & .045 & .018 & .031 \\
\hline \multirow{9}{*}{12} & $\mathcal{M Z _ { t }}$ & & .067 & .056 & .063 & .056 & .048 & .064 & .042 & .042 & .044 & .044 & .231 & .083 & .036 & .020 & .028 \\
\hline & $T(\hat{\phi}$ & & .198 & .131 & .072 & .039 & .048 & .107 & .067 & .058 & .046 & .052 & .018 & .024 & .014 & .029 & .025 \\
\hline & $\mathcal{M} \mathcal{Z}_{\alpha}$ & & .054 & .048 & .044 & .049 & .030 & .052 & .036 & .035 & .032 & .037 & .212 & .074 & .028 & .012 & .022 \\
\hline & $t_{\phi}$ & & .031 & .036 & .040 & .027 & .038 & .034 & .029 & .038 & .034 & .043 & .012 & .010 & .011 & .017 & .013 \\
\hline & $\mathcal{M S B}$ & & .043 & .034 & .042 & .038 & .030 & .044 & .027 & .022 & .028 & .030 & .197 & .064 & .022 & .007 & .017 \\
\hline & $\mathcal{M} \mathcal{Z}_{t, M}$ & & .045 & .044 & .058 & .053 & .047 & .047 & .035 & .038 & .042 & .043 & .204 & .074 & .033 & .019 & .026 \\
\hline & $t_{\phi, M}$ & & .172 & .113 & .069 & .037 & .047 & .086 & .058 & .052 & .044 & .052 & .010 & .016 & .014 & .028 & .024 \\
\hline & $T(\hat{\phi}-1)_{\Lambda}$ & & .084 & .060 & .055 & .036 & .043 & .072 & .050 & .050 & .045 & .050 & .022 & .020 & .014 & . 022 & .020 \\
\hline & $\mathcal{M} \mathcal{Z}_{\alpha, M}$ & & .113 & .078 & .072 & .058 & .050 & .106 & .073 & .048 & .045 & .044 & .291 & .102 & .040 & .021 & .028 \\
\hline \multirow{9}{*}{24} & $\mathcal{M \mathcal { Z } _ { t }}$ & & .056 & .046 & .060 & .046 & .048 & .074 & .040 & .042 & .034 & .035 & .330 & .115 & .033 & .009 & .022 \\
\hline & $T(\hat{\phi}$ & & .263 & .193 & .091 & .049 & .05 & .123 & .091 & .070 & .059 & .05 & .015 & .021 & .017 & .018 & .018 \\
\hline & $\mathcal{M} \mathcal{Z}_{\alpha}$ & & .053 & .032 & .056 & .035 & .039 & .060 & .037 & .029 & .028 & .03 & .312 & .106 & .028 & .008 & .018 \\
\hline & $t_{\phi}$ & & .036 & .051 & .043 & .032 & .041 & .028 & .044 & .045 & .040 & .040 & .010 & .010 & .010 & .009 & .010 \\
\hline & $\mathcal{M S B}$ & & .039 & .030 & .041 & .030 & .030 & .053 & .028 & .027 & .021 & .020 & .288 & .091 & .022 & .006 & .012 \\
\hline & $\mathcal{M} \mathcal{Z}_{t, M}$ & & .030 & .031 & .052 & .040 & .042 & .048 & . 029 & .035 & .032 & .032 & .283 & .098 & .028 & .008 & .020 \\
\hline & & & .221 & .164 & .081 & .044 & .049 & .087 & .076 & .062 & .054 & .048 & .009 & .015 & .014 & .016 & .017 \\
\hline & $T(\hat{\phi}-1)_{1}$ & & .089 & .084 & .057 & .040 & .046 & .077 & .075 & .062 & .051 & .047 & .028 & .021 & .013 & .011 & .012 \\
\hline & $\mathcal{M} \mathcal{Z}_{\alpha, M}$ & & .135 & .082 & .070 & .050 & .048 & .129 & .071 & .052 & .037 & .036 & .405 & .148 & .039 & .011 & .022 \\
\hline \multirow{9}{*}{48} & $\mathcal{M}$ & & .051 & .052 & .064 & .060 & .03 & .085 & .042 & .031 & .029 & .03 & .483 & .186 & .036 & .007 & .014 \\
\hline & $T(\hat{\phi}-1$ & & .420 & .253 & .106 & .062 & .052 & .184 & 1117 & .074 & .065 & .06 & .016 & .021 & .019 & .017 & .024 \\
\hline & $\mathcal{M} \mathcal{Z}_{\alpha}$ & & .051 & .049 & .048 & .032 & .031 & .072 & .028 & .033 & .025 & .021 & .460 & .169 & .031 & .006 & .010 \\
\hline & t & & .032 & .044 & .046 & .044 & .039 & .035 & .042 & .041 & .043 & .046 & .009 & .010 & .010 & .010 & .015 \\
\hline & $\mathcal{M S B}$ & & .031 & .028 & .042 & .036 & .019 & .068 & .027 & .016 & .017 & .020 & .437 & .153 & .024 & .004 & .007 \\
\hline & $\mathcal{M} \mathcal{Z}_{t, N}$ & & .020 & .026 & .049 & .048 & .030 & .053 & .027 & .020 & . 022 & .026 & .406 & .153 & .028 & .005 & .010 \\
\hline & $t_{\phi, M}$ & & .337 & .198 & .090 & .054 & .044 & .126 & .086 & .057 & .053 & .055 & .007 & .013 & .014 & .014 & .022 \\
\hline & $T(\hat{\phi}-1)$ & & .108 & .084 & .060 & .049 & .043 & .109 & .076 & .059 & .053 & .054 & .027 & .022 & .012 & .013 & .016 \\
\hline & $\mathcal{M} \mathcal{Z}_{\alpha, M}$ & & .146 & .088 & .076 & .065 & .038 & .165 & . 070 & .038 & .032 & .031 & .573 & .222 & .041 & .008 & .014 \\
\hline
\end{tabular}

Note: Case $\psi=0, \phi=\boldsymbol{\imath}_{n}, \delta=0.2$. Dependence scheme 3 . 
Table A-4-Rejection Rates of the Tests.

\begin{tabular}{|c|c|c|c|c|c|c|c|c|c|c|c|c|c|c|c|c|c|}
\hline \multirow[b]{2}{*}{$n$} & & \multirow[b]{2}{*}{$T$} & \multicolumn{5}{|c|}{$\tau=0.1$} & \multicolumn{5}{|c|}{$\tau=0.5$} & \multicolumn{5}{|c|}{$\tau=0.9$} \\
\hline & & & 30 & 50 & 100 & 150 & 200 & 30 & 50 & 100 & 150 & 200 & 30 & 50 & 100 & 150 & 200 \\
\hline \multirow{9}{*}{8} & $\mathcal{M Z _ { t }}$ & & .026 & .009 & .005 & .003 & .006 & .011 & .013 & .016 & .020 & .016 & .013 & .014 & .033 & .021 & .032 \\
\hline & $T(\hat{\phi}-1)$ & & .162 & .229 & .216 & .186 & .172 & .119 & .095 & .066 & .060 & .055 & .067 & .050 & .056 & .047 & .054 \\
\hline & $\mathcal{M Z _ { \alpha }}$ & & .011 & .003 & .003 & .002 & .002 & .004 & .006 & .010 & .010 & .011 & .006 & .007 & .020 & .013 & .023 \\
\hline & $t_{\phi}$ & & .020 & .037 & .050 & .058 & .051 & .012 & .018 & .022 & .025 & .028 & .006 & .014 & .023 & .018 & .034 \\
\hline & $\mathcal{M S B}$ & & .007 & .002 & .002 & .001 & .002 & .004 & .006 & .010 & .010 & .011 & .006 & .007 & .020 & .013 & .023 \\
\hline & $\mathcal{M} \mathcal{Z}_{t, M}$ & & .020 & .008 & .004 & .003 & .006 & .008 & .011 & .016 & .020 & .017 & .010 & .013 & .032 & .021 & .032 \\
\hline & $t_{\phi, M}$ & & .148 & .220 & .213 & .186 & .174 & .103 & .088 & .065 & .060 & .056 & .053 & .044 & .054 & .047 & .055 \\
\hline & $T(\hat{\phi}-1)_{M}$ & & .035 & .051 & .061 & .069 & .060 & .027 & .030 & .028 & .030 & .032 & .016 & .021 & .033 & .026 & .035 \\
\hline & $\mathcal{M} \mathcal{Z}_{\alpha, M}$ & & .022 & .006 & .003 & .003 & .004 & .015 & .015 & .015 & .020 & .017 & .025 & .024 & .035 & .022 & .030 \\
\hline \multirow{9}{*}{12} & $\mathcal{M Z _ { t }}$ & & .035 & .012 & .002 & .003 & .008 & .010 & .010 & .013 & .015 & .017 & .016 & .018 & .018 & .026 & .026 \\
\hline & $T(\hat{\phi}$ & & .214 & .277 & .261 & .228 & .201 & .140 & .110 & .084 & .069 & .064 & .066 & .064 & .056 & .052 & .058 \\
\hline & $\mathcal{M} \mathcal{Z}_{\alpha}$ & & .020 & .006 & .002 & .002 & .006 & .003 & .003 & .007 & .010 & .010 & .007 & .007 & .012 & .017 & .015 \\
\hline & $t_{\phi}$ & & .020 & .044 & .063 & .066 & .062 & .008 & . 020 & .024 & .030 & .027 & .006 & .012 & .018 & .021 & .030 \\
\hline & $\mathcal{M S B}$ & & .014 & .004 & .001 & .002 & .005 & .003 & .003 & .007 & .010 & .010 & .007 & .007 & .012 & .017 & .015 \\
\hline & $\mathcal{M} \mathcal{Z}_{t, M}$ & & .029 & .007 & .002 & .002 & .008 & .006 & .008 & .011 & .014 & .016 & .008 & .014 & .016 & .024 & .026 \\
\hline & $t_{\phi, M}$ & & .182 & .254 & .252 & .226 & .200 & .113 & .096 & .080 & .065 & .062 & .054 & .057 & .052 & .050 & .056 \\
\hline & $T(\hat{\phi}$ & & .037 & .066 & .078 & .078 & .072 & .028 & .033 & .031 & .038 & .034 & .022 & .023 & .024 & . 030 & .034 \\
\hline & $\mathcal{M} \mathcal{Z}_{\alpha, M}$ & & .033 & .010 & .003 & .003 & .006 & .016 & .014 & .014 & .015 & .017 & .030 & .026 & .020 & .027 & .027 \\
\hline \multirow{9}{*}{24} & $\mathcal{M Z _ { t }}$ & & .040 & .009 & .003 & .002 & .004 & .013 & .005 & .011 & .015 & .012 & .018 & .014 & .021 & .023 & .025 \\
\hline & $T(\hat{\phi}-1)$ & & .312 & .382 & .353 & .306 & .248 & .182 & .144 & .090 & .088 & .07 & .089 & .072 & .061 & .053 & .053 \\
\hline & $\mathcal{M} \mathcal{Z}_{\alpha}$ & & .020 & .004 & .002 & .001 & .004 & .007 & .002 & .006 & .010 & .007 & .009 & .009 & .012 & .013 & .014 \\
\hline & $t_{\phi}$ & & .028 & .048 & .071 & .074 & .072 & .011 & .018 & .025 & .034 & .029 & .005 & .008 & .016 & .023 & .028 \\
\hline & $\mathcal{M S B}$ & & .014 & .002 & .002 & .001 & .002 & .007 & .002 & .006 & .010 & .007 & .009 & .009 & .012 & .013 & .014 \\
\hline & $\mathcal{M} \mathcal{Z}_{t, M}$ & & .031 & .008 & .003 & .002 & .004 & .010 & .004 & .009 & .013 & .011 & .010 & .012 & .017 & . 020 & .024 \\
\hline & & & .268 & .344 & .334 & .296 & .242 & .138 & .115 & .078 & .082 & .066 & .061 & .057 & .057 & .049 & .049 \\
\hline & $T(\hat{\phi}-1)_{1}$ & & .056 & .083 & .084 & .090 & .080 & .028 & .034 & .033 & .039 & .033 & .020 & .018 & .025 & .028 & .031 \\
\hline & $\mathcal{M} \mathcal{Z}_{\alpha, M}$ & & .039 & .008 & .002 & .001 & .004 & .020 & .012 & .014 & .015 & .011 & .040 & .024 & .025 & .024 & .025 \\
\hline \multirow{9}{*}{48} & $\mathcal{M}$ & & .049 & .011 & .002 & .001 & .00 & .015 & .006 & .009 & .010 & .00 & .014 & .012 & .020 & .018 & .015 \\
\hline & $T(\hat{\phi}-1$ & & .435 & .516 & .488 & .416 & .335 & .262 & 197 & .112 & .099 & .087 & .119 & .090 & .062 & .058 & .055 \\
\hline & $\mathcal{M} \mathcal{Z}_{\alpha}$ & & .024 & .006 & .001 & .000 & .002 & .008 & .002 & .006 & .007 & .003 & .006 & .005 & .014 & .010 & .010 \\
\hline & t & & .032 & .065 & .082 & .095 & .084 & .010 & .019 & .024 & .026 & .036 & .004 & .010 & .016 & .018 & .026 \\
\hline & $\mathcal{M S B}$ & & .018 & .003 & .000 & .000 & .001 & .008 & .002 & .006 & .007 & .003 & .006 & .005 & .014 & .010 & .010 \\
\hline & $\mathcal{M} \mathcal{Z}_{t, N}$ & & .032 & .007 & .002 & .001 & .001 & .007 & .002 & .006 & .008 & .006 & .005 & .006 & .016 & .014 & .013 \\
\hline & $t_{\phi, M}$ & & .353 & .453 & .457 & .387 & .311 & .181 & 146 & .092 & .084 & .075 & .072 & .065 & .048 & .049 & .050 \\
\hline & $T(\hat{\phi}-1)$ & & .072 & .100 & .099 & .108 & .092 & .031 & .037 & .034 & .031 & .042 & .018 & .026 & .024 & .023 & .031 \\
\hline & $\mathcal{M} \mathcal{Z}_{\alpha, M}$ & & .050 & .012 & .002 & .001 & .002 & .025 & . 008 & .012 & .011 & .007 & .030 & .024 & .024 & .018 & .015 \\
\hline
\end{tabular}

Note: Case $\psi=0, \phi=\boldsymbol{\imath}_{n}, \delta=5$. Dependence scheme 1 . 
Table A-5-Rejection Rates of the Tests.

\begin{tabular}{|c|c|c|c|c|c|c|c|c|c|c|c|c|c|c|c|c|c|}
\hline \multirow[b]{2}{*}{$n$} & & \multirow[b]{2}{*}{$T$} & \multicolumn{5}{|c|}{$\tau=0.1$} & \multicolumn{5}{|c|}{$\tau=0.5$} & \multicolumn{5}{|c|}{$\tau=0.9$} \\
\hline & & & 30 & 50 & 100 & 150 & 200 & 30 & 50 & 100 & 150 & 200 & 30 & 50 & 100 & 150 & 200 \\
\hline \multirow{9}{*}{8} & $\mathcal{M Z _ { t }}$ & & .028 & .007 & .003 & .004 & .006 & .014 & .010 & .019 & .016 & .016 & .018 & .020 & .025 & .032 & .029 \\
\hline & $T(\hat{\phi}-1)$ & & .164 & .198 & .194 & .188 & .160 & .118 & .092 & .071 & .059 & .058 & .068 & .054 & .051 & .054 & .048 \\
\hline & $\mathcal{M Z _ { \alpha }}$ & & .015 & .004 & .002 & .004 & .002 & .007 & .008 & .014 & .013 & .010 & .012 & .014 & .020 & .025 & .026 \\
\hline & $t_{\phi}$ & & .019 & .036 & .056 & .057 & .050 & .010 & .016 & .021 & .022 & .025 & .007 & .010 & .021 & .027 & .027 \\
\hline & $\mathcal{M S B}$ & & .012 & .002 & .002 & .003 & .002 & .005 & .004 & .008 & .008 & .011 & .010 & .009 & .015 & .018 & .019 \\
\hline & $\mathcal{M} \mathcal{Z}_{t, M}$ & & .024 & .006 & .003 & .004 & .006 & .010 & .008 & .018 & .016 & .017 & .015 & .017 & .025 & .032 & .030 \\
\hline & $t_{\phi, M}$ & & .151 & .189 & .190 & .188 & .162 & .103 & .086 & .069 & .059 & .058 & .054 & .048 & .049 & .054 & .050 \\
\hline & $T(\hat{\phi}-1)_{M}$ & & .036 & .054 & .066 & .067 & .060 & .026 & .024 & .028 & .030 & .030 & .020 & .017 & .027 & .034 & .034 \\
\hline & $\mathcal{M} \mathcal{Z}_{\alpha, M}$ & & .026 & .006 & .003 & .004 & .005 & .018 & .013 & .021 & .018 & .016 & .030 & .025 & .028 & .032 & .028 \\
\hline \multirow{9}{*}{12} & $\mathcal{M Z _ { t }}$ & & .028 & .008 & .006 & .002 & .004 & .011 & .011 & .011 & .017 & .013 & .020 & .016 & .020 & .031 & .026 \\
\hline & $T(\hat{\phi}$ & & .205 & .256 & .227 & .185 & .180 & .126 & .107 & .070 & .070 & .071 & .074 & .058 & .053 & .060 & .055 \\
\hline & $\mathcal{M} \mathcal{Z}_{\alpha}$ & & .012 & .005 & .004 & .001 & .003 & .006 & .010 & .011 & .014 & .010 & .012 & .010 & .021 & .024 & .020 \\
\hline & $t_{\phi}$ & & .020 & .042 & .063 & .052 & .055 & .008 & .014 & .025 & .024 & .033 & .005 & .010 & .020 & .032 & .028 \\
\hline & $\mathcal{M S B}$ & & .010 & .004 & .002 & .001 & .002 & .004 & .004 & .004 & .009 & .006 & .007 & .007 & .014 & .018 & .017 \\
\hline & $\mathcal{M} \mathcal{Z}_{t, M}$ & & .020 & .006 & .006 & .002 & .004 & .006 & .008 & .009 & .017 & .013 & .011 & .012 & .019 & .029 & .026 \\
\hline & $t_{\phi, M}$ & & .177 & .234 & .218 & .183 & 179 & .106 & .094 & .065 & .069 & .068 & .052 & .050 & .050 & .058 & .053 \\
\hline & $T(\hat{\phi}$ & & .041 & .058 & .075 & .063 & .061 & .025 & . 026 & .030 & .030 & .040 & .021 & .020 & .030 & .038 & .031 \\
\hline & $\mathcal{M} \mathcal{Z}_{\alpha, M}$ & & .025 & .008 & .005 & .002 & .003 & .017 & .015 & .012 & .017 & .012 & .034 & .020 & .023 & .030 & .027 \\
\hline \multirow{9}{*}{24} & $\mathcal{M Z _ { t }}$ & & .040 & .011 & .003 & .002 & .003 & .011 & .006 & .014 & .011 & .013 & .016 & .017 & .024 & .017 & .023 \\
\hline & $T(\hat{\phi}$ & & .295 & .336 & .304 & .254 & .222 & .164 & .126 & .080 & .072 & .07 & .081 & .076 & .057 & .044 & .052 \\
\hline & $\mathcal{M} \mathcal{Z}_{\alpha}$ & & .020 & .008 & .002 & .001 & .002 & .009 & .003 & .010 & .011 & .012 & .015 & .010 & .017 & .021 & .016 \\
\hline & $t_{\phi}$ & & .028 & .058 & .072 & .065 & .068 & .012 & .014 & .019 & .024 & .032 & .004 & .010 & .019 & .019 & .024 \\
\hline & $\mathcal{M S B}$ & & .018 & .004 & .001 & .001 & .001 & .004 & .003 & .006 & .007 & .006 & .010 & .008 & .016 & .012 & .012 \\
\hline & $\mathcal{M} \mathcal{Z}_{t, M}$ & & .028 & .008 & .003 & .002 & .003 & .007 & .006 & .011 & .010 & .012 & .007 & .012 & .021 & .015 & .023 \\
\hline & & & .257 & .308 & .290 & .246 & .216 & .127 & .106 & .071 & .068 & .068 & .056 & .057 & .050 & .041 & .049 \\
\hline & $T(\hat{\phi}-1)_{1}$ & & .057 & .087 & .089 & .076 & .080 & .031 & .030 & .026 & .031 & .038 & .018 & .022 & .024 & .024 & .030 \\
\hline & $\mathcal{M} \mathcal{Z}_{\alpha, M}$ & & .037 & .011 & .002 & .001 & .002 & .019 & .012 & .014 & .013 & .014 & .033 & .028 & .026 & .020 & .024 \\
\hline \multirow{9}{*}{48} & $\mathcal{M}$ & & .055 & .008 & .003 & .002 & .00 & .010 & .010 & .008 & .012 & .01 & .016 & .016 & .015 & .018 & .020 \\
\hline & $T(\hat{\phi}-1$ & & .372 & .441 & .401 & .352 & .308 & .216 & 159 & .097 & .084 & .079 & .087 & .087 & .063 & .058 & .053 \\
\hline & $\mathcal{M} \mathcal{Z}_{\alpha}$ & & .029 & .005 & .002 & .001 & .003 & .008 & .004 & .008 & .008 & .010 & .009 & .008 & .017 & .016 & .018 \\
\hline & $t_{t}$ & & .029 & .060 & .084 & .093 & .099 & .010 & .016 & .022 & . 022 & .030 & .003 & .010 & .017 & .016 & .027 \\
\hline & $\mathcal{M S B}$ & & .018 & .005 & .001 & .001 & .001 & .006 & .006 & .005 & .006 & .007 & .006 & .008 & .006 & .008 & .010 \\
\hline & $\mathcal{M} \mathcal{Z}_{t, N}$ & & .033 & .005 & .002 & .002 & .002 & .006 & .006 & .006 & .009 & .009 & .006 & .007 & .008 & .012 & .015 \\
\hline & $t_{\phi, M}$ & & .308 & .394 & .368 & .328 & .290 & .151 & 118 & .079 & .070 & .071 & .051 & .068 & .050 & .051 & .046 \\
\hline & $T(\hat{\phi}-1)$ & & .063 & .092 & .104 & .106 & .110 & .030 & .031 & .029 & .028 & .037 & .014 & .022 & .025 & .023 & .032 \\
\hline & $\mathcal{M} \mathcal{Z}_{\alpha, M}$ & & .050 & .008 & .002 & .002 & .003 & .019 & .014 & .008 & .012 & .011 & .035 & .024 & .019 & .020 & .018 \\
\hline
\end{tabular}

Note: Case $\psi=0, \phi=\boldsymbol{\imath}_{n}, \delta=5$. Dependence scheme 2 . 
Table A-6-Rejection Rates of the Tests.

\begin{tabular}{|c|c|c|c|c|c|c|c|c|c|c|c|c|c|c|c|c|c|}
\hline \multirow[b]{2}{*}{$n$} & & \multirow[b]{2}{*}{$T$} & \multicolumn{5}{|c|}{$\tau=0.1$} & \multicolumn{5}{|c|}{$\tau=0.5$} & \multicolumn{5}{|c|}{$\tau=0.9$} \\
\hline & & & 30 & 50 & 100 & 150 & 200 & 30 & 50 & 100 & 150 & 200 & 30 & 50 & 100 & 150 & 200 \\
\hline \multirow{9}{*}{8} & $\mathcal{M Z _ { t }}$ & & .018 & .015 & .012 & .012 & .017 & .016 & .013 & .018 & .022 & .025 & .016 & .023 & .024 & .031 & .031 \\
\hline & $T(\hat{\phi}-1)$ & & .106 & .111 & .112 & .098 & .087 & .090 & .087 & .057 & .050 & .052 & .068 & .056 & .047 & .048 & .048 \\
\hline & $\mathcal{M Z _ { \alpha }}$ & & .010 & .011 & .010 & .010 & .013 & .009 & .006 & .018 & .016 & .018 & .014 & .014 & .023 & .024 & .021 \\
\hline & $t_{\phi}$ & & .011 & .018 & .026 & .027 & .034 & .013 & .018 & .021 & .022 & .026 & .006 & .012 & .016 & .025 & .029 \\
\hline & $\mathcal{M S B}$ & & .011 & .009 & .007 & .008 & .011 & .008 & .006 & .012 & .015 & .015 & .010 & .011 & .016 & .014 & .018 \\
\hline & $\mathcal{M} \mathcal{Z}_{t, M}$ & & .014 & .013 & .012 & .012 & .018 & .012 & .010 & .018 & .022 & .025 & .011 & .018 & .023 & .031 & .031 \\
\hline & $t_{\phi, M}$ & & .091 & .108 & .110 & .098 & .089 & .076 & .080 & .056 & .050 & .053 & .056 & .052 & .046 & .048 & .049 \\
\hline & $T(\hat{\phi}-1)_{M}$ & & .025 & .031 & .033 & .032 & .041 & .022 & .029 & .029 & .028 & .032 & .017 & .022 & .022 & .032 & .033 \\
\hline & $\mathcal{M} \mathcal{Z}_{\alpha, M}$ & & .021 & .018 & .013 & .012 & .017 & .024 & .018 & .022 & .022 & .024 & .028 & .031 & .025 & .032 & .032 \\
\hline \multirow{9}{*}{12} & $\mathcal{M Z _ { t }}$ & & .019 & .013 & .013 & .014 & .016 & .014 & .012 & .017 & .020 & .019 & .016 & .017 & .026 & .027 & .024 \\
\hline & $T(\hat{\phi}$ & & .120 & .146 & .132 & .120 & .094 & .106 & .082 & .070 & .054 & .058 & .070 & .056 & .052 & .052 & .051 \\
\hline & $\mathcal{M} \mathcal{Z}_{\alpha}$ & & .011 & .009 & .010 & .010 & .013 & .007 & .009 & .014 & .016 & .017 & .011 & .011 & .012 & .026 & .023 \\
\hline & $t_{\phi}$ & & .008 & .022 & .029 & .034 & .033 & .007 & . 010 & .024 & .021 & .027 & .006 & .010 & .022 & . 022 & .025 \\
\hline & $\mathcal{M S B}$ & & .008 & .007 & .008 & .007 & .009 & .005 & .007 & .011 & .010 & .010 & .008 & .007 & .014 & .016 & .013 \\
\hline & $\mathcal{M} \mathcal{Z}_{t, M}$ & & .014 & .011 & .010 & .014 & .016 & .009 & .009 & .016 & .020 & .019 & .012 & .013 & .022 & .025 & .024 \\
\hline & $t_{\phi, M}$ & & .098 & .129 & .124 & .118 & .092 & .080 & .071 & .067 & .053 & .056 & .052 & .050 & .048 & .050 & .050 \\
\hline & $T(\hat{\phi}-1)_{\Lambda}$ & & .022 & .037 & .038 & .038 & .038 & .019 & . 021 & .030 & .029 & .033 & .016 & .020 & .027 & . 030 & .030 \\
\hline & $\mathcal{M} \mathcal{Z}_{\alpha, M}$ & & .025 & .019 & .015 & .015 & .016 & .023 & .016 & .020 & .020 & .018 & .030 & .024 & .030 & .026 & .024 \\
\hline \multirow{9}{*}{24} & $\mathcal{M Z _ { t }}$ & & .020 & .010 & .012 & .011 & .011 & .008 & .012 & .015 & .016 & .018 & .011 & .018 & .023 & .023 & .025 \\
\hline & $T(\hat{\phi}$ & & .157 & .185 & .152 & .137 & .12 & .136 & 108 & .069 & .064 & .06 & .086 & .078 & .054 & .056 & .058 \\
\hline & $\mathcal{M} \mathcal{Z}_{\alpha}$ & & .012 & .006 & .006 & .009 & .010 & .012 & .006 & .010 & .013 & .018 & .011 & .011 & .015 & .022 & .019 \\
\hline & $t_{\phi}$ & & .011 & .020 & .030 & .034 & .041 & .010 & .011 & .017 & .026 & .028 & .003 & .009 & .019 & .026 & .031 \\
\hline & $\mathcal{M S B}$ & & .010 & .005 & .003 & .006 & .008 & .004 & .006 & .009 & .012 & .013 & .006 & .010 & .014 & .015 & .018 \\
\hline & $\mathcal{M \mathcal { Z } _ { t , M }}$ & & .013 & .006 & .008 & .010 & .011 & .004 & .007 & .012 & .015 & .018 & .006 & .013 & .021 & .021 & .022 \\
\hline & & & .124 & .158 & .140 & .131 & .118 & .099 & .084 & .063 & .061 & .060 & .060 & .060 & .048 & .052 & .055 \\
\hline & $T(\hat{\phi}-1)_{1}$ & & .027 & .036 & .038 & .039 & .045 & .022 & .024 & .023 & .029 & .031 & .012 & .021 & .027 & .033 & .036 \\
\hline & $\mathcal{M} \mathcal{Z}_{\alpha, M}$ & & .028 & .015 & .011 & .012 & .012 & .023 & .021 & .018 & .016 & .019 & .032 & .030 & .030 & .026 & .026 \\
\hline \multirow{9}{*}{48} & $\mathcal{M}$ & & .021 & .010 & .010 & .008 & .01 & .011 & .006 & .019 & .016 & .01 & .016 & .013 & .016 & . 020 & .015 \\
\hline & $T(\hat{\phi}-1$ & & .217 & .252 & .220 & .180 & .160 & .176 & . 138 & .092 & .078 & .060 & .115 & .092 & .072 & .060 & .048 \\
\hline & $\mathcal{M} \mathcal{Z}_{\alpha}$ & & .011 & .006 & .007 & .006 & .012 & .015 & .008 & .007 & .014 & .010 & .012 & .008 & .017 & . 020 & .017 \\
\hline & t & & .010 & .023 & .044 & .042 & .044 & .005 & .016 & .024 & . 026 & .026 & .004 & .012 & .020 & .025 & .020 \\
\hline & $\mathcal{M S B}$ & & .009 & .005 & .005 & .006 & .010 & .007 & .002 & .010 & .007 & .007 & .008 & .008 & .008 & .011 & .011 \\
\hline & $\mathcal{M} \mathcal{Z}_{t, N}$ & & .013 & .005 & .008 & .006 & .012 & .006 & .002 & .015 & .011 & .010 & .007 & .007 & .011 & .016 & .014 \\
\hline & $t_{\phi, M}$ & & .155 & .208 & .194 & .162 & . 146 & .115 & 102 & .075 & .067 & .05 & .069 & .065 & .056 & .053 & .038 \\
\hline & $T(\hat{\phi}-1)$ & & .026 & .043 & .050 & .051 & .048 & .019 & .034 & .033 & .032 & .030 & .020 & .026 & .028 & .031 & .022 \\
\hline & $\mathcal{M} \mathcal{Z}_{\alpha, M}$ & & .031 & .014 & .010 & .008 & .016 & .020 & . 011 & .021 & .018 & .014 & .038 & .021 & .020 & .022 & .015 \\
\hline
\end{tabular}

Note: Case $\psi=0, \phi=\boldsymbol{\imath}_{n}, \delta=5$. Dependence scheme 3 . 
Table A-7-Rejection Rates of the Tests.

\begin{tabular}{|c|c|c|c|c|c|c|c|c|c|c|c|c|c|c|c|c|c|}
\hline \multirow[b]{2}{*}{$n$} & & \multirow[b]{2}{*}{$T$} & \multicolumn{5}{|c|}{$\tau=0.1$} & \multicolumn{5}{|c|}{$\tau=0.5$} & \multicolumn{5}{|c|}{$\tau=0.9$} \\
\hline & & & 30 & 50 & 100 & 150 & 200 & 30 & 50 & 100 & 150 & 200 & 30 & 50 & 100 & 150 & 200 \\
\hline \multirow{9}{*}{8} & $\mathcal{M Z _ { t }}$ & & .171 & .338 & .856 & .992 & 1.00 & .188 & .255 & .603 & .896 & .990 & .534 & .410 & .399 & .354 & .561 \\
\hline & $T(\hat{\phi}-1)$ & & .211 & .244 & .599 & .915 & .996 & .142 & 148 & .366 & .692 & .922 & .035 & .092 & .118 & .162 & .230 \\
\hline & $\mathcal{M} \mathcal{Z}_{\alpha}$ & & .121 & .253 & .778 & .979 & 1.00 & .138 & 177 & .466 & .802 & .961 & .502 & .370 & .359 & .306 & .518 \\
\hline & $t_{\phi}$ & & .042 & .112 & .501 & .887 & .992 & .075 & .104 & .305 & .638 & .907 & .040 & .073 & .098 & .150 & .212 \\
\hline & $\mathcal{M S B}$ & & .121 & .253 & .778 & .979 & 1.00 & .138 & .177 & .466 & .802 & .961 & .471 & .331 & .315 & .261 & .457 \\
\hline & $\mathcal{M} \mathcal{Z}_{t, M}$ & & .134 & .309 & .850 & .992 & 1.00 & .152 & .229 & .592 & .895 & .990 & .496 & .386 & .389 & .352 & .562 \\
\hline & $t_{\phi, M}$ & & .188 & .225 & .592 & .915 & .996 & .125 & . 136 & .360 & .692 & .924 & .026 & .082 & .114 & .162 & .230 \\
\hline & $T(\hat{\phi}$ & & .100 & .169 & .568 & .914 & .997 & .131 & .152 & .374 & .694 & .926 & .078 & .119 & .132 & .171 & .243 \\
\hline & $\mathcal{M} \mathcal{Z}_{\alpha, M}$ & & .286 & .416 & .874 & .992 & 1.00 & .282 & .323 & .626 & .899 & .987 & .617 & .462 & .419 & .361 & .561 \\
\hline \multirow{9}{*}{12} & $\mathcal{M} \mathcal{Z}_{t}$ & & .300 & .617 & .998 & 1.00 & 1.00 & .188 & .227 & .579 & .909 & .994 & .620 & .455 & .445 & .356 & .629 \\
\hline & $T(\hat{\phi}-1)$ & & .316 & .447 & .923 & 1.00 & 1.00 & .158 & .172 & .377 & .735 & .950 & .035 & .094 & .115 & .178 & .262 \\
\hline & $\mathcal{M} \mathcal{Z}_{\alpha}$ & & .211 & .464 & .991 & 1.00 & 1.00 & .143 & .151 & .436 & .813 & .980 & .588 & .421 & .398 & .311 & .583 \\
\hline & $t_{\phi}$ & & .072 & .199 & .851 & .999 & 1.00 & .073 & .114 & .294 & .674 & .934 & .040 & .072 & .107 & .150 & .231 \\
\hline & $\mathcal{M S B}$ & & .211 & .464 & .991 & 1.00 & 1.00 & .143 & .151 & .436 & .813 & .980 & .562 & .376 & .345 & .263 & .516 \\
\hline & $\mathcal{M} \mathcal{Z}_{t, M}$ & & .225 & .566 & .998 & 1.00 & 1.00 & .148 & .192 & .558 & .904 & .994 & .574 & .420 & .425 & .346 & .625 \\
\hline & $t_{\phi, M}$ & & .271 & .410 & .914 & 1.00 & 1.00 & .126 & .150 & .353 & .726 & .949 & .025 & .079 & .106 & .170 & .258 \\
\hline & $T(\hat{\phi}$ & & .156 & .314 & .902 & 1.00 & 1.00 & .134 & .165 & .366 & .730 & .950 & .088 & .113 & .132 & .177 & .270 \\
\hline & $\mathcal{M} \mathcal{Z}_{\alpha, M}$ & & .480 & .726 & .998 & 1.00 & 1.00 & .293 & .298 & .620 & .912 & .994 & .708 & .515 & .468 & .368 & .626 \\
\hline \multirow{9}{*}{24} & $\mathcal{M Z}$ & & .197 & .414 & .985 & 1.00 & 1.00 & .198 & .192 & .484 & .862 & .992 & .824 & .629 & .578 & .448 & .798 \\
\hline & $T(\hat{\phi}-1)$ & & .358 & .393 & .866 & .997 & 1.00 & .183 & .165 & .342 & .690 & .939 & .048 & .114 & .159 & .226 & .346 \\
\hline & $\mathcal{M} \mathcal{Z}_{\alpha}$ & & .140 & .296 & .949 & 1.00 & 1.00 & .157 & 139 & .345 & .724 & .962 & .798 & .596 & .533 & .393 & .750 \\
\hline & $t_{\phi}$ & & .060 & .134 & .732 & .993 & 1.00 & .066 & .094 & .260 & .604 & .919 & .047 & .089 & .129 & . 194 & .309 \\
\hline & $\mathcal{M S B}$ & & .140 & .296 & .949 & 1.00 & 1.00 & .157 & 139 & .345 & .724 & .962 & .768 & .554 & .468 & .333 & .691 \\
\hline & $\mathcal{M} \mathcal{Z}_{t, N}$ & & .122 & .330 & .982 & 1.00 & 1.00 & .144 & .150 & .441 & .849 & .991 & .770 & .576 & .546 & .428 & .792 \\
\hline & $t_{\phi, M}$ & & .297 & .351 & .844 & .997 & 1.00 & .138 & .138 & .312 & .674 & .938 & .031 & .082 & .142 & .213 & .335 \\
\hline & $T(\hat{\phi}-1)_{M}$ & & .142 & .236 & .813 & .996 & 1.00 & .156 & 153 & .329 & .681 & .940 & .117 & .162 & .170 & .232 & .348 \\
\hline & $\mathcal{M} \mathcal{Z}_{\alpha, M}$ & & .408 & .574 & .990 & 1.00 & 1.00 & .331 & .290 & .541 & .876 & .992 & .896 & .711 & .620 & .464 & .799 \\
\hline \multirow{9}{*}{48} & $\mathcal{M}$ & & .256 & .492 & .999 & 1.00 & 1.00 & .270 & .246 & .656 & .985 & 1.00 & .921 & .730 & .607 & .396 & .786 \\
\hline & $T(\hat{\phi}-1)$ & & .526 & .574 & .953 & 1.00 & 1.00 & .257 & .241 & .505 & .906 & .998 & .045 & .109 & .148 & .234 & .347 \\
\hline & $\mathcal{M} \mathcal{Z}_{\alpha}$ & & .187 & .350 & .991 & 1.00 & 1.0 & .209 & .172 & .465 & .929 & 1.00 & .908 & .698 & .548 & .352 & .742 \\
\hline & $t_{\phi}$ & & .062 & .179 & .846 & 1.00 & 1.00 & .078 & .114 & .378 & .834 & .996 & .051 & .081 & .122 & 191 & .303 \\
\hline & $\mathcal{M S B}$ & & .187 & .350 & .991 & 1.00 & 1.00 & .209 & .172 & .465 & .929 & 1.00 & .894 & .656 & .479 & .281 & .666 \\
\hline & $\mathcal{M} \mathcal{Z}_{t, \Lambda}$ & & .127 & .349 & .999 & 1.00 & 1.00 & .176 & .163 & .578 & .982 & 1.00 & .874 & .655 & .543 & .354 & .767 \\
\hline & $t_{\phi, M}$ & & .420 & .493 & .940 & 1.00 & 1.00 & .180 & 177 & .450 & .885 & .998 & .026 & .069 & .124 & .210 & .314 \\
\hline & $T(\hat{\phi}-$ & & .193 & .308 & .912 & 1.00 & 1.00 & .200 & .204 & .472 & .893 & .999 & .122 & .153 & .166 & .230 & .340 \\
\hline & $\mathcal{M} \mathcal{Z}_{\alpha, M}$ & & .537 & .701 & 1.00 & 1.00 & 1.00 & .449 & .366 & .722 & .990 & 1.00 & .966 & .803 & .650 & .415 & .791 \\
\hline
\end{tabular}

Note: Case $\psi=0, \phi=\left(\boldsymbol{\imath}_{n / 2}^{\prime}, \widetilde{\phi}_{n / 2}^{\prime}\right)^{\prime}$ with $\left(\widetilde{\boldsymbol{\phi}}_{n / 2}\right)_{i} \sim \mathcal{U}(.75,1), \delta=0.2$. Dependence scheme 1 . 
Table A-8-Rejection Rates of the Tests.

\begin{tabular}{|c|c|c|c|c|c|c|c|c|c|c|c|c|c|c|c|c|c|}
\hline \multirow[b]{2}{*}{$n$} & & \multirow[b]{2}{*}{$T$} & \multicolumn{5}{|c|}{$\tau=0.1$} & \multicolumn{5}{|c|}{$\tau=0.5$} & \multicolumn{5}{|c|}{$\tau=0.9$} \\
\hline & & & 30 & 50 & 100 & 150 & 200 & 30 & 50 & 100 & 150 & 200 & 30 & 50 & 100 & 150 & 200 \\
\hline \multirow{9}{*}{8} & $\mathcal{M Z _ { t }}$ & & .170 & .332 & .798 & .982 & 1.00 & .166 & .206 & .451 & .740 & .927 & .446 & .312 & .322 & .256 & .437 \\
\hline & $T(\hat{\phi}-1)$ & & .225 & .265 & .562 & .865 & .995 & .120 & .134 & .263 & .534 & .799 & .035 & .066 & .086 & . 120 & .184 \\
\hline & $\mathcal{M} \mathcal{Z}_{\alpha}$ & & .251 & .478 & .960 & 1.00 & 1.00 & .150 & 142 & .295 & .540 & .785 & .423 & .284 & .288 & .218 & .399 \\
\hline & $t_{\phi}$ & & .057 & .122 & .450 & .827 & .991 & .062 & .089 & .221 & .491 & .770 & .032 & .055 & .076 & .106 & .174 \\
\hline & $\mathcal{M S B}$ & & .115 & .236 & .696 & .952 & .999 & .120 & .143 & .327 & .622 & .865 & .394 & .253 & .245 & .182 & .344 \\
\hline & $\mathcal{M} \mathcal{Z}_{t, M}$ & & .137 & .302 & .791 & .982 & 1.00 & .135 & .182 & .445 & .739 & .928 & .415 & .294 & .315 & .255 & .442 \\
\hline & $t_{\phi, M}$ & & .203 & .248 & .556 & .864 & .995 & .104 & . 122 & .257 & .533 & .802 & .028 & .059 & .083 & . 120 & .184 \\
\hline & $T(\hat{\phi}$ & & .118 & .176 & .514 & .864 & .994 & .114 & .136 & .261 & .540 & .798 & .058 & .090 & .094 & .127 & .194 \\
\hline & $\mathcal{M} \mathcal{Z}_{\alpha, M}$ & & .280 & .406 & .818 & .984 & 1.00 & .242 & .259 & .475 & .744 & .925 & .528 & .362 & .338 & .259 & .438 \\
\hline \multirow{9}{*}{12} & $\mathcal{M} \mathcal{Z}_{t}$ & & .239 & .442 & .947 & .999 & 1.00 & .192 & .227 & .565 & .860 & .985 & .644 & .501 & .489 & .410 & .675 \\
\hline & $T(\hat{\phi}-1)$ & & .296 & .335 & .768 & .976 & .999 & .151 & .154 & .362 & .675 & .918 & .050 & .113 & .151 & .194 & .312 \\
\hline & $\mathcal{M} \mathcal{Z}_{\alpha}$ & & .217 & .462 & .962 & 1.00 & 1.00 & .190 & .275 & .694 & .952 & .997 & .619 & .467 & .453 & .362 & .635 \\
\hline & $t_{\phi}$ & & .072 & .157 & .663 & .964 & .999 & .063 & .094 & .306 & .624 & .894 & .054 & .090 & .137 & .175 & .290 \\
\hline & $\mathcal{M S B}$ & & .166 & .320 & .892 & .998 & 1.00 & .147 & .155 & .426 & .774 & .958 & .589 & .434 & .405 & .305 & .578 \\
\hline & $\mathcal{M} \mathcal{Z}_{t, M}$ & & .180 & .389 & .944 & .999 & 1.00 & .157 & .201 & .544 & .854 & .986 & .599 & .467 & .474 & .402 & .673 \\
\hline & $t_{\phi, M}$ & & .258 & .309 & .760 & .974 & .999 & .122 & .134 & .346 & .671 & .918 & .039 & .094 & .143 & .190 & .310 \\
\hline & $T(\hat{\phi}$ & & .150 & .223 & .734 & .977 & .999 & .132 & .148 & .361 & .677 & .916 & .114 & .150 & .165 & .209 & .319 \\
\hline & $\mathcal{M} \mathcal{Z}_{\alpha, M}$ & & .394 & .543 & .952 & .999 & 1.00 & .293 & .298 & .594 & .864 & .986 & .729 & .564 & .512 & .418 & .669 \\
\hline \multirow{9}{*}{24} & $\mathcal{M Z}$ & & .223 & .443 & .957 & 1.00 & 1.00 & .230 & .226 & .548 & .861 & .986 & .728 & .529 & .463 & .329 & .626 \\
\hline & $T(\hat{\phi}-1)$ & & .360 & .414 & .813 & .986 & 1.00 & .186 & .189 & .386 & .715 & .934 & .040 & .095 & .132 & .168 & .276 \\
\hline & $\mathcal{M} \mathcal{Z}_{\alpha}$ & & .174 & .358 & .902 & .999 & 1.00 & .220 & .230 & .546 & .881 & .983 & .712 & .508 & .429 & .293 & .582 \\
\hline & $t_{\phi}$ & & .054 & .157 & .704 & .978 & .999 & .068 & . 106 & .316 & .658 & .918 & .038 & .074 & .110 & 142 & .248 \\
\hline & $\mathcal{M S B}$ & & .158 & .320 & .912 & .999 & 1.00 & .177 & .157 & .426 & .774 & .960 & .688 & .469 & .380 & .243 & .520 \\
\hline & $\mathcal{M} \mathcal{Z}_{t, N}$ & & .138 & .360 & .948 & 1.00 & 1.00 & .163 & .178 & .522 & .856 & .986 & .682 & .488 & .439 & .317 & .619 \\
\hline & $t_{\phi, M}$ & & .296 & .367 & .793 & .985 & 1.00 & .144 & .156 & .363 & .702 & .932 & .024 & .075 & .122 & .157 & .267 \\
\hline & $T(\hat{\phi}-1)_{M}$ & & .141 & .253 & .770 & .985 & 1.00 & .163 & 172 & .384 & .707 & .933 & .093 & .126 & .143 & .174 & .280 \\
\hline & $\mathcal{M} \mathcal{Z}_{\alpha, M}$ & & .413 & .567 & .966 & 1.00 & 1.00 & .362 & .314 & .595 & .871 & .987 & .807 & .604 & .502 & .342 & .628 \\
\hline \multirow{9}{*}{48} & $\mathcal{M}$ & & .265 & .535 & .990 & 1.00 & 1.00 & .263 & .227 & .554 & .898 & .987 & .832 & .603 & .491 & .310 & .615 \\
\hline & $T(\hat{\phi}-1)$ & & .478 & .538 & .908 & .996 & 1.00 & .239 & .226 & .439 & .774 & .962 & .039 & .096 & .118 & .154 & .272 \\
\hline & $\mathcal{M} \mathcal{Z}_{\alpha}$ & & .212 & .412 & .956 & 1.00 & 1.00 & .215 & 182 & .427 & .821 & .974 & .816 & .575 & .455 & .275 & .577 \\
\hline & $t_{\phi}$ & & .063 & .196 & .827 & .995 & 1.00 & .068 & .113 & .334 & .712 & .947 & .045 & .067 & .092 & .126 & .236 \\
\hline & $\mathcal{M S B}$ & & .185 & .404 & .971 & 1.00 & 1.00 & .214 & .158 & .398 & .794 & .963 & .791 & .535 & .400 & .220 & .507 \\
\hline & $\mathcal{M} \mathcal{Z}_{t, \Lambda}$ & & .142 & .421 & .987 & 1.00 & 1.00 & .179 & .152 & .494 & .881 & .986 & .766 & .530 & .439 & .276 & .591 \\
\hline & $t_{\phi, M}$ & & .385 & .463 & .890 & .996 & 1.00 & .158 & 182 & .395 & .756 & .958 & .018 & .065 & .096 & .132 & .250 \\
\hline & $T(\hat{\phi}-$ & & .172 & .325 & .876 & .997 & 1.00 & .186 & .196 & .416 & .762 & .958 & .108 & .129 & .120 & .152 & .262 \\
\hline & $\mathcal{M} \mathcal{Z}_{\alpha, M}$ & & .507 & .692 & .994 & 1.00 & 1.00 & .416 & .332 & .620 & .910 & .988 & .897 & .676 & .524 & .322 & .620 \\
\hline
\end{tabular}

Note: Case $\psi=0, \phi=\left(\boldsymbol{\imath}_{n / 2}^{\prime}, \widetilde{\phi}_{n / 2}^{\prime}\right)^{\prime}$ with $\left(\widetilde{\boldsymbol{\phi}}_{n / 2}\right)_{i} \sim \mathcal{U}(.75,1), \delta=0.2$. Dependence scheme 2 . 
Table A-9-Rejection Rates of the Tests.

\begin{tabular}{|c|c|c|c|c|c|c|c|c|c|c|c|c|c|c|c|c|c|}
\hline \multirow[b]{2}{*}{$n$} & & \multirow[b]{2}{*}{$T$} & \multicolumn{5}{|c|}{$\tau=0.1$} & \multicolumn{5}{|c|}{$\tau=0.5$} & \multicolumn{5}{|c|}{$\tau=0.9$} \\
\hline & & & 30 & 50 & 100 & 150 & 200 & 30 & 50 & 100 & 150 & 200 & 30 & 50 & 100 & 150 & 200 \\
\hline \multirow{9}{*}{8} & $\mathcal{M Z _ { t }}$ & & .262 & .551 & .992 & 1.00 & 1.00 & .218 & .313 & .752 & .978 & .999 & .580 & .514 & .602 & .610 & .798 \\
\hline & $T(\hat{\phi}-1)$ & & .289 & .356 & .860 & .996 & 1.00 & .160 & .200 & .516 & .857 & .981 & .063 & .150 & .225 & .306 & .432 \\
\hline & $\mathcal{M} \mathcal{Z}_{\alpha}$ & & .207 & .429 & .955 & .999 & 1.00 & .162 & .232 & .573 & .888 & .988 & .546 & .478 & .562 & .565 & .765 \\
\hline & $t_{\phi}$ & & .091 & .196 & .784 & .993 & 1.00 & .081 & .138 & .447 & .823 & .977 & .053 & .120 & .200 & .294 & .420 \\
\hline & $\mathcal{M S B}$ & & .194 & .429 & .961 & 1.00 & 1.00 & .160 & .224 & .612 & .943 & .995 & .505 & .426 & .500 & .486 & .712 \\
\hline & $\mathcal{M \mathcal { Z } _ { t , M }}$ & & .219 & .515 & .989 & 1.00 & 1.00 & .182 & .286 & .742 & .977 & .999 & .540 & .486 & .594 & .608 & .800 \\
\hline & $t_{\phi, M}$ & & .260 & .334 & .851 & .996 & 1.00 & .136 & . 187 & .504 & .856 & .982 & .049 & .139 & .219 & .306 & .435 \\
\hline & $T(\hat{\phi}$ & & .170 & .274 & .836 & .996 & 1.00 & .152 & 198 & .524 & .869 & .981 & .103 & .177 & .243 & .329 & .458 \\
\hline & $\mathcal{M} \mathcal{Z}_{\alpha, M}$ & & .405 & .644 & .994 & 1.00 & 1.00 & .326 & .377 & .772 & .977 & .999 & .658 & .575 & .619 & .614 & .793 \\
\hline \multirow{9}{*}{12} & $\mathcal{M Z _ { t }}$ & & .268 & .542 & .992 & 1.00 & 1.00 & .218 & .302 & .774 & .982 & 1.00 & .457 & .353 & .375 & .354 & .580 \\
\hline & $T(\hat{\phi}-1)$ & & .321 & .419 & .885 & 1.00 & 1.00 & .159 & .213 & .522 & .892 & .996 & .045 & .084 & .132 & .188 & .265 \\
\hline & $\mathcal{M} \mathcal{Z}_{\alpha}$ & & .198 & .370 & .930 & 1.00 & 1.00 & .172 & .190 & .513 & .838 & .980 & .428 & .309 & .335 & .304 & .534 \\
\hline & $t_{\phi}$ & & .080 & .208 & .808 & .999 & 1.00 & .084 & .136 & .440 & .847 & .992 & .030 & .063 & .101 & .167 & .241 \\
\hline & $\mathcal{M S B}$ & & .179 & .398 & .970 & 1.00 & 1.00 & .166 & .204 & .618 & .944 & .999 & .394 & .276 & .289 & .260 & .478 \\
\hline & $\mathcal{M} \mathcal{Z}_{t, M}$ & & .196 & .482 & .990 & 1.00 & 1.00 & .170 & .258 & .758 & .981 & 1.00 & .406 & .314 & .360 & .340 & .575 \\
\hline & $t_{\phi, M}$ & & .276 & .381 & .878 & 1.00 & 1.00 & .133 & .191 & .510 & .888 & .996 & .032 & .072 & .120 & .183 & .263 \\
\hline & $T(\hat{\phi}$ & & .176 & .312 & .864 & 1.00 & 1.00 & .157 & .209 & .525 & .888 & .994 & .068 & .099 & .134 & .190 & .269 \\
\hline & $\mathcal{M} \mathcal{Z}_{\alpha, M}$ & & .450 & .644 & .993 & 1.00 & 1.00 & .342 & .401 & .803 & .985 & 1.00 & .540 & .416 & .403 & .360 & .580 \\
\hline \multirow{9}{*}{24} & $\mathcal{M Z _ { t }}$ & & .275 & .579 & 1.00 & 1.00 & 1.00 & .180 & .194 & .502 & .873 & .990 & .697 & .501 & .535 & .470 & .786 \\
\hline & $T(\hat{\phi}-1)$ & & .442 & .532 & .964 & 1.00 & 1.00 & .181 & .204 & .379 & .697 & .949 & .052 & .124 & .188 & .279 & .424 \\
\hline & $\mathcal{M} \mathcal{Z}_{\alpha}$ & & .228 & .530 & .998 & 1.00 & 1.00 & .218 & .235 & .647 & .963 & 1.00 & .671 & .461 & .492 & .428 & .750 \\
\hline & $t_{\phi}$ & & .077 & .223 & .905 & 1.00 & 1.00 & .075 & . 106 & .290 & .620 & .925 & .041 & .071 & .148 & .242 & .393 \\
\hline & $\mathcal{M S B}$ & & .186 & .417 & .995 & 1.00 & 1.00 & .143 & .140 & .351 & .742 & .962 & .644 & .414 & .433 & .364 & .689 \\
\hline & $\mathcal{M} \mathcal{Z}_{t, N}$ & & .172 & .481 & 1.00 & 1.00 & 1.00 & .128 & .151 & .460 & .864 & .990 & .634 & .444 & .506 & .448 & .781 \\
\hline & $t_{\phi, M}$ & & .366 & .468 & .952 & 1.00 & 1.00 & .142 & .166 & .353 & .681 & .947 & .029 & .091 & .168 & .265 & .413 \\
\hline & $T(\hat{\phi}-1)_{M}$ & & .207 & .352 & .948 & 1.00 & 1.00 & .161 & . 183 & .363 & .684 & .947 & .098 & .134 & .195 & .276 & .426 \\
\hline & $\mathcal{M} \mathcal{Z}_{\alpha, M}$ & & .520 & .738 & 1.00 & 1.00 & 1.00 & .319 & .290 & .554 & .882 & .992 & .794 & .594 & .570 & .489 & .790 \\
\hline \multirow{9}{*}{48} & $\mathcal{M}$ & & .315 & .699 & 1.00 & 1.00 & 1.00 & .306 & .287 & .775 & .999 & 1.00 & .871 & .690 & .686 & .593 & .921 \\
\hline & $T(\hat{\phi}-1)$ & & .600 & .687 & .996 & 1.00 & 1.00 & .282 & .294 & .620 & .967 & 1.00 & .068 & .139 & .249 & .360 & .542 \\
\hline & $\mathcal{M} \mathcal{Z}_{\alpha}$ & & .186 & .356 & .990 & 1.00 & 1.00 & .279 & .258 & .718 & .996 & 1.00 & .855 & .660 & .642 & .545 & .895 \\
\hline & $t_{\phi}$ & & .088 & .264 & .979 & 1.00 & 1.00 & .081 & .151 & .476 & .927 & 1.00 & .031 & .084 & .188 & .305 & .492 \\
\hline & $\mathcal{M S B}$ & & .224 & .506 & 1.00 & 1.00 & 1.00 & .232 & .196 & .600 & .986 & 1.00 & .826 & .604 & .564 & .456 & .833 \\
\hline & $\mathcal{M \mathcal { Z } _ { t , \Lambda }}$ & & .169 & .542 & 1.00 & 1.00 & 1.00 & .192 & .194 & .722 & .998 & 1.00 & .804 & .612 & .631 & .552 & .908 \\
\hline & $t_{\phi, M}$ & & .477 & .588 & .994 & 1.00 & 1.00 & .192 & .224 & .561 & .958 & 1.00 & .036 & .092 & .206 & .326 & .512 \\
\hline & $T(\hat{\phi}-$ & & .244 & .452 & .993 & 1.00 & 1.00 & .220 & .250 & .585 & .960 & 1.00 & .113 & .158 & .241 & .357 & .541 \\
\hline & $\mathcal{M} \mathcal{Z}_{\alpha, M}$ & & .633 & .868 & 1.00 & 1.00 & 1.00 & .494 & .440 & .843 & .999 & 1.00 & .940 & .775 & .735 & .617 & .923 \\
\hline
\end{tabular}

Note: Case $\psi=0, \phi=\left(\boldsymbol{\imath}_{n / 2}^{\prime}, \widetilde{\phi}_{n / 2}^{\prime}\right)^{\prime}$ with $\left(\widetilde{\boldsymbol{\phi}}_{n / 2}\right)_{i} \sim \mathcal{U}(.75,1), \delta=0.2$. Dependence scheme 3 . 
Table A-10-Rejection Rates of the Tests.

\begin{tabular}{|c|c|c|c|c|c|c|c|c|c|c|c|c|c|c|c|c|c|}
\hline \multirow[b]{2}{*}{$n$} & & \multirow[b]{2}{*}{$T$} & \multicolumn{5}{|c|}{$\tau=0.1$} & \multicolumn{5}{|c|}{$\tau=0.5$} & \multicolumn{5}{|c|}{$\tau=0.9$} \\
\hline & & & 30 & 50 & 100 & 150 & 200 & 30 & 50 & 100 & 150 & 200 & 30 & 50 & 100 & 150 & 200 \\
\hline \multirow{9}{*}{8} & $\mathcal{M Z _ { t }}$ & & .136 & .111 & .142 & .230 & .352 & .042 & .079 & .406 & .776 & .954 & .158 & .422 & .984 & 1.00 & 1.00 \\
\hline & $T(\hat{\phi}-1)$ & & .573 & .616 & .721 & .790 & .847 & .272 & .393 & .735 & .951 & .996 & .292 & .583 & .992 & 1.00 & 1.00 \\
\hline & $\mathcal{M} \mathcal{Z}_{\alpha}$ & & .102 & .084 & .124 & 192 & .315 & .028 & .048 & .301 & .644 & .890 & .105 & .302 & .955 & 1.00 & 1.00 \\
\hline & $t_{\phi}$ & & .081 & .204 & .435 & .604 & .693 & .054 & . 167 & .562 & .882 & .985 & .072 & .325 & .966 & 1.00 & 1.00 \\
\hline & $\mathcal{M S B}$ & & .081 & .074 & .105 & .159 & .271 & .028 & .048 & .301 & .644 & .890 & .105 & .302 & .955 & 1.00 & 1.00 \\
\hline & $\mathcal{M} \mathcal{Z}_{t, M}$ & & .120 & .104 & .140 & .230 & .355 & .031 & .071 & .396 & .774 & .955 & .122 & .384 & .983 & 1.00 & 1.00 \\
\hline & $t_{\phi, M}$ & & .540 & .599 & .717 & .790 & .848 & .240 & .370 & .728 & .950 & .996 & .246 & .554 & .991 & 1.00 & 1.00 \\
\hline & $T(\hat{\phi}$ & & .141 & .265 & .492 & .639 & .725 & .118 & .241 & .634 & .917 & .990 & .166 & .460 & .983 & 1.00 & 1.00 \\
\hline & $\mathcal{M} \mathcal{Z}_{\alpha, M}$ & & .156 & .123 & .153 & .235 & .347 & .074 & .112 & .434 & .778 & .952 & .262 & .514 & .986 & 1.00 & 1.00 \\
\hline \multirow{9}{*}{12} & $\mathcal{M \mathcal { Z } _ { t }}$ & & .134 & .092 & .113 & .161 & .290 & .056 & .110 & .610 & .958 & .999 & .151 & .428 & .992 & 1.00 & 1.00 \\
\hline & $T(\hat{\phi}-1)$ & & .660 & .685 & .750 & .787 & .848 & .357 & .563 & .906 & .998 & 1.00 & .323 & .639 & .996 & 1.00 & 1.00 \\
\hline & $\mathcal{M} \mathcal{Z}_{\alpha}$ & & .104 & .068 & .086 & .137 & .253 & .032 & .057 & .448 & .871 & .992 & .096 & .294 & .972 & 1.00 & 1.00 \\
\hline & $t_{\phi}$ & & .072 & .190 & .420 & .565 & .672 & .074 & .234 & .770 & .989 & 1.00 & .074 & .330 & .979 & 1.00 & 1.00 \\
\hline & $\mathcal{M S B}$ & & .090 & .055 & .067 & .110 & .208 & .032 & .057 & .448 & .871 & .992 & .096 & .294 & .972 & 1.00 & 1.00 \\
\hline & $\mathcal{M Z _ { t , M }}$ & & .110 & .079 & .103 & .156 & .289 & .038 & .084 & .588 & .954 & .998 & .108 & .375 & .990 & 1.00 & 1.00 \\
\hline & $t_{\phi, M}$ & & .608 & .660 & .738 & .784 & .846 & .302 & .512 & .898 & .998 & 1.00 & .267 & .596 & .994 & 1.00 & 1.00 \\
\hline & $T(\hat{\phi}$ & & .136 & .258 & .478 & .617 & .708 & .172 & .357 & .825 & .992 & 1.00 & .192 & .498 & .989 & 1.00 & 1.00 \\
\hline & $\mathcal{M} \mathcal{Z}_{\alpha, M}$ & & .161 & .100 & .121 & .165 & .293 & .099 & .164 & .642 & .958 & .999 & .272 & .540 & .995 & 1.00 & 1.00 \\
\hline \multirow{9}{*}{24} & $\mathcal{M Z}$ & & .238 & .149 & .186 & .258 & .411 & .054 & .073 & .534 & .939 & .998 & .128 & .395 & .997 & 1.00 & 1.00 \\
\hline & $T(\hat{\phi}-1)$ & & .849 & .873 & .928 & .956 & .974 & .437 & .568 & .924 & .998 & 1.00 & .339 & .659 & 1.00 & 1.00 & 1.00 \\
\hline & $\mathcal{M} \mathcal{Z}_{\alpha}$ & & .191 & .119 & .163 & .229 & .374 & .040 & .049 & .387 & .851 & .988 & .084 & .266 & .987 & 1.00 & 1.00 \\
\hline & $t_{\phi}$ & & .107 & .313 & .637 & .802 & .896 & .060 & .207 & .749 & .987 & 1.00 & .058 & .292 & .994 & 1.00 & 1.00 \\
\hline & $\mathcal{M S B}$ & & .161 & .098 & .128 & .184 & .321 & .040 & .049 & .387 & .851 & .988 & .084 & .266 & .987 & 1.00 & 1.00 \\
\hline & $\mathcal{M} \mathcal{Z}_{t, N}$ & & .184 & .123 & .169 & .244 & .399 & .037 & .055 & .494 & .934 & .998 & .071 & .309 & .996 & 1.00 & 1.00 \\
\hline & $t_{\phi, M}$ & & .794 & .849 & .922 & .954 & .974 & .340 & .502 & .911 & .998 & 1.00 & .259 & .591 & 1.00 & 1.00 & 1.00 \\
\hline & $T(\hat{\phi}-1)_{M}$ & & .212 & .420 & .702 & .841 & .916 & .161 & .324 & .827 & .993 & 1.00 & .172 & .484 & 1.00 & 1.00 & 1.00 \\
\hline & $\mathcal{M} \mathcal{Z}_{\alpha, M}$ & & .281 & .178 & .205 & .269 & .420 & .095 & .122 & .590 & .947 & .998 & .261 & .540 & .998 & 1.00 & 1.00 \\
\hline \multirow{9}{*}{48} & $\mathcal{M Z}$ & & .245 & .138 & .122 & .159 & .311 & .070 & .072 & .590 & .980 & 1.0 & .108 & .304 & .997 & 1.00 & 1.00 \\
\hline & $T(\hat{\phi}-1)$ & & .909 & .936 & .962 & .975 & .986 & .564 & .697 & .984 & 1.00 & 1.00 & .372 & .687 & 1.00 & 1.00 & 1.00 \\
\hline & $\mathcal{M} \mathcal{Z}_{\alpha}$ & & .184 & .113 & .104 & . 135 & .276 & .049 & .036 & .416 & .919 & 1.00 & .068 & .187 & .987 & 1.00 & 1.00 \\
\hline & $t_{\phi}$ & & .110 & .292 & .636 & .808 & .898 & .056 & .238 & .866 & .998 & 1.00 & .025 & .263 & .995 & 1.00 & 1.00 \\
\hline & $\mathcal{M S B}$ & & .153 & .090 & .078 & .101 & .220 & .049 & .036 & .416 & .919 & 1.00 & .068 & .187 & .987 & 1.00 & 1.00 \\
\hline & $\mathcal{M Z _ { t , N }}$ & & .180 & .101 & .097 & .136 & .278 & .040 & .037 & .512 & .973 & 1.0 & .049 & .194 & .997 & 1.00 & 1.00 \\
\hline & $t_{\phi, M}$ & & .843 & .906 & .948 & .971 & .982 & .400 & .601 & .977 & 1.00 & 1.00 & .237 & .574 & 1.00 & 1.00 & 1.00 \\
\hline & $T(\hat{\phi}-1$ & & .227 & .424 & .708 & .838 & .916 & .194 & 411 & .931 & .999 & 1.00 & .135 & .452 & 1.00 & 1.00 & 1.00 \\
\hline & $\mathcal{M} \mathcal{Z}_{\alpha, M}$ & & .282 & .162 & .130 & .166 & .307 & .124 & .134 & .660 & .986 & 1.00 & .279 & .490 & .999 & 1.00 & 1.00 \\
\hline
\end{tabular}

Note: Case $\psi=0, \phi=\left(\boldsymbol{\imath}_{n / 2}^{\prime}, \widetilde{\phi}_{n / 2}^{\prime}\right)^{\prime}$ with $\left(\widetilde{\phi}_{n / 2}\right)_{i} \sim \mathcal{U}(.75,1), \delta=5$. Dependence scheme 1 . 
Table A-11-Rejection Rates of the Tests.

\begin{tabular}{|c|c|c|c|c|c|c|c|c|c|c|c|c|c|c|c|c|c|}
\hline \multirow[b]{2}{*}{$n$} & & \multirow[b]{2}{*}{$T$} & \multicolumn{5}{|c|}{$\tau=0.1$} & \multicolumn{5}{|c|}{$\tau=0.5$} & \multicolumn{5}{|c|}{$\tau=0.9$} \\
\hline & & & 30 & 50 & 100 & 150 & 200 & 30 & 50 & 100 & 150 & 200 & 30 & 50 & 100 & 150 & 200 \\
\hline \multirow{9}{*}{8} & $\mathcal{M Z _ { t }}$ & & .170 & .131 & .194 & .260 & .428 & .042 & .071 & .381 & .776 & .933 & .144 & .367 & .941 & .999 & 1.00 \\
\hline & $T(\hat{\phi}-1)$ & & .593 & .648 & .754 & .809 & .864 & .264 & .339 & .672 & .910 & .988 & .250 & .513 & .962 & 1.00 & 1.00 \\
\hline & $\mathcal{M} \mathcal{Z}_{\alpha}$ & & .131 & .111 & .168 & .220 & .386 & .020 & .035 & .174 & .346 & .547 & .114 & .298 & .912 & .999 & 1.00 \\
\hline & $t_{\phi}$ & & .094 & .250 & .505 & .643 & .755 & .053 & .144 & .528 & .845 & .976 & .069 & .280 & .912 & .998 & 1.00 \\
\hline & $\mathcal{M S B}$ & & .110 & .101 & .140 & .190 & .344 & .022 & .041 & .288 & .682 & .881 & .087 & .266 & .881 & .998 & 1.00 \\
\hline & $\mathcal{M \mathcal { Z } _ { t , M }}$ & & .153 & .122 & .188 & .260 & .431 & .032 & .058 & .376 & .775 & .936 & .113 & .331 & .934 & .999 & 1.00 \\
\hline & $t_{\phi, M}$ & & .560 & .633 & .752 & .808 & .864 & .230 & .318 & .666 & .910 & .988 & .209 & .487 & .959 & 1.00 & 1.00 \\
\hline & $T(\hat{\phi}$ & & .160 & .317 & .557 & .674 & .779 & .110 & .212 & .595 & .876 & .983 & .153 & .400 & .938 & 1.00 & 1.00 \\
\hline & $\mathcal{M} \mathcal{Z}_{\alpha, M}$ & & .191 & .151 & .214 & .263 & .426 & .068 & .095 & .413 & .788 & .935 & .228 & .451 & .948 & .999 & 1.00 \\
\hline \multirow{9}{*}{12} & $\mathcal{M} \mathcal{Z}_{t}$ & & .188 & .144 & .189 & .266 & .402 & .062 & .124 & .593 & .927 & .991 & .115 & .287 & .898 & .998 & 1.00 \\
\hline & $T(\hat{\phi}-1)$ & & .674 & .710 & .797 & .844 & .878 & .370 & .536 & .878 & .990 & 1.00 & .235 & .476 & .936 & .999 & 1.00 \\
\hline & $\mathcal{M} \mathcal{Z}_{\alpha}$ & & .152 & .108 & .164 & .234 & .356 & .041 & .066 & .421 & .773 & .948 & .055 & .143 & .700 & .975 & 1.00 \\
\hline & $t_{\phi}$ & & .104 & .256 & .543 & .679 & .765 & .082 & .252 & .752 & .972 & 1.00 & .042 & .218 & .856 & .996 & 1.00 \\
\hline & $\mathcal{M S B}$ & & .132 & .088 & .143 & .190 & .307 & .042 & .074 & .460 & .854 & .977 & .071 & .196 & .826 & .994 & 1.00 \\
\hline & $\mathcal{M} \mathcal{Z}_{t, M}$ & & .165 & .125 & .180 & .259 & .399 & .046 & .097 & .571 & .926 & .991 & .080 & .244 & .890 & .998 & 1.00 \\
\hline & $t_{\phi, M}$ & & .631 & .686 & .786 & .842 & .877 & .310 & .500 & .868 & .990 & 1.00 & .188 & .437 & .931 & .999 & 1.00 \\
\hline & $T(\hat{\phi}$ & & .198 & .348 & .596 & .710 & .787 & .178 & .358 & .814 & .980 & 1.00 & .119 & .345 & .898 & .998 & 1.00 \\
\hline & $\mathcal{M} \mathcal{Z}_{\alpha, M}$ & & .222 & .161 & .208 & .271 & .399 & .103 & .168 & .628 & .930 & .990 & .200 & .377 & .911 & .999 & 1.00 \\
\hline \multirow{9}{*}{24} & $\mathcal{M Z}$ & & .191 & .113 & .154 & .184 & .320 & .045 & .080 & .420 & .794 & .948 & .160 & .470 & .989 & 1.00 & 1.00 \\
\hline & $T(\hat{\phi}-1)$ & & .720 & .760 & .800 & .848 & .880 & .384 & .482 & .822 & .957 & .995 & .390 & .712 & .998 & 1.00 & 1.00 \\
\hline & $\mathcal{M Z _ { \alpha }}$ & & .146 & .090 & .132 & .160 & .285 & .039 & .074 & .471 & .856 & .979 & .088 & .248 & .920 & 1.00 & 1.00 \\
\hline & $t_{\phi}$ & & .092 & .239 & .495 & .656 & .753 & .058 & . 167 & .628 & .903 & .988 & .074 & .381 & .989 & 1.00 & 1.00 \\
\hline & $\mathcal{M S B}$ & & .126 & .079 & .098 & .126 & .243 & .029 & .053 & .312 & .687 & .886 & .095 & .349 & .974 & 1.00 & 1.00 \\
\hline & $\mathcal{M} \mathcal{Z}_{t, N}$ & & .148 & .097 & .141 & .175 & .309 & .030 & .058 & .390 & .785 & .947 & .088 & .398 & .988 & 1.00 & 1.00 \\
\hline & $t_{\phi, M}$ & & .660 & .728 & .788 & .842 & .876 & .310 & .424 & .804 & .954 & .995 & .297 & .649 & .997 & 1.00 & 1.00 \\
\hline & $T(\hat{\phi}-1)_{M}$ & & .176 & .320 & .554 & .696 & .778 & .156 & .278 & .702 & .924 & .992 & .210 & .560 & .994 & 1.00 & 1.00 \\
\hline & $\mathcal{M} \mathcal{Z}_{\alpha, M}$ & & .227 & .126 & .163 & .198 & .323 & .090 & .121 & .475 & .810 & .950 & .320 & .603 & .992 & 1.00 & 1.00 \\
\hline \multirow{9}{*}{48} & $\mathcal{M}$ & & .293 & .188 & .191 & .256 & .424 & .049 & .052 & .386 & .785 & .950 & .142 & .376 & .984 & 1.00 & 1.00 \\
\hline & $T(\hat{\phi}-1)$ & & .856 & .882 & .915 & .934 & .953 & .437 & .523 & .829 & .980 & .998 & .413 & .681 & .994 & 1.00 & 1.00 \\
\hline & $\mathcal{M} \mathcal{Z}_{\alpha}$ & & .230 & .155 & .164 & .224 & .386 & .054 & .081 & .520 & .898 & .983 & .088 & .264 & .959 & 1.00 & 1.00 \\
\hline & $t_{\phi}$ & & .119 & .334 & .659 & .804 & .876 & .044 & .165 & .618 & .931 & .994 & .046 & .305 & .966 & 1.00 & 1.00 \\
\hline & $\mathcal{M S B}$ & & .200 & .131 & .134 & .184 & .325 & .036 & .038 & .257 & .670 & .880 & .085 & .245 & .959 & 1.00 & 1.00 \\
\hline & $\mathcal{M} \mathcal{Z}_{t, \Lambda}$ & & .223 & .142 & .154 & .228 & .403 & .028 & .037 & .317 & .760 & .94 & .064 & .261 & .978 & 1.00 & 1.00 \\
\hline & $t_{\phi, M}$ & & .780 & .836 & .899 & .929 & .950 & .327 & 438 & .798 & .972 & .998 & .271 & .592 & .992 & 1.00 & 1.00 \\
\hline & $T(\hat{\phi}-$ & & .243 & .459 & .713 & .826 & .897 & .146 & .278 & .697 & .949 & .996 & .183 & .489 & .983 & 1.00 & 1.00 \\
\hline & $\mathcal{M} \mathcal{Z}_{\alpha, M}$ & & .341 & .216 & .211 & .267 & .429 & .098 & .095 & .443 & .801 & .952 & .300 & .542 & .987 & 1.00 & 1.00 \\
\hline
\end{tabular}

Note: Case $\psi=0, \phi=\left(\boldsymbol{\imath}_{n / 2}^{\prime}, \widetilde{\phi}_{n / 2}^{\prime}\right)^{\prime}$ with $\left(\widetilde{\phi}_{n / 2}\right)_{i} \sim \mathcal{U}(.75,1), \delta=5$. Dependence scheme 2. 
Table A-12-Rejection Rates of the Tests.

\begin{tabular}{|c|c|c|c|c|c|c|c|c|c|c|c|c|c|c|c|c|c|}
\hline \multirow[b]{2}{*}{$n$} & & \multirow[b]{2}{*}{$T$} & \multicolumn{5}{|c|}{$\tau=0.1$} & \multicolumn{5}{|c|}{$\tau=0.5$} & \multicolumn{5}{|c|}{$\tau=0.9$} \\
\hline & & & 30 & 50 & 100 & 150 & 200 & 30 & 50 & 100 & 150 & 200 & 30 & 50 & 100 & 150 & 200 \\
\hline \multirow{9}{*}{8} & $\mathcal{M Z _ { t }}$ & & .218 & .456 & .904 & .977 & .990 & .120 & .283 & .887 & .996 & 1.00 & .161 & .493 & .991 & 1.00 & 1.00 \\
\hline & $T(\hat{\phi}-1)$ & & .483 & .694 & .970 & .997 & .999 & .338 & .535 & .956 & .999 & 1.00 & .295 & .622 & .994 & 1.00 & 1.00 \\
\hline & $\mathcal{M} \mathcal{Z}_{\alpha}$ & & .182 & .407 & .886 & .973 & .988 & .070 & 186 & .720 & .949 & .994 & .079 & .196 & .780 & .992 & 1.00 \\
\hline & $t_{\phi}$ & & .126 & .395 & .922 & .991 & .998 & .097 & .285 & .894 & .998 & 1.00 & .082 & .374 & .979 & 1.00 & 1.00 \\
\hline & $\mathcal{M S B}$ & & .150 & .338 & .861 & .968 & .987 & .072 & .186 & .807 & .990 & .999 & .103 & .358 & .979 & 1.00 & 1.00 \\
\hline & $\mathcal{M} \mathcal{Z}_{t, M}$ & & .188 & .428 & .902 & .977 & .990 & .089 & .247 & .881 & .997 & 1.00 & .128 & .454 & .990 & 1.00 & 1.00 \\
\hline & $t_{\phi, M}$ & & .442 & .674 & .970 & .997 & .999 & .292 & .508 & .952 & .999 & 1.00 & .253 & .591 & .994 & 1.00 & 1.00 \\
\hline & $T(\hat{\phi}$ & & .226 & .502 & .944 & .992 & .998 & .190 & .402 & .930 & .999 & 1.00 & .182 & .516 & .989 & 1.00 & 1.00 \\
\hline & $\mathcal{M} \mathcal{Z}_{\alpha, M}$ & & .289 & .518 & .910 & .978 & .990 & .193 & .358 & .898 & .997 & 1.00 & .270 & .586 & .992 & 1.00 & 1.00 \\
\hline \multirow{9}{*}{12} & $\mathcal{M} \mathcal{Z}_{t}$ & & .092 & .175 & .560 & .815 & .928 & .078 & .176 & .737 & .964 & .994 & .067 & .157 & 692 & .976 & 1.00 \\
\hline & $T(\hat{\phi}-1)$ & & .369 & .486 & .780 & .934 & .978 & .263 & .423 & .874 & .991 & 1.00 & .167 & .294 & .777 & .981 & .999 \\
\hline & $\mathcal{M} \mathcal{Z}_{\alpha}$ & & .063 & .143 & .522 & .794 & .914 & .038 & .078 & .388 & .747 & .913 & .034 & .066 & .291 & .669 & .915 \\
\hline & $t_{\phi}$ & & .042 & .161 & .588 & .857 & .952 & .047 & .184 & .728 & .975 & .999 & .019 & .108 & .596 & .958 & .999 \\
\hline & $\mathcal{M S B}$ & & .052 & .115 & .472 & .765 & .891 & .046 & .110 & .626 & .932 & .987 & .040 & .101 & .561 & .939 & .998 \\
\hline & $\mathcal{M Z _ { t , M }}$ & & .069 & .147 & .545 & .810 & .927 & .051 & .146 & .715 & .962 & .994 & .044 & .130 & .674 & .975 & 1.00 \\
\hline & $t_{\phi, M}$ & & .316 & .455 & .772 & .931 & .978 & .213 & .392 & .862 & .991 & 1.00 & .133 & .260 & .764 & .979 & .999 \\
\hline & $T(\hat{\phi}$. & & .092 & .248 & .652 & .882 & .962 & .126 & .273 & .801 & .984 & 1.00 & .068 & .185 & .680 & .969 & .999 \\
\hline & $\mathcal{M} \mathcal{Z}_{\alpha, M}$ & & .130 & .214 & .582 & .822 & .928 & .127 & .241 & .765 & .966 & .994 & .120 & .207 & .720 & .978 & 1.00 \\
\hline \multirow{9}{*}{24} & $\mathcal{M Z}$ & & .167 & .283 & .837 & .985 & .999 & .066 & .170 & .737 & .989 & 1.00 & .142 & .446 & .999 & 1.00 & 1.00 \\
\hline & $T(\hat{\phi}-1)$ & & .559 & .695 & .954 & .998 & 1.00 & .340 & .492 & .908 & .999 & 1.00 & .339 & .708 & .999 & 1.00 & 1.00 \\
\hline & $\mathcal{M} \mathcal{Z}_{\alpha}$ & & .125 & .236 & .801 & .980 & .999 & .088 & .256 & .946 & 1.00 & 1.00 & .087 & .275 & .975 & 1.00 & 1.00 \\
\hline & $t_{\phi}$ & & .067 & .281 & .852 & .991 & 1.00 & .044 & .180 & .751 & .994 & 1.00 & .047 & .349 & .994 & 1.00 & 1.00 \\
\hline & $\mathcal{M S B}$ & & .091 & .196 & .750 & .970 & .998 & .042 & .106 & .602 & .966 & .999 & .097 & .293 & .993 & 1.00 & 1.00 \\
\hline & $\mathcal{M} \mathcal{Z}_{t, N}$ & & .114 & .233 & .820 & .985 & .999 & .042 & .122 & .705 & .989 & 1.00 & .084 & .340 & .998 & 1.00 & 1.00 \\
\hline & $t_{\phi, M}$ & & .493 & .639 & .948 & .998 & 1.00 & .255 & .422 & .897 & .998 & 1.00 & .246 & .640 & .999 & 1.00 & 1.00 \\
\hline & $T(\hat{\phi}-1)_{l}$ & & .169 & .406 & .894 & .994 & 1.00 & .132 & .301 & .835 & .996 & 1.00 & .176 & .545 & .998 & 1.00 & 1.00 \\
\hline & $\mathcal{M} \mathcal{Z}_{\alpha, M}$ & & .241 & .354 & .861 & .985 & .999 & .130 & .257 & .781 & .990 & 1.00 & .284 & .602 & 1.00 & 1.00 & 1.00 \\
\hline \multirow{9}{*}{48} & $\mathcal{M Z}$ & & .245 & .316 & .899 & .999 & 1.00 & .090 & .221 & .912 & 1.00 & 1.00 & .142 & .474 & 1.00 & 1.00 & 1.00 \\
\hline & $T(\hat{\phi}-1)$ & & .702 & .820 & .988 & 1.00 & 1.00 & .454 & .656 & .984 & 1.00 & 1.00 & .435 & .818 & 1.00 & 1.00 & 1.00 \\
\hline & $\mathcal{M} \mathcal{Z}_{\alpha}$ & & .190 & .271 & .862 & .997 & 1.00 & .076 & .175 & .891 & .999 & 1.00 & .100 & .262 & .991 & 1.00 & 1.00 \\
\hline & $t_{\phi}$ & & .070 & .336 & .921 & .998 & 1.00 & .041 & .242 & .927 & 1.00 & 1.00 & .050 & .361 & 1.00 & 1.00 & 1.00 \\
\hline & $\mathcal{M S B}$ & & .160 & .219 & .821 & .994 & 1.00 & .054 & .136 & .822 & .998 & 1.00 & .095 & .315 & .998 & 1.00 & 1.00 \\
\hline & $\mathcal{M} \mathcal{Z}_{t, \Lambda}$ & & .157 & .241 & .874 & .998 & 1.00 & .041 & .134 & .880 & 1.00 & 1.00 & .071 & .331 & 1.00 & 1.00 & 1.00 \\
\hline & $t_{\phi, M}$ & & .591 & .763 & .984 & 1.00 & 1.00 & .320 & .562 & .976 & 1.00 & 1.00 & .286 & .724 & 1.00 & 1.00 & 1.00 \\
\hline & $T(\hat{\phi}-$ & & .210 & .488 & .954 & .999 & 1.00 & .164 & .423 & .958 & 1.00 & 1.00 & .201 & .609 & 1.00 & 1.00 & 1.00 \\
\hline & $\mathcal{M} \mathcal{Z}_{\alpha, M}$ & & .340 & .397 & .917 & .999 & 1.00 & .182 & .338 & .938 & 1.00 & 1.00 & .334 & .677 & 1.00 & 1.00 & 1.00 \\
\hline
\end{tabular}

Note: Case $\psi=0, \phi=\left(\boldsymbol{\imath}_{n / 2}^{\prime}, \widetilde{\phi}_{n / 2}^{\prime}\right)^{\prime}$ with $\left(\widetilde{\phi}_{n / 2}\right)_{i} \sim \mathcal{U}(.75,1), \delta=5$. Dependence scheme 3 . 
Table A-13-Rejection Rates of the Tests.

\begin{tabular}{|c|c|c|c|c|c|c|c|c|c|c|c|c|c|c|c|c|c|}
\hline \multirow[b]{2}{*}{$n$} & & \multirow[b]{2}{*}{$T$} & \multicolumn{5}{|c|}{$\tau=0.1$} & \multicolumn{5}{|c|}{$\tau=0.5$} & \multicolumn{5}{|c|}{$\tau=0.9$} \\
\hline & & & 30 & 50 & 100 & 150 & 200 & 30 & 50 & 100 & 150 & 200 & 30 & 50 & 100 & 150 & 200 \\
\hline \multirow{9}{*}{8} & $\mathcal{M Z _ { t }}$ & & .134 & .165 & .392 & .685 & .911 & .169 & .186 & .333 & .551 & .778 & .370 & .222 & .150 & .137 & .278 \\
\hline & $T(\hat{\phi}-1)$ & & .201 & .189 & .290 & .454 & .774 & .107 & .130 & .206 & .350 & .588 & .022 & .050 & .049 & .083 & .125 \\
\hline & $\mathcal{M Z _ { \alpha }}$ & & .089 & .117 & .292 & .551 & .824 & .126 & .127 & .226 & .390 & .611 & .346 & .196 & .126 & .107 & .236 \\
\hline & $t_{\phi}$ & & .046 & .075 & .191 & .388 & .725 & .056 & .087 & .170 & .310 & .546 & .022 & .033 & .039 & .064 & .107 \\
\hline & $\mathcal{M S B}$ & & .089 & .117 & .292 & .551 & .824 & .126 & . 127 & .226 & .390 & .611 & .325 & .175 & .106 & .077 & .188 \\
\hline & $\mathcal{M} \mathcal{Z}_{t, M}$ & & .101 & .149 & .384 & .684 & .911 & .138 & .167 & .324 & .550 & .780 & .338 & .201 & .146 & .137 & .281 \\
\hline & $t_{\phi, M}$ & & .177 & .179 & .284 & .454 & .775 & .091 & . 116 & .204 & .349 & .593 & .017 & .046 & .047 & .083 & .126 \\
\hline & $T(\hat{\phi}-1)_{M}$ & & .082 & .114 & .237 & .447 & .767 & .104 & .130 & .218 & .360 & .594 & .044 & .051 & .051 & .082 & .130 \\
\hline & $\mathcal{M} \mathcal{Z}_{\alpha, M}$ & & .220 & .214 & .420 & .689 & .904 & .264 & .248 & .356 & .548 & .762 & .440 & .258 & .160 & .140 & .272 \\
\hline \multirow{9}{*}{12} & $\mathcal{M Z _ { t }}$ & & .154 & .213 & .547 & .871 & .991 & .156 & . 158 & .280 & .436 & .670 & .578 & .366 & .313 & .246 & .460 \\
\hline & $T(\hat{\phi}-1)$ & & .254 & .276 & .413 & .630 & .923 & .123 & .120 & .194 & .304 & .511 & .026 & .060 & .096 & .145 & .209 \\
\hline & $\mathcal{M} \mathcal{Z}_{\alpha}$ & & .099 & .142 & .385 & .726 & .948 & .113 & .104 & .180 & .298 & .503 & .547 & .330 & .272 & 197 & .410 \\
\hline & & & .052 & .092 & .258 & .533 & .886 & .060 & .077 & . 147 & .258 & .458 & .029 & .052 & .073 & . 110 & .183 \\
\hline & $\mathcal{M S B}$ & & .099 & .142 & .385 & .726 & .948 & .113 & .104 & . 180 & .298 & .503 & .512 & .293 & .219 & .147 & .346 \\
\hline & $\mathcal{M} \mathcal{Z}_{t, M}$ & & .102 & .179 & .526 & .866 & .990 & .117 & .127 & .260 & .425 & .669 & .534 & .336 & .297 & .239 & .457 \\
\hline & $t_{\phi, M}$ & & .224 & .251 & .397 & .620 & .922 & .102 & .104 & . 186 & .296 & .507 & .018 & .052 & .087 & .138 & .207 \\
\hline & $T(\hat{\phi}$ & & .116 & .147 & .324 & .600 & .917 & .119 & .117 & 193 & .299 & .510 & .066 & .079 & .098 & . 148 & .216 \\
\hline & $\mathcal{M} \mathcal{Z}_{\alpha, M}$ & & .268 & .288 & .580 & .870 & .987 & .255 & .217 & .304 & .445 & .662 & .668 & .412 & .334 & .249 & .458 \\
\hline \multirow{9}{*}{24} & $\mathcal{M Z}$ & & .178 & .270 & .754 & .993 & 1.00 & .181 & .143 & .242 & .379 & .589 & .701 & .426 & .254 & .161 & .411 \\
\hline & $T(\hat{\phi}$ & & .395 & .396 & .622 & .879 & .998 & .166 & .140 & .202 & .304 & .502 & .030 & .054 & .077 & . 126 & .201 \\
\hline & $\mathcal{M} \mathcal{Z}_{\alpha}$ & & .126 & .182 & .578 & .958 & 1.00 & .141 & .104 & . 156 & .249 & .412 & .675 & .399 & .225 & .134 & .362 \\
\hline & $t_{\phi}$ & & .058 & .114 & .401 & .791 & .996 & .055 & .076 & . 149 & .246 & .438 & .031 & .035 & .058 & .093 & .176 \\
\hline & $\mathcal{M S B}$ & & .126 & .182 & .578 & .958 & 1.00 & .141 & .104 & .156 & .249 & .412 & .646 & .371 & .180 & .094 & .292 \\
\hline & $\mathcal{M} \mathcal{Z}_{t, M}$ & & .108 & .207 & .729 & .992 & 1.00 & .129 & . 107 & .210 & .362 & .583 & .642 & .377 & .229 & . 150 & .396 \\
\hline & $t_{\phi, M}$ & & .335 & .347 & .591 & .870 & .998 & .122 & .119 & .185 & .286 & .494 & .018 & .039 & .069 & .114 & .191 \\
\hline & $T(\hat{\phi}-1)_{M}$ & & .150 & .193 & .492 & .860 & .998 & .141 & 132 & 192 & .294 & .497 & .068 & .072 & .080 & .116 & .205 \\
\hline & $\mathcal{M} \mathcal{Z}_{\alpha, M}$ & & .364 & .410 & .795 & .994 & 1.00 & .294 & .218 & .283 & .402 & .590 & .795 & .504 & .286 & .177 & .412 \\
\hline \multirow{9}{*}{48} & $\mathcal{M z}$ & & .145 & .202 & .536 & .945 & .99 & .219 & .152 & .232 & .376 & .64 & .887 & .544 & .298 & .143 & .443 \\
\hline & $T(\hat{\phi}-1)$ & & .510 & .444 & .548 & .727 & .988 & .213 & 178 & .244 & .360 & .602 & .029 & .061 & .084 & . 130 & .226 \\
\hline & $\mathcal{M} \mathcal{Z}_{\alpha}$ & & .098 & .126 & .370 & .800 & .989 & .178 & .104 & . 139 & .236 & .440 & .869 & .515 & .265 & . 112 & .384 \\
\hline & $t_{\phi}$ & & .044 & .104 & .277 & .576 & .960 & .064 & .087 & .170 & .278 & .529 & .034 & .041 & .057 & .092 & .192 \\
\hline & $\mathcal{M S B}$ & & .098 & .126 & .370 & .800 & .989 & .178 & .104 & .139 & .236 & .440 & .838 & .470 & .212 & .080 & .300 \\
\hline & $\mathcal{M} \mathcal{Z}_{t, \Lambda}$ & & .068 & .118 & .461 & .931 & .998 & .141 & .093 & . 177 & .329 & .614 & .824 & .473 & .252 & . 109 & .410 \\
\hline & $t_{\phi, M}$ & & .398 & .360 & .495 & .689 & .985 & .142 & . 130 & .208 & .323 & .576 & .013 & .035 & .064 & . 106 & .204 \\
\hline & $T(\hat{\phi}-1)$ & & .142 & .174 & .371 & .664 & .982 & .171 & .150 & .222 & .335 & .582 & .084 & .081 & .083 & . 112 & .212 \\
\hline & $\mathcal{M} \mathcal{Z}_{\alpha, M}$ & & .343 & .329 & .608 & .951 & .998 & .393 & .238 & .281 & .412 & .650 & .939 & .625 & .338 & . 153 & .447 \\
\hline
\end{tabular}

Note: Case $\psi=0, \phi=\widetilde{\phi}_{n}$ with $\left(\widetilde{\phi}_{n}\right)_{i} \sim \mathcal{U}(.9,1), \delta=0.2$. Dependence scheme 1 . 
Table A-14-Rejection Rates of the Tests.

\begin{tabular}{|c|c|c|c|c|c|c|c|c|c|c|c|c|c|c|c|c|c|}
\hline \multirow[b]{2}{*}{$n$} & & \multirow[b]{2}{*}{$T$} & \multicolumn{5}{|c|}{$\tau=0.1$} & \multicolumn{5}{|c|}{$\tau=0.5$} & \multicolumn{5}{|c|}{$\tau=0.9$} \\
\hline & & & 30 & 50 & 100 & 150 & 200 & 30 & 50 & 100 & 150 & 200 & 30 & 50 & 100 & 150 & 200 \\
\hline \multirow{9}{*}{8} & $\mathcal{M Z _ { t }}$ & & .180 & .248 & .587 & .860 & .973 & .141 & .140 & .225 & .361 & .486 & .425 & .311 & .271 & .245 & .398 \\
\hline & $T(\hat{\phi}-1)$ & & .222 & .236 & .420 & .641 & .896 & .097 & . 106 & .145 & .248 & .360 & .026 & .061 & .086 & .130 & .178 \\
\hline & $\mathcal{M Z _ { \alpha }}$ & & .130 & .169 & .363 & .641 & .834 & .099 & .098 & .123 & .175 & .233 & .397 & .281 & .237 & .206 & .352 \\
\hline & $t_{\phi}$ & & .050 & .103 & .312 & .581 & .868 & .044 & .070 & .117 & .215 & .328 & .024 & .042 & .071 & .110 & .162 \\
\hline & $\mathcal{M S B}$ & & .124 & .172 & .453 & .752 & .931 & .102 & .090 & .150 & .259 & .355 & .370 & .249 & .197 & .156 & .298 \\
\hline & $\mathcal{M} \mathcal{Z}_{t, N}$ & & .146 & .224 & .578 & .860 & .974 & .115 & .121 & .215 & .360 & .488 & .392 & .292 & .266 & .244 & .401 \\
\hline & $t_{\phi, M}$ & & .198 & .222 & .416 & .640 & .897 & .076 & .096 & .141 & .247 & .362 & .021 & .051 & .084 & .130 & .180 \\
\hline & $T(\hat{\phi}$ & & .108 & .140 & .363 & .631 & .892 & .091 & .106 & .148 & .246 & .362 & .055 & .082 & .098 & .134 & .187 \\
\hline & $\mathcal{M} \mathcal{Z}_{\alpha, M}$ & & .297 & .312 & .604 & .856 & .968 & .214 & .187 & .240 & .363 & .478 & .504 & .355 & .288 & .245 & .391 \\
\hline \multirow{9}{*}{12} & $\mathcal{M Z _ { t }}$ & & .127 & .187 & .416 & .670 & .880 & .166 & 170 & .308 & .461 & .634 & .518 & .341 & .279 & .227 & .404 \\
\hline & $T(\hat{\phi}-1)$ & & .244 & .235 & .316 & .453 & .748 & .118 & .123 & .206 & .313 & .502 & .031 & .055 & .092 & .122 & 199 \\
\hline & $\mathcal{M} \mathcal{Z}_{\alpha}$ & & .169 & .236 & .568 & .855 & .968 & .146 & .153 & .249 & .442 & .633 & .490 & .316 & .237 & .186 & .360 \\
\hline & $t_{\phi}$ & & .051 & .079 & .196 & .376 & .693 & .056 & .084 & .160 & .270 & .455 & .025 & .043 & .066 & .097 & .171 \\
\hline & $\mathcal{M S B}$ & & .084 & .122 & .307 & .535 & .777 & .120 & .113 & .213 & .333 & .485 & .461 & .280 & .196 & .148 & .296 \\
\hline & $\mathcal{M Z _ { t , M }}$ & & .094 & .157 & .400 & .666 & .878 & .129 & 142 & .297 & .455 & .633 & .468 & .314 & .267 & .220 & .402 \\
\hline & $t_{\phi, M}$ & & .213 & .216 & .303 & .449 & .747 & .095 & .108 & .199 & .307 & .501 & .022 & .044 & .085 & .119 & .197 \\
\hline & $T(\hat{\phi}-$ & & .098 & .127 & .249 & .437 & .732 & .112 & .126 & .206 & .309 & .500 & .055 & .078 & .091 & .126 & .200 \\
\hline & $\mathcal{M} \mathcal{Z}_{\alpha, M}$ & & .229 & .253 & .447 & .674 & .876 & .276 & .225 & .333 & .463 & .620 & .599 & .388 & .298 & .231 & .398 \\
\hline \multirow{9}{*}{24} & $\mathcal{M Z _ { t }}$ & & .163 & .211 & .530 & .819 & .961 & .171 & 149 & .254 & .434 & .592 & .668 & .431 & .319 & .220 & .444 \\
\hline & $T(\hat{\phi}-1)$ & & .346 & .316 & .433 & .642 & .900 & .163 & .139 & .206 & .334 & .505 & .030 & .068 & .094 & .142 & .214 \\
\hline & $\mathcal{M} \mathcal{Z}_{\alpha}$ & & .128 & .162 & .434 & .721 & .905 & .160 & .139 & .219 & .378 & .530 & .645 & .400 & .279 & .184 & .399 \\
\hline & $t_{\phi}$ & & .051 & .098 & .279 & .558 & .862 & .057 & . 080 & .146 & .276 & .453 & .032 & .046 & .072 & .114 & .189 \\
\hline & $\mathcal{M S B}$ & & .114 & .144 & .398 & .720 & .912 & .132 & .103 & .178 & .308 & .448 & .626 & .369 & 230 & .134 & .341 \\
\hline & $\mathcal{M} \mathcal{Z}_{t, M}$ & & .102 & .161 & .500 & .810 & .961 & .126 & .116 & .230 & .420 & .586 & .614 & .386 & .288 & .204 & .436 \\
\hline & $t_{\phi, M}$ & & .289 & .281 & .412 & .633 & .897 & .122 & .114 & . 182 & .320 & .501 & .017 & .050 & .085 & .134 & .209 \\
\hline & $T(\hat{\phi}-1)_{M}$ & & .138 & .161 & .347 & .610 & .890 & .140 & .135 & .191 & .324 & .502 & .070 & .092 & .100 & .139 & .218 \\
\hline & $\mathcal{M} \mathcal{Z}_{\alpha, M}$ & & .310 & .304 & .564 & .821 & .960 & .296 & .223 & .294 & .451 & .588 & .757 & .507 & .358 & .233 & .449 \\
\hline \multirow{9}{*}{48} & $\mathcal{M Z}$ & & .164 & .188 & .475 & .776 & .932 & .214 & .150 & .205 & .356 & .508 & .768 & .465 & .253 & .140 & .379 \\
\hline & $T(\hat{\phi}-1)$ & & .430 & .406 & .474 & .603 & .874 & .196 & .183 & .222 & .320 & .473 & .024 & .056 & .076 & .120 & .196 \\
\hline & $\mathcal{M} \mathcal{Z}_{\alpha}$ & & .150 & .211 & .546 & .814 & .956 & .176 & .114 & .146 & .248 & .346 & .755 & .442 & .228 & .112 & .338 \\
\hline & $t_{\phi}$ & & .053 & .105 & .278 & .501 & .834 & .055 & .087 & .161 & .257 & .424 & .028 & .039 & .054 & .076 & .150 \\
\hline & $\mathcal{M S B}$ & & .115 & .129 & .343 & .650 & .860 & .170 & .105 & . 132 & .229 & .362 & .732 & .403 & .192 & .076 & .272 \\
\hline & $\mathcal{M} \mathcal{Z}_{t, N}$ & & .086 & .127 & .420 & .753 & .929 & .138 & . 100 & .165 & .320 & .491 & .706 & .404 & .218 & .119 & .356 \\
\hline & $t_{\phi, M}$ & & .350 & .347 & .436 & .574 & .866 & .135 & . 134 & . 192 & .290 & .452 & .012 & .036 & .058 & .101 & .172 \\
\hline & $T(\phi-1)$ & & .150 & .184 & .356 & .561 & .857 & .160 & 149 & .204 & .300 & .465 & .074 & .077 & .079 & .101 & .170 \\
\hline & $\mathcal{M} \mathcal{Z}_{\alpha, M}$ & & .326 & .294 & .520 & .790 & .931 & .352 & .229 & .247 & .376 & .513 & .847 & .546 & 282 & .150 & .381 \\
\hline
\end{tabular}

Note: Case $\psi=0, \phi=\widetilde{\phi}_{n}$ with $\left(\widetilde{\phi}_{n}\right)_{i} \sim \mathcal{U}(.9,1), \delta=0.2$. Dependence scheme 2 . 
Table A-15-Rejection Rates of the Tests.

\begin{tabular}{|c|c|c|c|c|c|c|c|c|c|c|c|c|c|c|c|c|c|}
\hline \multirow[b]{2}{*}{$n$} & & \multirow[b]{2}{*}{$T$} & \multicolumn{5}{|c|}{$\tau=0.1$} & \multicolumn{5}{|c|}{$\tau=0.5$} & \multicolumn{5}{|c|}{$\tau=0.9$} \\
\hline & & & 30 & 50 & 100 & 150 & 200 & 30 & 50 & 100 & 150 & 200 & 30 & 50 & 100 & 150 & 200 \\
\hline \multirow{9}{*}{8} & $\mathcal{M Z _ { t }}$ & & .140 & .191 & .474 & .805 & .965 & .148 & .166 & .323 & .524 & .756 & .419 & .316 & .364 & .368 & .557 \\
\hline & $T(\hat{\phi}-1)$ & & .229 & .221 & .336 & .547 & .865 & .120 & 138 & .217 & .357 & .588 & .038 & .085 & .138 & .204 & .298 \\
\hline & $\mathcal{M Z _ { \alpha }}$ & & .131 & .237 & .600 & .919 & .997 & .139 & .148 & .264 & .450 & .664 & .402 & .286 & .320 & .320 & .510 \\
\hline & $t_{\phi}$ & & .050 & .084 & .240 & .478 & .826 & .061 & .099 & .172 & .316 & .553 & .028 & .060 & .109 & .180 & .278 \\
\hline & $\mathcal{M S B}$ & & .094 & .127 & .353 & .656 & .895 & .104 & 110 & .222 & .380 & .609 & .382 & .252 & .266 & .258 & .442 \\
\hline & $\mathcal{M} \mathcal{Z}_{t, M}$ & & .106 & .171 & .467 & .805 & .966 & .122 & .140 & .312 & .523 & .758 & .396 & .293 & .353 & .367 & .562 \\
\hline & $t_{\phi, M}$ & & .208 & .204 & .326 & .546 & .868 & .100 & .130 & .211 & .357 & .590 & .029 & .077 & .134 & .203 & .302 \\
\hline & $T(\hat{\phi}-1)_{M}$ & & .105 & .136 & .292 & .538 & .860 & .121 & .143 & .217 & .360 & .594 & .060 & .099 & .140 & .213 & .306 \\
\hline & $\mathcal{M} \mathcal{Z}_{\alpha, M}$ & & .239 & .248 & .503 & .802 & .962 & .229 & .220 & .349 & .530 & .742 & .498 & .371 & .388 & .377 & .554 \\
\hline \multirow{9}{*}{12} & $\mathcal{M Z _ { t }}$ & & .108 & .126 & .306 & .510 & .756 & .128 & . 121 & . 181 & .280 & .393 & .535 & .358 & .368 & .357 & .620 \\
\hline & $T(\hat{\phi}$ & & .262 & .204 & .244 & .326 & .605 & .130 & .117 & .146 & .206 & .310 & .041 & .095 & .140 & .224 & .344 \\
\hline & $\mathcal{M} \mathcal{Z}_{\alpha}$ & & .121 & .169 & .411 & .718 & .940 & .125 & .124 & .210 & .367 & .543 & .504 & .322 & .324 & .297 & .560 \\
\hline & & & .053 & .076 & .150 & .266 & .540 & .050 & . 067 & . 108 & . 166 & .268 & .029 & .050 & .104 & . 173 & .304 \\
\hline & $\mathcal{M S B}$ & & .066 & .078 & .209 & .376 & .594 & .095 & .079 & 108 & .177 & .272 & .469 & .280 & .269 & .230 & .478 \\
\hline & $\mathcal{M} \mathcal{Z}_{t, M}$ & & .071 & .102 & .290 & .501 & .753 & .099 & .096 & .162 & .268 & .392 & .484 & .327 & .358 & .349 & .618 \\
\hline & $t_{\phi, M}$ & & .224 & .187 & .233 & .320 & .600 & .102 & 101 & .135 & .203 & .311 & .031 & .079 & .130 & .218 & .339 \\
\hline & $T(\hat{\phi}$ & & .112 & .117 & .184 & .316 & .594 & .113 & . 106 & .144 & .204 & .308 & .068 & .100 & .140 & .215 & .352 \\
\hline & $\mathcal{M} \mathcal{Z}_{\alpha, M}$ & & .201 & .194 & .340 & .519 & .746 & .206 & .176 & .203 & .290 & .390 & .631 & .414 & .398 & .366 & .615 \\
\hline \multirow{9}{*}{24} & $\mathcal{M Z}$ & & .143 & .218 & .612 & .950 & .999 & .205 & .184 & .352 & .610 & .878 & .648 & .411 & .325 & .308 & .580 \\
\hline & $T(\hat{\phi}$ & & .408 & .367 & .491 & .752 & .986 & .189 & 191 & .299 & .468 & .742 & .039 & .084 & .120 & .210 & .336 \\
\hline & $\mathcal{M} \mathcal{Z}_{\alpha}$ & & .119 & .174 & .525 & .882 & .995 & .144 & . 121 & .207 & .331 & .539 & .616 & .383 & .282 & .252 & .526 \\
\hline & $t_{\phi}$ & & .063 & .127 & .300 & .651 & .971 & .075 & .114 & .230 & .404 & .684 & .024 & .043 & .083 & .156 & .280 \\
\hline & $\mathcal{M S B}$ & & .098 & .149 & .441 & .846 & .990 & .150 & .125 & .238 & .435 & .697 & .590 & .349 & .227 & .194 & .438 \\
\hline & $\mathcal{M} \mathcal{Z}_{t, M}$ & & .086 & .164 & .580 & .946 & .999 & .136 & . 137 & .314 & .592 & .878 & .588 & .361 & .293 & .286 & .571 \\
\hline & $t_{\phi, M}$ & & .338 & .314 & .458 & .737 & .986 & .138 & . 160 & .274 & .452 & .736 & .022 & .063 & . 103 & . 193 & .322 \\
\hline & $T(\hat{\phi}-1)_{\Lambda}$ & & .153 & .208 & .396 & .732 & .983 & .167 & .175 & .295 & .471 & .738 & .067 & .080 & .120 & 197 & .325 \\
\hline & $\mathcal{M} \mathcal{Z}_{\alpha, M}$ & & .313 & .324 & .675 & .956 & .999 & .344 & .274 & .418 & .633 & .869 & .754 & .481 & .371 & .323 & .588 \\
\hline \multirow{9}{*}{48} & $\mathcal{M z}$ & & .143 & .200 & .544 & .934 & .998 & .213 & .166 & .264 & .496 & .762 & .824 & .528 & .388 & .281 & .694 \\
\hline & $T(\hat{\phi}-1)$ & & .513 & .459 & .544 & .744 & .984 & .240 & .229 & .301 & .452 & .695 & .045 & .085 & .143 & .223 & .395 \\
\hline & $\mathcal{M} \mathcal{Z}_{\alpha}$ & & .141 & .166 & .536 & .930 & 1.00 & .184 & .133 & . 194 & .328 & .564 & .803 & .487 & .342 & .226 & .619 \\
\hline & $t_{\phi}$ & & .062 & .113 & .330 & .615 & .967 & .073 & 112 & .209 & .358 & .604 & .020 & .041 & .088 & .163 & .329 \\
\hline & $\mathcal{M S B}$ & & .095 & .120 & .374 & .789 & .984 & .161 & .114 & .168 & .314 & .536 & .777 & .440 & .278 & . 166 & .516 \\
\hline & $\mathcal{M \mathcal { Z } _ { t , N }}$ & & .061 & .113 & .466 & .922 & .998 & .130 & . 106 & .206 & .443 & .742 & .757 & .442 & .327 & .234 & .662 \\
\hline & $t_{\phi, M}$ & & .414 & .380 & .489 & .706 & .983 & .159 & . 169 & .250 & .412 & .670 & .021 & .059 & . 112 & 190 & .362 \\
\hline & $T(\hat{\phi}-1)$ & & .169 & .200 & .417 & .701 & .983 & .188 & . 187 & .266 & .419 & .666 & .067 & .089 & .125 & . 193 & .374 \\
\hline & $\mathcal{M} \mathcal{Z}_{\alpha, M}$ & & .329 & .328 & .620 & .944 & .998 & .382 & .262 & .316 & .524 & .769 & .896 & .621 & .437 & .308 & .698 \\
\hline
\end{tabular}

Note: Case $\psi=0, \phi=\widetilde{\phi}_{n}$ with $\left(\widetilde{\phi}_{n}\right)_{i} \sim \mathcal{U}(.9,1), \delta=0.2$. Dependence scheme 3 . 
Table A-16-Rejection Rates of the Tests.

\begin{tabular}{|c|c|c|c|c|c|c|c|c|c|c|c|c|c|c|c|c|c|}
\hline \multirow[b]{2}{*}{$n$} & & \multirow[b]{2}{*}{$T$} & \multicolumn{5}{|c|}{$\tau=0.1$} & \multicolumn{5}{|c|}{$\tau=0.5$} & \multicolumn{5}{|c|}{$\tau=0.9$} \\
\hline & & & 30 & 50 & 100 & 150 & 200 & 30 & 50 & 100 & 150 & 200 & 30 & 50 & 100 & 150 & 200 \\
\hline \multirow{9}{*}{8} & $\mathcal{M Z _ { t }}$ & & .122 & .094 & .121 & .189 & .308 & .024 & .032 & .106 & .185 & .281 & .082 & .167 & .640 & .974 & 1.00 \\
\hline & $T(\hat{\phi}-1)$ & & .731 & .740 & .783 & .830 & .870 & .210 & .251 & .321 & .460 & .628 & .203 & .350 & .783 & .990 & 1.00 \\
\hline & $\mathcal{M Z _ { \alpha }}$ & & .094 & .071 & .098 & .159 & .264 & .012 & .016 & .068 & .118 & .181 & .050 & .100 & .469 & .905 & .996 \\
\hline & $t_{\phi}$ & & .086 & .202 & .412 & .576 & .664 & .023 & .057 & .138 & .262 & .431 & .039 & .126 & .567 & .953 & 1.00 \\
\hline & $\mathcal{M S B}$ & & .085 & .055 & .080 & . 122 & .222 & .012 & .016 & .068 & .118 & .181 & .050 & .100 & .469 & .905 & .996 \\
\hline & $\mathcal{M} \mathcal{Z}_{t, M}$ & & .108 & .085 & .119 & .189 & .311 & .018 & .029 & .101 & .185 & .283 & .064 & .143 & .627 & .974 & 1.00 \\
\hline & $t_{\phi, M}$ & & .682 & .718 & .779 & .830 & .872 & .181 & .230 & .314 & .458 & .631 & .171 & .322 & .775 & .990 & 1.00 \\
\hline & $T(\hat{\phi}-1)_{M}$ & & .151 & .264 & .468 & .613 & .698 & .049 & .093 & .171 & .299 & .476 & .105 & .198 & .645 & .969 & 1.00 \\
\hline & $\mathcal{M} \mathcal{Z}_{\alpha, M}$ & & .146 & .105 & .125 & .193 & .299 & .040 & .044 & .116 & .195 & .277 & .142 & .229 & .659 & .971 & .999 \\
\hline \multirow{9}{*}{12} & $\mathcal{M Z _ { t }}$ & & .093 & .057 & .066 & .087 & .169 & .036 & .037 & . 148 & .300 & .471 & .060 & .092 & .306 & .720 & .954 \\
\hline & $T(\hat{\phi}-1)$ & & .690 & .723 & .732 & .746 & .780 & .289 & .288 & .463 & .657 & .844 & .164 & .216 & .507 & .849 & .987 \\
\hline & $\mathcal{M} \mathcal{Z}_{\alpha}$ & & .062 & .041 & .050 & .070 & .133 & .022 & .019 & .092 & .199 & .324 & .032 & .059 & .200 & .543 & .860 \\
\hline & & & .066 & .146 & .305 & .416 & .523 & .031 & .070 & .213 & .427 & .665 & .019 & .058 & .266 & .684 & .947 \\
\hline & $\mathcal{M S B}$ & & .048 & .034 & .038 & .055 & .104 & .022 & .019 & .092 & .199 & .324 & .032 & .059 & .200 & .543 & .860 \\
\hline & $\mathcal{M} \mathcal{Z}_{t, M}$ & & .074 & .049 & .059 & .082 & .166 & .026 & .029 & .136 & .292 & .468 & .035 & .078 & .281 & .710 & .954 \\
\hline & $t_{\phi, M}$ & & .637 & .694 & .723 & .740 & .778 & .235 & .260 & .446 & .649 & .844 & .124 & .187 & .492 & .844 & .987 \\
\hline & $T(\hat{\phi}$ & & .120 & .210 & .361 & .454 & .554 & .082 & .118 & .276 & .483 & .719 & .058 & .108 & .351 & .750 & .963 \\
\hline & $\mathcal{M Z}$ & & .102 & .058 & .066 & .088 & .169 & .055 & .058 & .165 & .308 & .464 & .104 & .130 & .340 & .719 & .948 \\
\hline \multirow{9}{*}{24} & $\mathcal{M Z}$ & & .118 & .054 & .046 & .072 & .127 & .032 & .029 & .147 & .280 & .474 & .046 & .083 & .381 & .866 & .997 \\
\hline & $T(\hat{\phi}$ & & .802 & .833 & .823 & .842 & .873 & .357 & .372 & .552 & .760 & .934 & .210 & .286 & .642 & .964 & 1.00 \\
\hline & $\mathcal{M} \mathcal{Z}_{\alpha}$ & & .072 & .038 & .035 & .056 & .108 & .021 & .016 & .096 & 191 & .318 & .027 & .047 & .252 & .695 & .963 \\
\hline & $t_{\phi}$ & & .063 & .173 & .353 & .466 & .594 & .030 & .071 & .268 & .491 & .787 & .018 & .064 & .357 & .848 & .996 \\
\hline & $\mathcal{M S B}$ & & .058 & .028 & .027 & .043 & .084 & .021 & .016 & .096 & .191 & .318 & .027 & .047 & .252 & .695 & .963 \\
\hline & $\mathcal{M} \mathcal{Z}_{t, M}$ & & .086 & .042 & .040 & .064 & .121 & .022 & .019 & . 126 & .263 & .457 & .024 & .056 & .338 & .858 & .997 \\
\hline & $t_{\phi, M}$ & & .720 & .800 & .808 & .829 & .867 & .285 & .315 & .524 & .748 & .930 & .146 & .230 & .608 & .960 & 1.00 \\
\hline & $T(\hat{\phi}-1)_{\Lambda}$ & & .125 & .238 & .416 & .523 & .632 & .088 & .134 & .342 & .556 & .837 & .066 & .122 & .460 & .902 & .998 \\
\hline & $\mathcal{M} \mathcal{Z}_{\alpha, M}$ & & .132 & .061 & .049 & .072 & .122 & .056 & .051 & .171 & .300 & .476 & .108 & .140 & .440 & .881 & .997 \\
\hline \multirow{9}{*}{48} & $\mathcal{M}$ & & .209 & .076 & .059 & .083 & $.16 s$ & .036 & .025 & .123 & .244 & .387 & .064 & .084 & .529 & .982 & 1.00 \\
\hline & $T(\hat{\phi}-1$ & & .946 & .962 & .958 & .970 & .980 & .454 & .444 & .586 & .796 & .952 & .273 & .366 & .844 & 1.00 & 1.00 \\
\hline & $\mathcal{M} \mathcal{Z}_{\alpha}$ & & .149 & .057 & .045 & .063 & .136 & .022 & . 016 & .074 & . 150 & .235 & .035 & .043 & .351 & .893 & 1.00 \\
\hline & $t_{\phi}$ & & .081 & .241 & .530 & .687 & .801 & .027 & .073 & .226 & .476 & .783 & .016 & .065 & .489 & .975 & 1.00 \\
\hline & $\mathcal{M S B}$ & & .125 & .044 & .035 & .043 & .097 & .022 & .016 & .074 & .150 & .235 & .035 & .043 & .351 & .893 & 1.00 \\
\hline & $\mathcal{M} \mathcal{Z}_{t, \Lambda}$ & & .143 & .051 & .045 & .067 & .141 & .018 & .016 & .091 & .203 & .354 & .026 & .040 & .452 & .977 & 1.00 \\
\hline & $t_{\phi, M}$ & & .892 & .942 & .947 & .964 & .977 & .325 & .350 & .526 & .768 & .944 & .167 & .273 & .802 & 1.00 & 1.00 \\
\hline & $T(\hat{\phi}-1)$ & & .198 & .354 & .600 & .739 & .836 & .086 & . 145 & .306 & .550 & .834 & .066 & .152 & .623 & .988 & 1.00 \\
\hline & $\mathcal{M} \mathcal{Z}_{\alpha, M}$ & & .248 & .084 & .060 & .083 & .166 & .071 & . 041 & . 142 & .264 & .395 & .149 & .157 & .602 & .985 & 1.00 \\
\hline
\end{tabular}

Note: Case $\psi=0, \phi=\widetilde{\phi}_{n}$ with $\left(\widetilde{\phi}_{n}\right)_{i} \sim \mathcal{U}(.9,1), \delta=5$. Dependence scheme 1. 
Table A-17-Rejection Rates of the Tests.

\begin{tabular}{|c|c|c|c|c|c|c|c|c|c|c|c|c|c|c|c|c|c|}
\hline \multirow[b]{2}{*}{$n$} & & \multirow[b]{2}{*}{$T$} & \multicolumn{5}{|c|}{$\tau=0.1$} & \multicolumn{5}{|c|}{$\tau=0.5$} & \multicolumn{5}{|c|}{$\tau=0.9$} \\
\hline & & & 30 & 50 & 100 & 150 & 200 & 30 & 50 & 100 & 150 & 200 & 30 & 50 & 100 & 150 & 200 \\
\hline \multirow{9}{*}{8} & $\mathcal{M Z}_{t}$ & & .094 & .053 & .066 & .106 & .165 & .029 & .043 & .174 & .326 & .492 & .052 & .073 & .228 & .490 & .716 \\
\hline & $T(\hat{\phi}-1)$ & & .560 & .585 & .592 & .611 & .666 & .258 & .278 & .434 & .583 & .776 & .128 & .173 & .337 & .627 & .815 \\
\hline & $\mathcal{M} \mathcal{Z}_{\alpha}$ & & .059 & .038 & .051 & .088 & .141 & .025 & .036 & .156 & .300 & .458 & .052 & .084 & .325 & .672 & .900 \\
\hline & $t_{\phi}$ & & .060 & .137 & .262 & .352 & .438 & .040 & .089 & .230 & .418 & .635 & .016 & .055 & .200 & .481 & .719 \\
\hline & $\mathcal{M S B}$ & & .050 & .030 & .040 & .068 & .112 & .015 & .026 & .106 & .226 & .353 & .031 & .044 & .158 & .375 & .585 \\
\hline & $\mathcal{M} \mathcal{Z}_{t, M}$ & & .080 & .045 & .062 & .106 & .166 & .023 & .038 & .166 & .325 & .493 & .041 & .062 & .221 & .488 & .718 \\
\hline & $t_{\phi, M}$ & & .516 & .570 & .587 & .610 & .666 & .230 & .263 & .427 & .584 & .778 & .109 & .161 & .330 & .623 & .816 \\
\hline & $T(\hat{\phi}-1)_{M}$ & & .104 & .187 & .293 & .387 & .469 & .085 & .128 & .290 & .462 & .672 & .050 & .092 & .248 & .535 & .754 \\
\hline & $\mathcal{M} \mathcal{Z}_{\alpha, M}$ & & .101 & .060 & .066 & .108 & .163 & .054 & .070 & .184 & .330 & .479 & .089 & .100 & .240 & .497 & .705 \\
\hline \multirow{9}{*}{12} & $\mathcal{M Z _ { t }}$ & & .096 & .047 & .055 & .078 & .142 & .030 & .039 & .132 & .277 & .407 & .066 & .121 & .425 & .786 & .944 \\
\hline & $T(\hat{\phi}$ & & .569 & .604 & .622 & .646 & .676 & .237 & .266 & .407 & .559 & .733 & .174 & .266 & .581 & .866 & .972 \\
\hline & $\mathcal{M} \mathcal{Z}_{\alpha}$ & & .064 & .031 & .040 & .060 & .118 & .026 & .038 & .166 & .340 & .503 & .041 & .076 & .246 & .544 & .756 \\
\hline & & & .055 & .132 & .252 & .365 & .437 & .024 & . 060 & 197 & .384 & .592 & .025 & .082 & .382 & .763 & .940 \\
\hline & $\mathcal{M S B}$ & & .052 & .028 & .028 & .046 & .093 & .016 & .020 & .087 & .186 & .291 & .036 & .078 & .299 & .672 & .889 \\
\hline & $\mathcal{M} \mathcal{Z}_{t, M}$ & & .080 & .040 & .050 & .074 & .140 & .022 & .029 & .123 & .269 & .403 & .045 & .100 & .406 & .781 & .944 \\
\hline & $t_{\phi, M}$ & & .523 & .582 & .614 & .640 & .674 & .194 & .233 & .395 & .552 & .732 & .144 & .240 & .568 & .861 & .973 \\
\hline & $T(\hat{\phi}$ & & .110 & .184 & .296 & .397 & .470 & .071 & .103 & .255 & .436 & .633 & .070 & .149 & .458 & .799 & .950 \\
\hline & $\mathcal{M} \mathcal{Z}_{\alpha, M}$ & & .103 & .051 & .057 & .076 & .141 & .052 & .059 & .145 & .282 & .401 & .116 & .163 & .450 & .784 & .941 \\
\hline \multirow{9}{*}{24} & $\mathcal{M \mathcal { Z } _ { t }}$ & & .144 & .064 & .065 & .090 & .178 & .034 & .036 & .150 & .342 & .516 & .055 & .098 & .376 & .738 & .925 \\
\hline & $T(\hat{\phi}$ & & .721 & .761 & .748 & .778 & .810 & .334 & .367 & .514 & .711 & .860 & .192 & .278 & .586 & .856 & .966 \\
\hline & $\mathcal{M} \mathcal{Z}_{\alpha}$ & & .100 & .045 & .048 & .072 & .148 & .022 & .027 & .117 & .209 & .326 & .044 & .064 & .296 & .664 & .886 \\
\hline & $t_{\phi}$ & & .071 & .194 & .378 & .507 & .584 & .039 & .087 & .260 & .510 & .734 & .016 & .063 & .369 & .721 & .932 \\
\hline & $\mathcal{M S B}$ & & .076 & .035 & .035 & .058 & .114 & .019 & .022 & .095 & .238 & .362 & .029 & .058 & .271 & .616 & .858 \\
\hline & $\mathcal{M} \mathcal{Z}_{t, M}$ & & .114 & .054 & .054 & .084 & .168 & .020 & .022 & . 128 & .328 & .515 & .032 & .068 & .354 & .728 & .924 \\
\hline & $t_{\phi, M}$ & & .650 & .729 & .733 & .773 & .803 & .266 & .317 & .485 & .701 & .857 & .138 & .231 & .564 & .850 & .966 \\
\hline & $T(\hat{\phi}-1)_{\Lambda}$ & & .137 & .263 & .429 & .548 & .614 & .099 & .159 & .334 & .571 & .778 & .061 & .128 & .450 & .778 & .946 \\
\hline & $\mathcal{M} \mathcal{Z}_{\alpha, M}$ & & .164 & .077 & .072 & .092 & .177 & .064 & .061 & .173 & .362 & .513 & .114 & .156 & .415 & .749 & .922 \\
\hline \multirow{9}{*}{48} & $\mathcal{M}$ & & .178 & .070 & .058 & .068 & .14 & .033 & .031 & .099 & .220 & .324 & .058 & .085 & .405 & .774 & .955 \\
\hline & $T(\hat{\phi}-1$ & & .796 & .834 & .828 & .834 & .858 & .389 & .358 & .453 & .622 & .767 & .244 & .307 & .639 & .900 & .984 \\
\hline & $\mathcal{M} \mathcal{Z}_{\alpha}$ & & .123 & .052 & .044 & .051 & .118 & .032 & . 026 & . 108 & .257 & .390 & .040 & .061 & .347 & .706 & .917 \\
\hline & $t_{\phi}$ & & .084 & .216 & .426 & .569 & .653 & .025 & .068 & .188 & .379 & .598 & .018 & .062 & .380 & .777 & .960 \\
\hline & $\mathcal{M S B}$ & & .103 & .040 & .028 & .039 & .086 & .020 & .018 & .058 & .148 & .210 & .032 & .044 & .281 & .658 & .894 \\
\hline & $\mathcal{M} \mathcal{Z}_{t, \Lambda}$ & & .120 & .048 & .042 & .051 & .123 & .018 & .018 & .072 & .197 & .300 & .022 & .048 & .359 & .758 & .952 \\
\hline & $t_{\phi, M}$ & & .716 & .795 & .804 & .820 & .850 & .287 & .281 & .404 & .590 & .750 & .158 & .231 & .594 & .888 & .983 \\
\hline & $T(\hat{\phi}-1)$ & & .176 & .302 & .483 & .606 & .682 & .088 & . 132 & .247 & .434 & .644 & .069 & .138 & .476 & .828 & .968 \\
\hline & $\mathcal{M} \mathcal{Z}_{\alpha, M}$ & & .203 & .085 & .060 & .067 & .141 & .068 & .052 & . 117 & .234 & .327 & .126 & .142 & .455 & .786 & .954 \\
\hline
\end{tabular}

Note: Case $\psi=0, \phi=\widetilde{\phi}_{n}$ with $\left(\widetilde{\phi}_{n}\right)_{i} \sim \mathcal{U}(.9,1), \delta=5$. Dependence scheme 2 . 
Table A-18-Rejection Rates of the Tests.

\begin{tabular}{|c|c|c|c|c|c|c|c|c|c|c|c|c|c|c|c|c|c|}
\hline \multirow[b]{2}{*}{$n$} & & \multirow[b]{2}{*}{$T$} & \multicolumn{5}{|c|}{$\tau=0.1$} & \multicolumn{5}{|c|}{$\tau=0.5$} & \multicolumn{5}{|c|}{$\tau=0.9$} \\
\hline & & & 30 & 50 & 100 & 150 & 200 & 30 & 50 & 100 & 150 & 200 & 30 & 50 & 100 & 150 & 200 \\
\hline \multirow{9}{*}{8} & $\mathcal{M Z}$ & & .080 & .106 & .312 & .580 & .842 & .047 & .079 & .317 & .644 & .855 & .074 & .130 & .473 & .860 & .989 \\
\hline & $T(\hat{\phi}-1)$ & & .364 & .438 & .630 & .809 & .946 & .217 & .267 & .516 & .788 & .943 & .154 & .240 & .599 & .904 & .993 \\
\hline & $\mathcal{M Z _ { \alpha }}$ & & .059 & .081 & .272 & .528 & .804 & .030 & .072 & .245 & .553 & .777 & .054 & .125 & .518 & .915 & .997 \\
\hline & $t_{\phi}$ & & .042 & .118 & .379 & .640 & .868 & .033 & .076 & .308 & .638 & .884 & .028 & .090 & .398 & .808 & .981 \\
\hline & $\mathcal{M S B}$ & & .042 & .065 & .222 & .460 & .748 & .027 & .049 & .221 & .498 & .755 & .040 & .083 & .342 & .742 & .964 \\
\hline & $\mathcal{M} \mathcal{Z}_{t, N}$ & & .065 & .093 & .303 & .578 & .844 & .035 & .068 & .311 & .644 & .856 & .059 & .115 & .458 & .860 & .989 \\
\hline & $t_{\phi, M}$ & & .333 & .422 & .622 & .809 & .946 & .184 & .243 & .505 & .788 & .944 & .132 & .222 & .591 & .904 & .994 \\
\hline & $T(\hat{\phi}$ & & .082 & .173 & .438 & .682 & .891 & .077 & .133 & .375 & .682 & .909 & .068 & .142 & .481 & .850 & .984 \\
\hline & $\mathcal{M} \mathcal{Z}_{\alpha, M}$ & & .100 & .132 & .329 & .583 & .834 & .083 & .107 & .340 & .646 & .848 & .126 & .177 & .496 & .863 & .988 \\
\hline \multirow{9}{*}{12} & $\mathcal{M Z _ { t }}$ & & .058 & .071 & .191 & .416 & .656 & .040 & .069 & .295 & .592 & .843 & .066 & .124 & .486 & .893 & .994 \\
\hline & $T(\hat{\phi}-1)$ & & .364 & .405 & .550 & .730 & .854 & .233 & .288 & .539 & .791 & .951 & .187 & .256 & .642 & .936 & .997 \\
\hline & $\mathcal{M} \mathcal{Z}_{\alpha}$ & & .034 & .052 & .156 & .353 & .603 & .047 & .075 & .347 & .749 & .939 & .043 & .094 & .359 & .795 & .976 \\
\hline & $t_{\phi}$ & & .026 & .080 & .264 & .481 & .723 & .027 & .078 & .296 & .609 & .874 & .026 & .076 & .390 & .831 & .988 \\
\hline & $\mathcal{M S B}$ & & .025 & .043 & .122 & .297 & .537 & .022 & .039 & .194 & .436 & .711 & .040 & .076 & .339 & .769 & .969 \\
\hline & $\mathcal{M Z _ { t , M }}$ & & .038 & .060 & .180 & .409 & .653 & .025 & .056 & .282 & .586 & .840 & .044 & .098 & .465 & .888 & .994 \\
\hline & $t_{\phi, M}$ & & .308 & .375 & .536 & .726 & .854 & .196 & .258 & .521 & .787 & .952 & .148 & .225 & .629 & .935 & .996 \\
\hline & $T(\hat{\phi}$ & & .066 & .126 & .322 & .529 & .752 & .076 & .128 & .371 & .672 & .903 & .072 & .142 & .492 & .886 & .991 \\
\hline & $\mathcal{M} \mathcal{Z}_{\alpha, M}$ & & .086 & .087 & .206 & .412 & .649 & .081 & .102 & .320 & .597 & .832 & .128 & .167 & .516 & .889 & .994 \\
\hline \multirow{9}{*}{24} & $\mathcal{M Z _ { t }}$ & & .069 & .059 & .152 & .357 & .619 & .050 & .074 & .356 & .746 & .943 & .056 & .107 & .470 & .894 & .997 \\
\hline & $T(\hat{\phi}-1)$ & & .448 & .482 & .605 & .757 & .878 & .312 & .378 & .670 & .918 & .990 & .192 & .291 & .662 & .954 & 1.00 \\
\hline & $\mathcal{M} \mathcal{Z}_{\alpha}$ & & .049 & .041 & .125 & .312 & .563 & .039 & .064 & .350 & .728 & .947 & .043 & .078 & . 344 & .776 & .978 \\
\hline & $t_{\phi}$ & & .030 & .078 & .266 & .503 & .721 & .028 & .092 & .391 & .778 & .963 & .021 & .070 & .394 & .857 & .995 \\
\hline & $\mathcal{M S B}$ & & .038 & .032 & .102 & .254 & .499 & .033 & .048 & .250 & .606 & .855 & .036 & .062 & .322 & .765 & .978 \\
\hline & $\mathcal{M} \mathcal{Z}_{t, M}$ & & .049 & .044 & .138 & .346 & .615 & .028 & .052 & .328 & .736 & .942 & .033 & .072 & 426 & .888 & .997 \\
\hline & $t_{\phi, M}$ & & .372 & .436 & .584 & .749 & .876 & .237 & .325 & .648 & .915 & .989 & .131 & .244 & 632 & .952 & 1.00 \\
\hline & $T(\hat{\phi}-1)_{M}$ & & .075 & .129 & .321 & .563 & .756 & .098 & .163 & .492 & .836 & .977 & .058 & .144 & .502 & .901 & .998 \\
\hline & $\mathcal{M} \mathcal{Z}_{\alpha, M}$ & & .095 & .080 & .177 & .370 & .622 & .102 & .119 & .407 & .759 & .943 & .119 & .176 & .526 & .900 & .997 \\
\hline \multirow{9}{*}{48} & $\mathcal{M Z}$ & & .074 & .060 & .153 & .378 & .636 & .046 & .070 & .340 & .754 & .95 & .048 & .078 & .334 & .814 & .986 \\
\hline & $T(\hat{\phi}-1)$ & & .562 & .641 & .721 & .850 & .928 & .379 & .457 & .708 & .941 & .996 & .241 & .294 & .623 & .934 & .998 \\
\hline & $\mathcal{M} \mathcal{Z}_{\alpha}$ & & .050 & .044 & .125 & .336 & .580 & .033 & .037 & .205 & .520 & .807 & .043 & .093 & .482 & .934 & 1.00 \\
\hline & $t_{\phi}$ & & .024 & .096 & .300 & .564 & .785 & .025 & .095 & .383 & .792 & .986 & .011 & .047 & .303 & .777 & .988 \\
\hline & $\mathcal{M S B}$ & & .037 & .032 & .097 & .278 & .509 & .028 & .038 & .230 & .593 & .880 & .026 & .042 & .211 & .630 & .946 \\
\hline & $\mathcal{M} \mathcal{Z}_{t, \Lambda}$ & & .044 & .037 & .127 & .353 & .612 & .022 & .040 & .294 & .726 & .955 & .023 & .043 & .272 & .783 & .985 \\
\hline & $t_{\phi, M}$ & & .451 & .576 & .680 & .830 & .918 & .267 & .364 & .664 & .932 & .996 & .153 & .214 & .558 & .924 & .998 \\
\hline & $T(\phi-1)$ & & .087 & .158 & .359 & .618 & .818 & .098 & .185 & .483 & .854 & .989 & .058 & .113 & .406 & .846 & .992 \\
\hline & $\mathcal{M} \mathcal{Z}_{\alpha, M}$ & & .111 & .082 & .170 & .390 & .632 & .098 & .115 & .396 & .774 & .959 & .115 & .141 & .396 & .834 & .985 \\
\hline
\end{tabular}

Note: Case $\psi=0, \phi=\widetilde{\phi}_{n}$ with $\left(\widetilde{\phi}_{n}\right)_{i} \sim \mathcal{U}(.9,1), \delta=5$. Dependence scheme 3. 